\title{
The psychological burden of the COVID-19 pandemic is associated with anti-systemic attitudes and political violence
}

\author{
Henrikas Bartusevičius ${ }^{1, *}$, Alexander Bor ${ }^{2}$, Frederik Jørgensen ${ }^{2}$, and Michael Bang \\ Petersen $^{2}$ \\ ${ }^{1}$ Peace Research Institute Oslo \\ ${ }^{2}$ Department of Political Science, Aarhus University \\ *Corresponding author: henrikas@prio.org
}

June 14, 2021

Manuscript accepted for publication in Psychological Science

(Changes might occur between this and the published version)

\begin{abstract}
What are the consequences of the COVID-19 pandemic for people's political attitudes and behavior? We tested, specifically, whether the psychological burden of the COVID-19 pandemic relates to anti-systemic attitudes (dissatisfaction with the fundamental social and political order), peaceful political activism, and political violence. Nationally representative two-wave panel data were collected via online surveys of adults in the United States, Denmark, Italy, and Hungary $(N \mathrm{~s}=6,131$ and 4,568 in Waves 1 and 2 respectively). Overall, levels of anti-systemic attitudes were low and only a small share of interviewees reported behavioral intentions to participate and actual participation in political violence. However, pre-registered analyses indicated that perceived COVID-19 burden was associated with antisystemic attitudes and intentions to engage in political violence. In the US, COVID-19 burden was also associated with self-reported engagement in violence surrounding the Black Lives Matter protests and counter-protests. We found less robust evidence that perceived COVID-19 burden was associated with peaceful activism.
\end{abstract}

\section{Statement of Relevance}

In 2020, many countries experienced a large number of demonstrations, some with lethal violence. We investigated whether the psychological burden of the COVID-19 pandemic played a role in these events. Over 6,000 adults from the US, Denmark, Italy, and Hungary were asked whether the COVID-19 pandemic negatively affected their health, finances, relationships, and rights. Subsequently, interviewees reported anti-systemic attitudes (dissatisfaction with their societies and governments), and whether they were motivated to engage, or had already engaged, in protests and political violence. Overall, levels of antisystemic attitudes were low and only a small portion of interviewees reported motivations to engage and actual engagement in political violence. However, people who felt a larger psychological burden from the pandemic also had more destructive attitudes toward their societies and governments as well as stronger motivations to participate in political violence. Beyond their impact on public health and the economy, pandemics thus constitute a psychological burden that may disrupt the relationship between citizens and their societies and governments. An important part of successful pandemic management is therefore to prevent citizens' alienation from the social and political system.

\section{Acknowledgements}

This research has been supported by Carlsbergfondet grant CF20-0044 awarded to Michael Bang Petersen 
In 2020, the United States saw more than 22,000 demonstrations - the world's highest annual incidence. ${ }^{1}$ A major protest wave started in May, when demonstrations against police brutality under the slogan "Black Lives Matter" (BLM) erupted after the murder of George Floyd. Eventually, some protests and counter-protests involved rioting, clashes with the police, and altercations with heavily armed militia. Although the vast majority of events linked to BLM were peaceful (Kishi \& Jones 2020), at least 25 Americans died during the unrest (Beckett 2020). The BLM protests occurred against a historical backdrop of racial injustice and increasing political polarization in the US. However, the timing of these events raises an important question about their underlying causes: the eruption of protests and counter-protests coincided with the outbreak of the most severe global crisis of the 21st century - the COVID-19 pandemic.

High demonstration incidence in 2020 was not limited to the US: compared to 2019, demonstrations increased by $7 \%$ worldwide (Kishi et al. 2021). The three other countries examined in the present research —Denmark, Hungary, and Italy —also recorded hundreds and thousands of demonstrations, with a higher incidence in the second half of 2020, potentially after the adverse effects of the pandemic had accumulated. ${ }^{2}$ Indeed, many events were directly linked to the pandemic, particularly to restrictions imposed by governments ("lockdowns") to halt the infections. For example, in Denmark, anti-lockdown protesters torched a human-sized figure of the prime minister (Ilsøe 2021); in Italy, an anti-lockdown protest turned into a riot, wounding ten police officers (Donato \& Dewan 2020); in Hungary, students destroyed dormitories with hammers after the prime minister announced that higher education moved online (Annár 2020); in the US, armed anti-lockdown protesters entered the Michigan State Capitol (BBC News 2020).

The link between the psychological burden of the COVID-19 pandemic and antigovernment sentiments features prominently in public debates, with anger over restricted rights and economic hardship often cited among the causes of unrest (Henley 2020). Yet, systematic evidence on these associations remains limited. Some studies examine how the pandemic affects political attitudes, for example, support for illiberal policies (Arceneaux, Bakker, Hobolt, \& De Vries 2020), demand for autocratic leadership (Amat, Arenas, Falcó-Gimeno, \& Muñoz 2020), and approval of governments following lockdows (Bækgaard, Christensen, Madsen, \& Mikkelsen

\footnotetext{
1 "Demonstrations" include all events coded with event type protest and all events coded with sub-event type violent demonstration in ACLED (Raleigh, Linke, Hegre, \& Karlsen 2010). Below, "demonstration" and "protest" interchangeably refer to these events.

${ }^{2}$ Denmark, Hungary, and Italy experienced, respectively, 570, 200, and 5562 demonstrations in 2020, of which $57 \%, 65 \%$, and $54 \%$ (respectively) occurred after 30 June (Raleigh et al. 2010).
} 
2020). Yet, to our knowledge, no published work has investigated the link between the burden of COVID-19 and anti-systemic sentiments, i.e., dissatisfaction with the fundamental political and social order.

Although the literature on the COVID-19 pandemic and political attitudes is expanding, the pandemic's effects on political behavior remain largely unexplored. One ongoing project investigates the pandemic's effects on protesting in the US, finding a positive link between financial losses and self-reported participation in the BLM demonstrations (Arora 2020). However, this research has been limited to the US, economic hardship, and protesting in support of BLM. Some related research exists at a higher level of aggregation. Iacoella, Justino, and Martorano (2021) report that stringent government measures were associated with protest incidence in the US, but only in counties with considerable economic inequality. However, this research did not collect individual-level data. Hence, although Iacoella et al. (2021) theorize about psychological processes underpinning protesting, they did not directly measure people's perceptions of COVID-19 burden and motivations to engage in protests. Altogether, we have little evidence on - and an urgent need to understand - how the COVID-19 pandemic affects people's political attitudes and behavior, in particular hostility toward governments and the system writ large.

Here, we examine the association between the psychological burden of living through the pandemic, or COVID-19 burden, and anti-systemic attitudes and behaviors, including their most hostile forms. Specifically, we focus on the recently established construct of the Need for Chaos: "a desire for a new beginning through the destruction of order and established structures" (Arceneaux et al. 2021; Petersen, Osmundsen, \& Arceneaux 2018). This construct reflects generalized aggressive desires elicited, in part, by feelings of social exclusion and a lack of control over life. In this way, need for chaos likely involves strong feelings of "upward contempt", i.e., elite-directed contempt, which has been found to motivate "non-normative forms of action that challenge the legitimacy of the current social system" (Becker \& Tausch 2015). While need for chaos represents an extreme form of anti-systemic attitudes, recent research suggests that such hostile sentiments may have some hold in up to $40 \%$ of the population in Western countries (Arceneaux et al. 2021).

Furthermore, we analyze political activism, understood here as participation in collective action for political causes. Our goal is to explain participation in collective action, not individual 
behavior directed at improving personal conditions (Wright, Taylor, \& Moghaddam 1990). In collective action, a group member engages as a representative of the group and the action is directed at improving the condition of the entire group (Wright et al. 1990). Political causes include incompatibilities over state- or national-level politics, for example, the form of state governance, particular policies, or laws. Protests against stringent anti-COVID-19 policies or the criminal justice systems are examples of political activism. When political activism involves violence, we refer to it as "political violence".

\section{How can the psychological burden of COVID-19 promote anti-systemic atti- tudes and behaviors?}

The pandemic and lockdowns can erode social relationships (Killgore, Cloonen, Taylor, \& Dailey 2020), undermine physical and mental health (Clemmensen, Petersen, \& Sørensen 2020; Cullen, Gulati, \& Kelly 2020), induce disease-related fears (Ornell, Schuch, Sordi, \& Kessler 2020), and generate economic losses (Laborde, Martin, \& Vos 2020). These outcomes, in turn, can increase social exclusion - a predictor of aggression (Twenge, Baumeister, Tice, \& Stucke 2001) — or promote risk-seeking aimed at preventing losses (Kahneman \& Tversky 1984). Socioeconomic losses can also create frustrations, leading to aggression via the frustration-aggression link (Berkowitz 1989). Such aggression can be directed toward actors that are held responsible for the adverse effects of the pandemic, which are typically governments.

The theorized psychological pathways - connecting the pandemic's adverse effects to antigovernment attitudes and behaviors - is consistent with extant research on political violence. Radicalization research suggests that social exclusion or marginalization can activate a "quest for significance", a key motivator of violent extremism (Kruglanski et al. 2014). Research on need for chaos indicates that marginalization also promotes a generalized desire to "burn down" established societal and political structures (Arceneaux et al. 2020; Petersen et al. 2018). Furthermore, authoritarianism research shows that societal threat (e.g., deteriorating national economy) promotes endorsement of the use of force among authoritarians (Feldman \& Stenner 1997).

The pandemic potentially generates anti-government sentiments and behaviors via several pandemic-specific pathways (e.g., unprecedented social exclusion); however, it also likely affects psychological variables and pathways emphasized in extant collective action models (van 
Zomeren, Postmes, \& Spears 2008). The pandemic can disproportionally afflict particular social groups (Arora 2020), generating anger over group-based injustice. Anger shared among members of a disadvantaged group is a key motivator of participation in collective action (van Zomeren et al. 2008). The pandemic can concurrently undermine people's sense of political efficacy (i.e., beliefs about the ability to effect political change), because collective action is impeded by lockdowns and governments are seen as having greater powers to enforce stringent policies than they would during normal times. Low political efficacy, in turn, has been show to predict engagement in non-normative (violent), rather than normative (peaceful), collective action (Becker \& Tausch 2015).

In the US, the COVID-19 pandemic coincided with salient events of police brutality, causing widespread anger over another group-based injustice. The murder of George Floyd may have served as a major catalyzing event, unleashing anger concurrently caused by the pandemic. The combination of COVID-19 burden and police brutality potentially created "a perfect storm", leading to a wave of contention in the US and beyond (Kishi \& Jones 2020).

\section{Hypotheses}

We tested, specifically, whether the psychological burden of the COVID-19 pandemic is associated with anti-systemic attitudes (need for chaos) (H1) and antigovernment behaviors (peaceful activism and political violence) (H2). We also tested whether the association between COVID19 burden and antigovernment behaviors is moderated by other disruptive events. Given the massive demonstrations following the murder of George Floyd, we predicted that police violence may act as a catalyst igniting activism and violence among those already suffering from the pandemic. Specifically, we tested whether perceptions and self-reported experience of police violence increased (i.e., moderated) the association between perceived COVID-19 burden and antigovernment behaviors (H3).

\section{Method}

\section{Data}

We collected two-wave panel data (i.e., repeated measurements of individuals) via online surveys of adults in countries with different degrees of political polarization, or animosity across partisan 
lines, and expected COVID-19 burden: the US, Denmark, Italy, and Hungary $\left(N_{\mathrm{s}}=6,131\right.$ and 4,568 in Waves 1 and 2 respectively). At the time of the surveys, Denmark and Hungary were considerably less affected by COVID-19 in terms of cases and deaths than Italy and the US. Furthermore, political polarization was high in Hungary and the US, more moderate in Italy, and low in Denmark (Coppedge et al. 2020), both in general and in debates about the COVID19 specifically. By collecting data in these four countries we thus aimed to assess whether our results generalize to contexts with varying degrees of polarization and psychological COVID19 burden. In addition, the four countries varied with respect to democracy level. Whereas Denmark and Italy were classified as highly democratic regimes, the US and Hungary recently experienced democratic backsliding (Repucci 2020).

Wave 1 was collected in the second half of April 2020 and Wave 2 between the second half of June and the end of July 2020. All surveys were administered in native languages and conducted by the survey agency YouGov. YouGov quota-sampled for age, gender, geography, and education to obtain nationally representative samples. For Wave 1, we asked YouGov to collect 1,500 completed questionnaires in each country. No a priori power analyses were conducted. Post-hoc sensitivity analyses demonstrate that the main models can detect small associations with $80 \%$ power at $5 \%$ alpha, with the exception of the interaction tests (H3) in the US; Section S17 in the Supplemental Material online provides details.

In Wave 2, we aimed to recruit as many as possible from Wave 1 but had no fixed target. In Wave 2, the data collection stopped when the survey agency deemed that it was not realistic to collect more responses. $75 \%$ of Wave 1 interviewees completed Wave 2 (76\% in the US, $85 \%$ in Denmark, $80 \%$ in Italy, and 58\% in Hungary). Our analyses below include tests of potential attrition bias. We did not have access to the data before the data collection stopped. In the main analyses, we coded don't know and prefer not to state as missing values.

\section{Outcomes}

To test H1, we used a validated Need for Chaos Scale (Petersen et al. 2018). Interviewees indicated their agreement with eight items on a seven-point Likert scale (S1 provides item formulations). The scale showed satisfactory reliability across the four samples and the two waves: Cronbach's $\alpha$ s ranged from .84 (Hungary) to .90 (the US) in Wave 1, and from .85 
(Hungary and Italy) to .90 (the US) in Wave 2.

To assess political and non-political aspects of need for chaos, we used the two sub-scales:

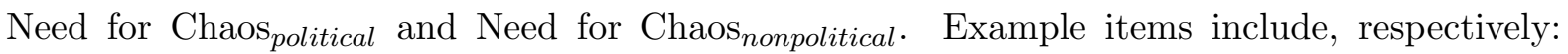
"When I think about our political and social institutions, I cannot help thinking 'just let them all burn" "; "I fantasize about a natural disaster wiping out most of humanity such that a small group of people can start all over". For Need for Chaospolitical, Cronbach's $\alpha$ s ranged from .74 (Italy) to .83 (Denmark) in Wave 1, and from .76 (Italy) to .81 (the US and Denmark) in Wave 2. For Need for Chaos $_{\text {nonpolitical }}, \alpha$ s ranged from .78 (Italy) to .88 (the US) in Wave 1, and from .79 (Denmark) to .89 (the US) in Wave 2.

To test H2, we used two validated scales: Activism Intention Scale and Radicalism Intention Scale (Moskalenko \& McCauley 2009). The first scale measures behavioral intentions to engage in peaceful political activism (e.g., "I would travel for one hour to join in a public protest, or demonstration in support of my group") and the second scale measures behavioral intentions to engage in political violence (e.g., "I would participate in a public protest against oppression of my group even if I thought the protest might turn violent") (see S2 for other items). Both scales were measured on a seven-point Likert scale and were obtained only in Wave 2. For non-violent intentions, $\alpha$ s ranged from .85 (Italy and Hungary) to .87 (Denmark). For violent intentions, $\alpha$ s ranged from .82 (Italy) to .85 (Denmark and Hungary). Behavioral intentions correlate with actual behavior (Sheeran 2002), including participation in collective action (van Zomeren et al. 2008) and fighting in armed conflicts (Gómez et al. 2017).

Interviewees may be unwilling to report intentions to engage in political violence, for example, due to self-representation concerns. Therefore, we also measured behavioral intentions to engage in violence via a list experiment, an item-count technique. The list experiment allowed us to estimate the proportion of the sample agreeing with the sensitive statement without asking individual interviewees to explicitly express support for it. To elaborate, we assigned a random half of interviewees to the BASELINE LIST with four neutral statements (e.g., "I enjoy listening to music"; see S3 for other items), and the other half to the TREATMENT LIST that included the same four neutral statements plus the sensitive statement: "I would use violence against the government or other authorities (for example, during a protest)". Subsequently, we asked the interviewees to indicate how many of the statements they agree with. Since interviewees 
indicated the number of statements they agree with, rather than agreement with particular statements, we expected the list experiment to reduce socially desirable responding.

Analysis of a list experiment assumes that agreement with neutral statements is on average the same for interviewees presented with a BASELINE LIST and those presented with a TREATMENT LIST. Given this, the standard procedure for analyzing a list experiment involves, first, generating subsamples based on predictor scores and, second, estimating the proportion of interviewees (within each subsample) who agree with the sensitive item. This proportion is estimated by subtracting the mean agreement for the BASELINE LIST from the mean agreement for the TREATMENT LIST. This is a standard difference-in-means estimator. We report estimates generated by this estimator below, and those generated by more complex estimators in S13.

We also obtained self-reports of participation in protests and political violence using standardized questions from the Global Barometer Surveys. Interviewees indicated whether they "attended a demonstration or a protest march" and whether they "used force or violence for a political cause" using a five-point scale from no, would never do this to yes, often (S4 provides complete question formulation). We expected this outcome to be relevant only in the analysis of the US sample, because none of the other countries recently experienced protest events of such large scale.

Finally, in the US sample we also obtained self-reports of participation, specifically, in the BLM protests and counter-protests. We used the formulation from the Global Barometer Surveys as a template, supplemented with specific questions about engagement in various activities (see Fig. 2) during the demonstrations. S5 provides complete question formulation.

\section{Predictors}

To measure COVID-19 burden, we introduced a formative index, the Perceived COVID-19 Burden Scale. Interviewees indicated their agreement with 10 items on a seven-point Likert scale, reflecting burden with respect to physical and mental health (e.g., "I have felt extremely unwell as a consequence of the coronavirus crisis"), finances/economy ("The coronavirus crisis has affected negatively my financial situation"), political rights ("The extraordinary measures taken by the government in response to the coronavirus crisis make me concerned about my democratic rights"), social life ("My social life has suffered a great deal due to the coronavirus 
crisis"), and state protection ("The coronavirus crisis made me realize that all individuals can only rely on themselves"). See S6 for other items.

To assess the interaction with police violence (i.e., H3), we obtained two measures. First, we measured perceived and self-reported experience of police violence with the Police Violence Scale. The scale reflects interviewees' perceptions of police violence (a) among typical people, (b) among friends and family, and (c) self-reported personal experience of police violence (e.g., "short-term detainment" or being "beaten up by police"; see S7 for other items). Second, we embedded a randomized experiment in the questionnaire that aimed to manipulate the salience of police violence. The treatment and control conditions differed with respect to question orders. In the treatment condition, interviewees first replied to questions about police violence and then immediately to questions about political activism and political violence. In the control condition, interviewees replied to questions about outcomes first, and then to questions about police violence. This questions-as-treatment experiment (Transue 2007) tested whether manipulating the salience of police violence increased the association of perceived COVID-19 burden with political activism and political violence.

We also obtained a basic set of demographics: age (15 age categories from 18-22 to 90+), gender (man and woman coded 0 and 1 respectively), race (in the US-specific models; White, Black, Hispanic, Asian, Native American, Mixed, Other), and education (low, medium, and high). In the robustness analyses presented below, we controlled for additional variables. S8S10 provide descriptive statistics, histograms, and bivariate correlations for all predictors and outcomes.

\section{Modeling}

Perceived COVID-19 burden and anti-systemic attitudes (need for chaos) were measured at both survey waves. By contrast, intentions to engage in non-violent activism and political violence, as well as self-reported participation in violence were only measured at Wave 2. Given this, we estimated two types of models: (a) standard multiple regressions with predictors measured at Wave 1 and outcomes measured at Wave 2; these models were applicable to all our outcomes; (b) two-way linear fixed effects regressions with predictors and outcomes measured at both survey waves; these models were only applicable to need for chaos. 
The first type of models used between-individual variation in predictors and outcomes to estimate the coefficients (hence, below refereed to as "between-individual models"). These models were thus vulnerable to confounding by individual-level omitted variables. Therefore, we controlled for the demographics as described above. However, since we cannot account for all possible individual-level confounders, the estimates of the between-individual models should be interpreted as reflecting associations. We used Wave 1 predictors and Wave 2 outcomes to alleviate concerns over reverse causality. However, we cannot rule out the possibility that (unmeasured) outcomes prior to Wave 1 influenced Wave 1 predictors.

The second type of models used within-individual variation over time ("within-individual models"). These models are analogous to multilevel models commonly used in personality psychology to study psychological processes within people (Christ, Sibley, \& Wagner 2018); see also McNeish and Kelley (2019). In such multilevel models, repeated measurements of individuals constitute level-1 observations (e.g., experience of some events measured at daily intervals for the same person), and measurements of individual traits constitute level-2 observations. The key advantage of these models is that they allow estimating within-individual effects with time-invariant between-individual effects entirely removed from the coefficients. In linear two-way fixed effects models, as well as linear multilevel models, this is achieved by individuallevel demeaning, i.e., subtracting within-individual means of each variable from each observation. These models thus estimate whether within-individual changes in the predictors relate to within-individual changes in the outcomes. Since most individual traits remain constant over short periods of time, their influence on the within-individual variation in the predictors and outcomes is controlled for. As such, these models - by design - fully control for all (observable and unobservable) time-invariant characteristics. Given this, our main two-way fixed-effects specifications did not include any individual-level controls; we only included a dummy variable representing the survey waves, which controlled for the overall changes in the predictors and outcomes between the two waves. Importantly, while these estimators effectively control for all time-invariant characteristics, confounding from time-varying variables and reverse causality remain potential sources of bias. Hence, although our within-individual models address key sources of unmeasured confounding (e.g., stable individual differences), their estimates should also be interpreted as reflecting associations. 
We conducted tests on the individual samples and on the pooled sample (i.e., after merging samples from all countries into one). The within-individual models account for both individualand country-level time-invariant confounding. To account for country-level confounding in the between-individual models, we used country-level demeaning (McNeish \& Kelley 2019). To aid interpretation of coefficients, we rescaled all variables to range from 0 to 1 .

\section{Open Practices Statement}

The research plan was preregistered at the Open Science Framework (OSF) (link to the OSF pre-registration). The data files, command script, and the original questionnaire are deposited at our OSF project page (link to the OSF repository).

\section{Results}

Is the psychological burden of COVID-19 associated with anti-systemic attitudes? Yes. For comparability across outcomes, we first estimated between-individual models with the Perceived COVID-19 Burden Scale measured at Wave 1 and the Need for Chaos Scale measured at Wave 2. These models identified positive associations in the pooled and separate samples; see Figure 1. We then used within-individual models on the entire panel data. Perceived COVID-19 burden was associated with need for chaos, $b$ (unstandardised regression coefficient) $=0.11,95 \%$ CI $=[0.07,0.15]$. Subsequent analyses indicated that perceived COVID-19 burden was associated with both the political $(b=0.15,95 \% \mathrm{CI}=[0.10,0.21])$ and non-political $(b=0.08,95 \% \mathrm{CI}$ $=[0.04,0.12])$ components of need for chaos. In our data, the largest within-individual change in the Perceived COVID-19 Burden Scale from Wave 1 to Wave 2 was 0.54. According to our analyses, such a change in perceived COVID-19 burden would be associated with a $6 \%$ change in need for chaos.

Is the psychological burden of COVID-19 associated with non-violent political activism and political violence? Yes. Here and below, we estimate between-individual models. As shown in Figure 1 below, perceived COVID-19 burden was associated with both the Activism Intention Scale and Radicalism Intention Scale. A one-standard-deviation increase in the Perceived COVID-19 Burden Scale was associated with $2.2 \%$ and $3.8 \%$ increases in activism and radicalism intentions, respectively. The association between perceived COVID-19 burden and non-violent 

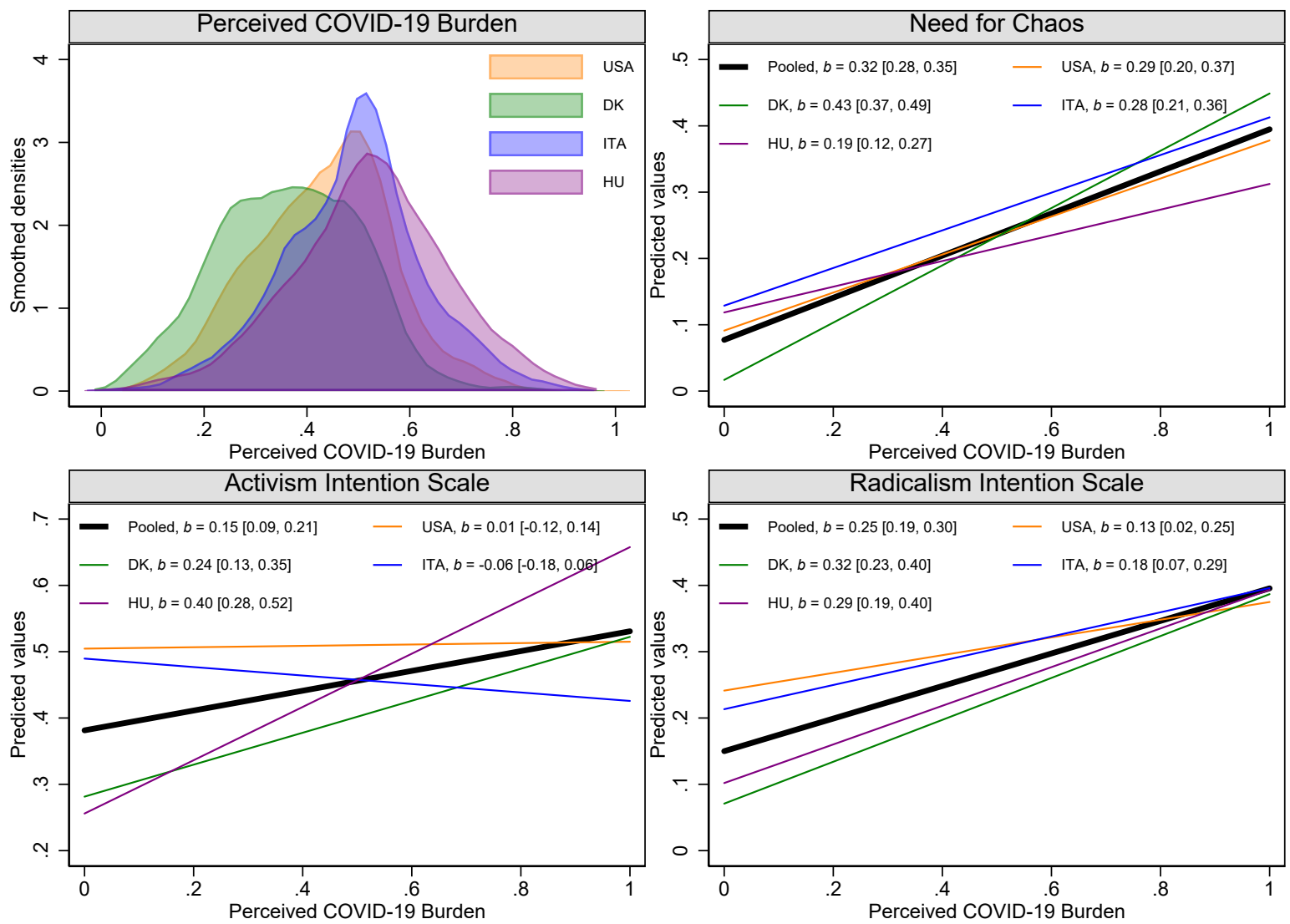

Figure 1: The relationship between the psychological burden of the COVID-19 pandemic and anti-systemic attitudes and behavior. All predictors and outcomes are rescaled to $0-1$.

activism was driven by Hungary and Denmark (Fig. 1). By contrast, perceived COVID-19 burden was consistently associated with radicalism in all four countries. Tables S19-S20 provide details.

Is the psychological burden of COVID-19 associated with intentions to engage in political violence measured with a list experiment? Yes. We first estimated the overall proportion of interviewees who agreed with the sensitive item: "I would use violence against the government or other authorities (for example, during a protest)". Here, we used a difference-in-means estimator and subtracted mean agreement (average number of statements interviewees agreed with) in the BASELINE LIST from the mean agreement in the TREATMENT LIST, $2.178-2.111=0.067$. The analysis thus suggests that $6.7 \%$ of interviewees agreed with the sensitive statement, i.e., expressed intentions to engage in political violence. For comparison, the proportion of interviewees who expressed intentions to engage in political violence, when asked directly ("Would you do this if you had the chance? Use force or violence for a political cause (for example, during 
a demonstration)" was $5.9 \%$ (among responders). We then generated two subsamples using a median split: low and high perceived COVID-19 burden ( $n \mathrm{~s}=2,118$ and 2,450, respectively). In turn, we estimated analogous proportions of interviewees in each subsample agreeing with the sensitive statement, which were $0.7 \%$ and $11.9 \%$, respectively. Hence, the proportion of interviewees who agreed with the sensitive statement was larger by 11.2 percentage points in the high-burden subsample. Subsequently, we conducted analogous analyses with alternative estimators, which allowed adding controls. Furthermore, instead of estimating agreement proportions in (arbitrarily-split) subsamples, these analyses allowed predicting the probability of agreeing with the sensitive item in response to one unit change in the continuous Perceived COVID-19 Burden Scale. We elaborate the results of these analyses in S12, which correspond to those produced by the difference-in-means estimator.

Is the psychological burden of COVID-19 associated with participation in protests and political violence in the US? Yes and no. Higher perceived COVID-19 burden was associated with self-reported participation in political violence $(b=0.15,95 \% \mathrm{CI}=[0.07,0.22])$, but not with self-reported participation in protests $(b=0.04,95 \% \mathrm{CI}=[-0.08,0.17])$ (Table S21).

Is the psychological burden of COVID-19 associated with participation, specifically, in the $B L M$ protests and counter-protests? Yes and no. As shown in Figure 2, higher perceived COVID-19 burden did not significantly relate to self-reported participation in protests in support of the BLM movement and protesting against rioting and looting. By contrast, higher perceived COVID-19 burden was significantly associated with engagement in all other actions, most of which are characterised by violence. Tables S22 and S23 report estimates for all predictors, including indicators of ethnicity, which were significantly associated with particular types of actions during the BLM protests and counter protests.

Does police violence increase (moderate) the association between perceived COVID-19 burden and antigovernment behaviors? No, with qualifications. We first analyzed the interaction between the Perceived COVID-19 Burden Scale and the binary indicator of assignment to treatment (the salience of police violence). In the pooled sample, the salience of police violence did not significantly moderate the association of perceived COVID-19 burden with the Activism Intention Scale (Table S24) and Radicalism Intention Scale (Table S25). Hence, disconfirming H3, the association between perceived COVID-19 burden and (non-violent and violent) intentions 


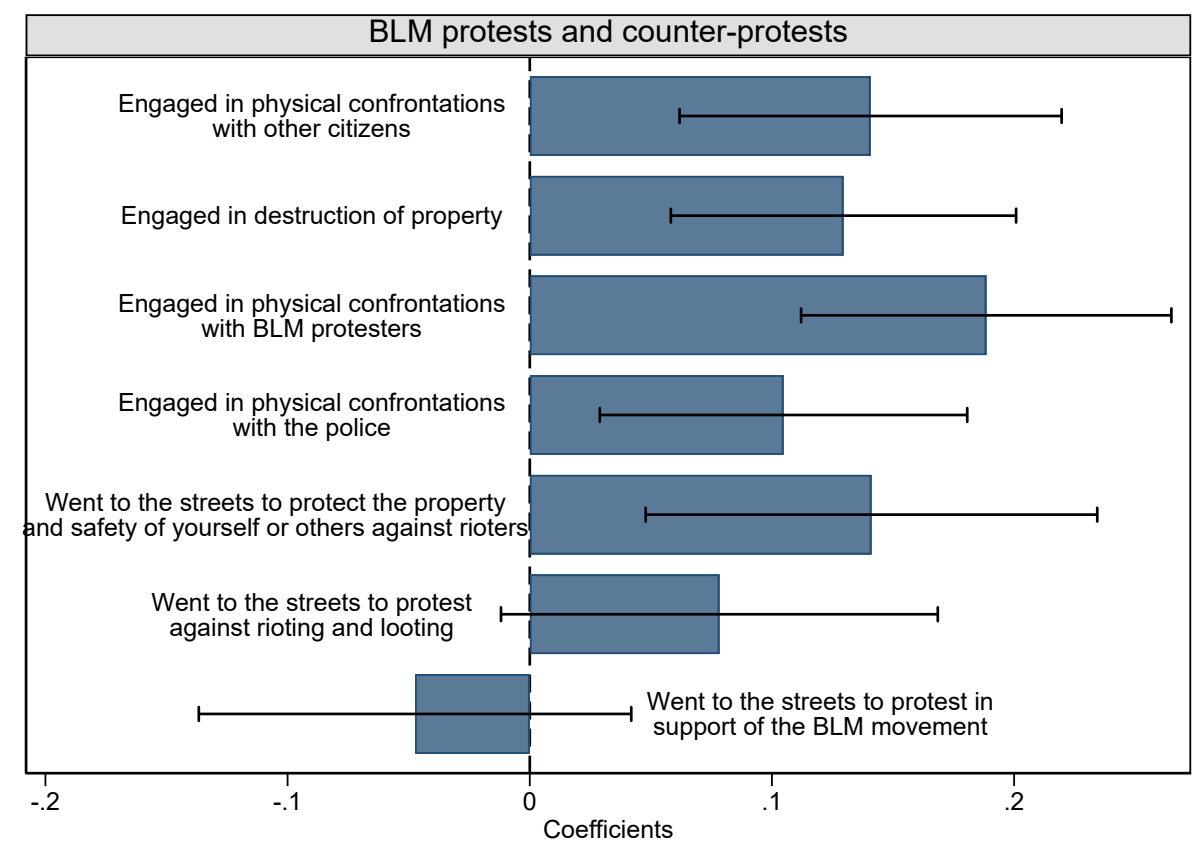

Figure 2: The relationship between the psychological burden of the COVID-19 pandemic and participation in the BLM protests and counter-protests. The figure reports regression coefficients (variables are rescaled to 0-1) and the corresponding $95 \%$ CIs.

was not significantly stronger among interviewees who were primed to consider police violence. As a non-preregistered extension, we also analyzed the treatment indicator as a predictor, rather than as a moderator, finding no significant effects on the two outcomes (Table S26).

Subsequently, we analyzed the Police Violence Scale, a measure of perceptions and selfreported experience of police violence, as another moderator. In the pooled sample, the scale did not significantly moderate the association of perceived COVID-19 burden with activism intentions (Table S27) but significantly and negatively moderated the association with radicalism intentions, $b=-0.40,95 \% \mathrm{CI}=[-0.64,-0.17]$. Hence, opposite to our expectation, the association between perceived COVID-19 burden and radicalism intentions was significantly weaker among interviewees who scored higher on the Police Violence Scale. Note, however, that the interaction term varied considerably across the four samples (e.g., it was non-significant in the US sample) (Table S28). We also analyzed the Police Violence Scale as a predictor, rather than as a moderator, and found significant coefficients in both activism $(b=0.35,95 \% \mathrm{CI}=[0.31,0.40])$ and radicalism $(b=0.46,95 \% \mathrm{CI}=[0.42,0.49])$ models (Table S29).

Turning to the US sample, specifically, the Police Violence Scale did not significantly mod- 
erate the associations of perceived COVID-19 burden with participation in protests, generally, and participation in protests in support of BLM, specifically. By contrast, the scale significantly moderated the association between perceived COVID-19 burden and self-reported participation in political violence, generally, $b=0.82,95 \% \mathrm{CI}=[0.49,1.16]$ (Table S30). Similarly, the scale also significantly moderated the associations of perceived COVID-19 burden and self-reported participation in the protests against rioting and looting $(b=0.42,95 \% \mathrm{CI}=[0.02,0.82])$, physical confrontation with the police $(b=0.50,95 \% \mathrm{CI}=[0.17,0.82])$, physical confrontation with BLM protesters $(b=0.59,95 \% \mathrm{CI}=[0.25,0.93])$, destruction of property $(b=0.77,95 \% \mathrm{CI}=$ $[0.47,1.08])$, physical confrontation with other citizens $(b=0.52,95 \% \mathrm{CI}=[0.18,0.86])$, but not the association with self-reported participation in the protests to protect property and the safety of oneself and others (Tables S32-S33). Thus, partly corroborating H3, the association of perceived COVID-19 burden with violence - but not with peaceful activism - was stronger among interviewees who scored higher or the Police Violence Scale. Finally, the Police Violence Scale, when analyzed as a predictor (rather than as a moderator), was significantly associated with all the BLM-related outcomes (Tables S31, S34-S35).

How robust are the results? (The following analyses were not pre-registered). First, we tested the sensitivity of our results to alternative measurement of perceived COVID-19 burden. Specifically, we re-tested $\mathrm{H} 1$ and $\mathrm{H} 2$ using a 7-item subscale that excluded political items (see S6). These tests produced estimates consistent with the main results (see Tables S36-S42), with one exception: in contrast to the complete scale, the non-political subscale was significantly associated with self-reported participation in non-violent protests in the US in general $(b=$ $0.16,95 \% \mathrm{CI}=[0.04,0.28])($ Table S40), and in support of the BLM movement $(b=0.12,95 \%$ $\mathrm{CI}=[0.04,0.20])$ and against rioting and looting $(b=0.10,95 \% \mathrm{CI}=[0.01,0.18])$ in particular (Table S41).

Second, we controlled for several additional variables: subjective socioeconomic status (SES), measured with the Subjective Social Status Scale (Operario, Adler, \& Williams 2004); COVID-19 infection ("Have you or someone in your close family ever been sick with COVID19?"; reply options: no, yes); and ideology (liberal vs. conservative views in the US; and left vs. right views in Denmark, Italy, and Hungary; see S13). Low-SES individuals may be particularly vulnerable to the adverse effects of the pandemic, and concurrently hold anti-systemic attitudes. 
Similarly, individuals who have been sick with COVID-19 (or have family members who have been sick with COVID-19) may experience the adverse effects more intensely, and concurrently blame governments for sickness. Finally, the pandemic was highly politicized, particularly in the US, potentially increasing political polarization. Hence, our observed association between perceived COVID-19 burden and anti-systemic attitudes and behaviors may in fact reflect political polarization causing both. In addition to the ideology control, we also conducted tests with an alternative: affective polarization (S14). We controlled for these additional variables in both between- and within-individual models. As mentioned, within-individual models fully partition out confounding by time-invariant characteristics; yet, they remain vulnerable to time-varying confounders, and perceptions of SES, infection, and ideology likely changed between the two waves, given the unfolding crisis. We found that the four controls did not notably attenuate the coefficients of interest (Tables S43-S56); although, the association of perceived COVID-19 burden with peaceful political activism and self-reported participation in (peaceful) protests became considerably stronger in the US subsample (see Tables S48 and S51).

Third, we examined particular components of the Perceived COVID-19 Burden Scale. Specifically, we tested $\mathrm{H} 1$ and $\mathrm{H} 2$ using five two-item subscales, reflecting burden with respect to physical and mental health (items 1 and 2), finances/economy (3 and 4), political rights (5 and 6), social life (7 and 8), and state protection (9 and 10) (S6 provides formulations). The analyses indicate that the association between perceived COVID-19 burden and need for chaos is driven by burden with respect to health $(b=0.05,95 \% \mathrm{CI}=[0.03,0.08])$, rights $(b=0.03,95 \% \mathrm{CI}$ $=[0.01,0.05])$, and finances $(b=0.02,95 \% \mathrm{CI}=[0.00,0.04])$ (within-individual specification with all subscales regressed in one block). Similarly, we found that the association between perceived COVID-19 burden and activism intentions is also driven by burden with respect to health $(b=0.11,95 \% \mathrm{CI}=[0.06,0.16])$, rights $(b=0.06,95 \% \mathrm{CI}=[0.02,0.10])$, and finances $(b=0.04,95 \% \mathrm{CI}=[0.01,0.08])$ (between-individual specification with all subscales regressed in one block, plus controls). Finally, the association between perceived COVID-19 burden and radicalism intentions was driven by burden with respect to health $(b=0.20,95 \% \mathrm{CI}=[0.16$, $0.25])$ and rights $(b=0.06,95 \% \mathrm{CI}=[0.03,0.09])$ (between-individual specification with all subscales regressed in one block, plus controls). Tables S57-S62 provide details.

Fourth, the tests of H3 assumed linear interaction effects. Specifically, this assumption 
states that as the moderator (police violence in our case) increases by one unit, the effect of the predictor (perceived COVID-19 burden) on the outcome (anti-systemic attitudes/behavior) changes by some coefficient $b$, and this change is constant across the range of all predictor values (Hainmueller, Mummolo, \& Xu 2019). However, empirical research suggests that the linear interaction effects assumption often fails, and that estimates of linear interaction models may be artifacts of modeling assumptions (Hainmueller et al. 2019). Therefore, we also tested nonlinear interactions using the INTERFLEX package in Stata (Hainmueller et al. 2019). Specifically, we estimated fully flexible models to detect potential non-linearities in the interactions. The estimates of the flexible models largely corresponded to the estimates of the linear models, suggesting that the main results reported above are unlikely to be artefacts of implausible modelling assumptions. We detail these analyses in S16.

Finally, $25 \%$ of interviewees dropped out of Wave 2; therefore, we assessed potential panel attrition bias (note that we only assess attrition bias in the between-individual models of need for chaos, since other outcomes were only measured at Wave 2). Non-zero attrition rate does not necessarily imply bias (e.g., attrition can be random). Bias occurs if attrition correlates with the outcome of interest. Drawing on Fitzgerald, Gottschalk, and Moffitt (1998), we first tested whether a lagged version (i.e., Wave 1) of the Need for Chaos Scale correlated with a binary indicator of attrition (coded 1 for dropping out of Wave 2). We found a positive association in a bivariate logit model $(\operatorname{logit}=0.83,95 \% \mathrm{CI}=[0.55,1.11])$ and a bivariate linear probability model $(b=0.16,95 \% \mathrm{CI}=[0.11,0.22])$. A significant association between a lagged outcome and attrition is an indication of attrition bias in the estimates of interest produced on the attrited sample (Fitzgerald et al. 1998). Subsequently, we tested whether this association remained significant when controlling for the predictors analyzed above-perceived COVID-19 burden, age, gender, education, subjective SES, infection, ideology, and country dummies - and found non-significant estimates, logit $=0.11,95 \% \mathrm{CI}=[-0.24,0.47]$ and $b=0.03,95 \% \mathrm{CI}$ $=[-0.04,0.09]$. This suggests that the residuals in the need for chaos model-containing the above-listed predictors - do not correlate with attrition, providing evidence against attrition bias in our results reported above. Further, the two models produced, respectively, pseudo $R^{2}=0.04$ and $R^{2}=0.04$, suggesting that the predictors and the need for chaos lag explained only about $4 \%$ of variation in attrition. These estimates correspond to several studies of panel 
attrition, which suggest that most attrition in panel surveys is random and, consequently, that attrition bias does not notably influence the estimates of interest (Fitzgerald et al. 1998). Note, however, that we only assessed observed correlates of attrition. Omitted variables could both explain a larger share of variation in attrition and - if correlated with our outcome - cause bias in the estimates produced on the attrited sample.

\section{Discussion}

Our analyses unequivocally supported H1, partly supported H2 (perceived COVID-19 burden was robustly associated with political violence, but not with peaceful activism), and only weakly supported H3. Specifically, we found that perceived COVID-19 burden relates to anti-systemic sentiments and intentions of political violence across the US, Denmark, Italy, and Hungary. In the US, furthermore, perceived COVID-19 burden was associated with self-reported violence during the BLM protests and counter-protests. We found less robust evidence that perceived COVID-19 burden shaped peaceful activism in the US.

Subsequently, we found no consistent evidence that the psychological effects of the pandemic were compounded by police violence in the US. Specifically, perceptions and self-reported experience of police violence increased the association of perceived COVID-19 burden with engagement in several violent actions during the BLM demonstrations and counter-demonstrations. However, our experiments did not support the claim that the salience of police violence increased these associations. Hence, perceived COVID-19 burden potentially drives anti-systemic behavior without additional catalyzing events. These findings do not legitimize or trivialize the negative impacts of police brutality. Indeed, our analyses suggest that perceptions and selfreported experience of police violence constitute an independent predictor of political violence.

\section{Limitations}

First, the within-individual models fully accounted for confounding by time-invariant individual differences, a major source of omitted-variable bias. However, these models could not rule out confounding by unmeasured time-variant characteristics, which potentially constitute a greater concern during a crisis. The between-individual models could rule out neither time-variant nor time-invariant confounding. All models were also vulnerable to reverse-causality bias. Al- 
together, this implies that we cannot buttress strong causal claims. Future studies should collect more than two survey waves, which provide additional means to address confounding and reverse-causality concerns (Leszczensky \& Wolbring 2019).

Second, although we found that the salience of police violence did not produce the hypothesized moderating effects, a possibility exists that our manipulation instrument was insufficiently potent to influence the variable of interest (i.e., people's thoughts about police violence). The null findings may also reflect pre-treatment effects: police violence was a salient issue during our surveys, particularly in the US.

Third, some outcomes (e.g., need for chaos) were associated with perceived COVID-19 burden similarly across all countries, suggesting that the findings generalize across contexts with varying degrees of COVID-19 burden, polarization, and democracy. For other outcomes (nonviolent activism), we observed between-country heterogeneity in the associations. Hence, some country-level characteristics potentially moderate these individual-level associations. Since we only analyzed samples from four countries, we could not formally assess cross-level interactions (and whether the between-country heterogeneity was statistically significant). Future studies are thus needed with a larger $\mathrm{N}$ of higher-level units.

Fourth, we relied on data from four countries frequently characterised as Western, educated, industrialised, rich and democratic (WEIRD) (with the potential exception of Hungary). Research is needed to assess generalization to non-WEIRD countries, where the risk of political violence is generally higher. If COVID-19 burden promotes unrest in WEIRD countries, having strong economies and established political institutions, then such burden may particularly increase the risk of unrest in countries lacking these features.

Finally, we attributed self-reported participation in violence during the BLM protests and counter-protests to perceived COVID-19 burden. However, it is possible that COVID-19 burden promoted participation in demonstrations that were originally peaceful but which turned violent in response to the use of force against the demonstrators. As emphasized, most of the demonstrations associated with the BLM movement were peaceful. By contrast, the government forces exercised heavy-handed approaches to engaging the demonstrators, often inflamed and legitimized by political figures, most notably the president of the US (Kishi \& Jones 2020). Compared to July/August 2019, during the same period in 2020, the use of state force against 
demonstrators rose six times and was disproportional compared to other demonstrations unrelated to the BLM (Kishi \& Jones 2020). The use of state force appears to have provoked - not discouraged - violence and destruction among hitherto peaceful protesters (Kishi \& Jones 2020).

\section{Conclusion}

The demonstrations and violence that marked 2020 were fuelled by many factors. In the US, for example, political polarization, police brutality, and racial injustice were among the most commonly cited ones. Increasingly, scholars and observers suggest that COVID-19 burden was also a major cause. Here, we report systematic evidence that corroborates this proposition. Our research thus suggests that the ongoing pandemic places many countries at an increased risk of political unrest. The violence that marked some of the 2020 demonstrations was likely a manifestation of the psychological toll the pandemic has had on citizens. Our findings constitute a reminder that the COVID-19 pandemic is an all-out crisis, carrying effects far beyond the domain of health. Successful pandemic management thus requires authorities and politicians to consider this disruptive potential both during and after pandemics. During pandemics, interventions should not be more burdensome than necessary and relief programs should be devised to buffer the burden. In the aftermath of pandemics, recovery programs cannot be limited to the domains of public health and the economy. It is key to also repair the relationship between citizens and the political system.

\section{Author contributions}

All the authors developed the study concept, designed the research, and collected data. H.B. and F.J. analyzed the data. All the authors drafted the manuscript and approved the final manuscript for submission.

\section{References}

Afrobarometer. (2015). Merged dataset, Round 5, 2011-2013. Retrieved 2020-11-18, from https://www . afrobarometer.org/ 
Amat, F., Arenas, A., Falcó-Gimeno, A., \& Muñoz, J. (2020). Pandemics meet democracy: Experimental evidence from the COVID-19 crisis in Spain. SocArXiv. doi: 10.31235/ osf.io/dkusw

Annár, D. (2020). Budapest dormitory damaged by students with a hammer. Daily News Hungary. Retrieved 2021-04-28, from https://dailynewshungary . com/budapest -dormitory-damaged-by-students-with-a-hammer/

Arceneaux, K., Bakker, B. N., Hobolt, S., \& De Vries, C. E. (2020). Is COVID-19 a threat to liberal democracy? PsyArXiv. doi: 10.31234/osf.io/8e4pa

Arceneaux, K., Gravelle, T. B., Osmundsen, M., Petersen, M. B., Reifler, J., \& Scotto, T. J. (2021). Some people just want to watch the world burn: The prevalence, psychology and politics of the 'Need for Chaos'. Philosophical Transactions of the Royal Society B, $376(1822), 20200147$.

Arora, M. (2020). How the coronavirus pandemic helped the Floyd protests become the biggest in U.S. history. The Washington Post. Retrieved 2020-1123, from https://www. washingtonpost.com/politics/2020/08/05/how-coronavirus -pandemic-helped-floyd-protests-become-biggest-us-history/

Bækgaard, M., Christensen, J., Madsen, J. K., \& Mikkelsen, K. S. (2020). Rallying around the flag in times of COVID-19: Societal lockdown and trust in democratic institutions. Journal of Behavioral Public Administration, 3(2).

BBC News. (2020). Coronavirus: Armed protesters enter Michigan statehouse. BBC News. Retrieved 2020-11-18, from https://www.bbc.com/news/world-us-canada-52496514

Becker, J. C., \& Tausch, N. (2015). A dynamic model of engagement in normative and nonnormative collective action: Psychological antecedents, consequences, and barriers. European Review of Social Psychology, 26(1), 43-92.

Beckett, L. (2020). At least 25 Americans were killed during protests and political unrest in 2020. The Guardian. Retrieved 2020-11-18, from https://www.theguardian.com/ world/2020/oct/31/americans-killed-protests-political-unrest-acled

Berkowitz, L. (1989). Frustration-aggression hypothesis: Examination and reformulation. Psychological bulletin, 106(1), 59-73.

Bloom, H. S. (1995). Minimum detectable effects: A simple way to report the statistical power 
of experimental designs. Evaluation Review, 19(5), 547-556.

Christ, O., Sibley, C. G., \& Wagner, U. (2018). Multilevel modeling in personality and social psychology. The Oxford handbook of personality and social psychology, 32, 239-261.

Clemmensen, C., Petersen, M. B., \& Sørensen, T. I. (2020). Will the COVID-19 pandemic worsen the obesity epidemic? Nature Reviews Endocrinology, 16(9), 469-470.

Coppedge, M., Gerring, J., Knutsen, C. H., Lindberg, S. I., Teorell, J., Altman, D., .. others (2020). V-dem [country-year/country-date] dataset v10. Varieties of Democracy (V-Dem) Project. doi: 10.23696/vdemds20

Cullen, W., Gulati, G., \& Kelly, B. (2020). Mental health in the COVID-19 pandemic. QJM: An International Journal of Medicine, 113(5), 311-312.

Donato, V. D., \& Dewan, A. (2020). Protesters clash with police in northern Italy as anger mounts over COVID-19 restrictions. CNN. Retrieved 2021-05-06, from https://edition .cnn.com/2020/10/27/europe/italy-coronavirus-protests-intl/index.html

Feldman, S., \& Stenner, K. (1997). Perceived threat and authoritarianism. Political Psychology, 18(4), 741-770.

Fitzgerald, J., Gottschalk, P., \& Moffitt, R. (1998). An analysis of sample attrition in panel data: The Michigan Panel Study of Income Dynamics. The Journal of Human Resources, 33(2), 251-299.

Gelman, A., Hill, J., \& Vehtari, A. (2020). Regression and other stories. Cambridge University Press.

Gómez, Á., López-Rodríguez, L., Sheikh, H., Ginges, J., Wilson, L., Waziri, H., .. Atran, S. (2017). The devoted actor's will to fight and the spiritual dimension of human conflict. Nature Human Behaviour, 1(9), 673-679.

Hainmueller, J., Mummolo, J., \& Xu, Y. (2019). How much should we trust estimates from multiplicative interaction models? Simple tools to improve empirical practice. Political Analysis, 27(2), 163-192.

Henley, J. (2020). Latest coronavirus lockdowns spark protests across Europe. The Guardian. Retrieved 2020-11-18, from https://www.theguardian.com/world/2020/ nov/02/latest-coronavirus-lockdowns-spark-protests-across-europe

Iacoella, F., Justino, P., \& Martorano, B. (2021). Do pandemics lead to rebellion? Policy 
responses to COVID-19, inequality, and protests in the USA (Tech. Rep.). World Institute for Development Economic Research (UNU-WIDER).

Ilsøe, T. M. (2021). Seks personer dømt efter men in black-demoer. DR-The Danish Broadcasting Company. Retrieved 2021-05-06, from https://www.dr.dk/nyheder/indland/ overblik-seks-personer-doemt-efter-men-black-demoer

Kahneman, D., \& Tversky, A. (1984). Choices, values, and frames. American Psychologist, $39(4), 341-350$.

Killgore, W. D., Cloonen, S. A., Taylor, E. C., \& Dailey, N. S. (2020). Loneliness: A signature mental health concern in the era of COVID-19. Psychiatry Research, 113117.

Kishi, R., \& Jones, S. (2020). Demonstrations and political violence in America: New data for summer 2020. acleddata.com. Retrieved 2020-11-18, from https://acleddata.com/2020/09/03/demonstrations-political-violence-in -america-new-data-for-summer-2020/

Kishi, R., Pavlik, M., Bynum, E., Miller, A., Goos, C., Satre, J., \& Jones, S. (2021). ACLED 2020: The year in review. acleddata.com. Retrieved 2021-05-15, from https://acleddata .com/2021/03/18/acled-2020-the-year-in-review/

Kruglanski, A. W., Gelfand, M. J., Bélanger, J. J., Sheveland, A., Hetiarachchi, M., \& Gunaratna, R. (2014). The psychology of radicalization and deradicalization: How significance quest impacts violent extremism. Political Psychology, 35, 69-93.

Laborde, D., Martin, W., \& Vos, R. (2020). Poverty and food insecurity could grow dramatically as COVID-19 spreads. International Food Policy Research Institute (IFPRI), Washington, $D C$.

Leszczensky, L., \& Wolbring, T. (2019). How to deal with reverse causality using panel data? Recommendations for researchers based on a simulation study. Sociological Methods 86 Research, 0049124119882473.

McNeish, D., \& Kelley, K. (2019). Fixed effects models versus mixed effects models for clustered data: Reviewing the approaches, disentangling the differences, and making recommendations. Psychological Methods, 24(1), 20.

Moskalenko, S., \& McCauley, C. (2009). Measuring political mobilization: The distinction between activism and radicalism. Terrorism and Political Violence, 21(2), 239-260. 
Operario, D., Adler, N. E., \& Williams, D. R. (2004). Subjective social status: Reliability and predictive utility for global health. Psychology \& Health, 19(2), 237-246.

Ornell, F., Schuch, J. B., Sordi, A. O., \& Kessler, F. H. P. (2020). Pandemic fear and COVID-19: Mental health burden and strategies. Brazilian Journal of Psychiatry, 42(3), 232-235.

Petersen, M. B., Osmundsen, M., \& Arceneaux, K. (2018). A "need for chaos" and the sharing of hostile political rumors in advanced democracies. PsyArXiv. doi: 10.31234/osf.io/6m4ts

Raleigh, C., Linke, A., Hegre, H., \& Karlsen, J. (2010). Introducing ACLED: an Armed Conflict Location and Event Dataset: Special data feature. Journal of peace research, 47(5), 651-660.

Repucci, S. (2020). A leaderless struggle for democracy. Highlights from Freedom House Annual Report on Political Rights and Civil Liberties: FREEDOM IN THE WORLD 2020.

Sheeran, P. (2002). Intention - behavior relations: A conceptual and empirical review. European Review of Social Psychology, 12(1), 1-36.

Transue, J. E. (2007). Identity salience, identity acceptance, and racial policy attitudes: American national identity as a uniting force. American Journal of Political Science, 51(1), 78-91.

Tsai, C.-l. (2019). Statistical analysis of the item-count technique using Stata. The Stata Journal, 19(2), 390-434.

Twenge, J. M., Baumeister, R. F., Tice, D. M., \& Stucke, T. S. (2001). If you can’t join them, beat them: Effects of social exclusion on aggressive behavior. Journal of Personality and Social Psychology, 81(6), 1058.

van Zomeren, M., Postmes, T., \& Spears, R. (2008). Toward an integrative social identity model of collective action: A quantitative research synthesis of three socio-psychological perspectives. Psychological Bulletin, $134(4), 504$.

Wright, S. C., Taylor, D. M., \& Moghaddam, F. M. (1990). Responding to membership in a disadvantaged group: From acceptance to collective protest. Journal of personality and social psychology, 58(6), 994-1003. 


\section{Supplemental Online Material (SOM-R) for}

The psychological burden of the COVID-19 pandemic is associated with anti-systemic attitudes and political violence

\section{Contents}

S1 Need for Chaos Scale

S2 Activism and Radicalism Intention Scales

S3 List experiment

S4 Self-reports of participation in protests and political violence

S5 Self-reports of participation in the BLM protests and counter-protests

S6 Perceived COVID-19 Burden Scale

S7 Police Violence Scale

S8 Descriptive Statistics

S9 Histograms

S10Bivariate correlations

S11Regression estimates: Main analyses

S12 Analysis of list experiment: Extensions

S13Ideology measures

S14 Affective polarization (right and left)

S15Regression estimates: Robustness tests and extensions 


\section{S1 Need for Chaos Scale}

How much do you disagree or agree with the following statements?

1. I get a kick when natural disasters strike in foreign countries.

2. I fantasize about a natural disaster wiping out most of humanity such that a small group of people can start all over.

3. I think society should be burned to the ground.

4. When I think about our political and social institutions, I cannot help thinking "just let them all burn".

5. We cannot fix the problems in our social institutions, we need to tear them down and start over.

6. I need chaos around me - it is too boring if nothing is going on.

7. Sometimes I just feel like destroying beautiful things.

8. There is no right and wrong in the world.

Note: The answer options ranged from strongly agree $=0$ to strongly disagree $=6$ (integers after the equality signs represent coding values). Note that in the main analyses we used a reversed scale, with higher scores indicating higher need for chaos. Items $3-5$ form the political NFC sub-scale $\left(\mathrm{NFC}_{\text {political }}\right)$. Items $1-2,6-8$ constitute the non-political NFC subscale $\left(\mathrm{NFC}_{\text {non-political }}\right)$. See the original article for further details on the scale (Petersen et al. 2018). 


\section{S2 Activism and Radicalism Intention Scales}

The following are some statements about things people might do as citizens. Please indicate how much you agree with each statement.

1. I would join/belong to an organization that seeks to improve my group's political and legal rights.

2. I would donate money to an organization that seeks to improve my group's political and legal rights.

3. I would volunteer my time working (i.e., write petitions, distribute flyers, recruit people, etc.) for an organization that seeks to improve my group's political and legal rights.

4. I would travel for one hour to join in a public protest, or demonstration in support of my group.

5. I would continue to support an organization that seeks to improve my group's political and legal rights even if the organization sometimes breaks the law.

6. I would continue to support an organization that seeks to improve my group's political and legal rights even if the organization sometimes resorts to violence.

7. I would participate in a public protest against oppression of my group even if I thought the protest might turn violent.

8. I would attack police or security forces if I saw them beating members of my group.

Note: The answer options ranged from strongly disagree $=0$ to strongly agree $=6$, and included prefer not to state. Items 1-4 form the Activism Intention Scale (AIS). Items 5-8 constitute the Radicalism Intention Scale (RIS). See the original article for details (Moskalenko \& McCauley 2009). 


\section{S3 List experiment}

Below are four statements. Please tell us with how many of them you agree. We do not need to know which ones you agree with, just how many.

[Neutral items]

1. I enjoy listening to music.

2. Schools should teach more biology.

3. Schools should teach more Christian values.

4. I would like to work as a cleaner.

[Treatment item]

5. I would use violence against the government or other authorities (for example, during a protest).

How many statements do you agree with?

NoTE: Random half of interviewees received only the neutral item list, and another half received the neutral item list plus the treatment item. The text in brackets constitutes our notes (the interviewees did not see these notes). The answer options ranged from 0 to 4 for interviewees receiving only the neutral list, and from 0 to 5 for interviewees receiving the neutral list and the treatment item. 


\section{S4 Self-reports of participation in protests and political vio- lence}

Here is a list of actions that people sometimes take as citizens. For each of these, please tell me whether you, personally, have done any of these things during the past year. If not, would you do this if you had the chance?

1. Attended a demonstration or a protest march.

2. Used force or violence for a political cause (for example, during a demonstration or protest march).

Note: The answer options were: no, would never do $=0$, no, but would do if had the chance $=1$, yes, once or twice $=2$, yes, several times $=3$, yes, often $=4$ (and included prefer not to state). The question formulation is taken from Afrobarometer (2015), a member of the Global Barometer Surveys. 


\section{S5 Self-reports of participation in the BLM protests and counter- protests}

During the past few weeks, demonstrations and protests took place across the United States. In the context of these events, have you, personally, done any of the following during the past few weeks? If not, would you do this if you had the chance?

1. Went to the streets to protest in support of the Black Lives Matter movement.

2. Went to the streets to protest against rioting and looting.

3. Went to the streets to protect the property and safety of yourself or others against rioters.

4. Engaged in physical confrontations with the police.

5. Engaged in physical confrontations with Black Lives Matter protesters.

6. Engaged in the destruction or of property.

7. Engaged in physical confrontations with other citizens.

Note: The answer options were: no, would never $d o=0$, no, but would do if had the chance $=1$, yes, once or twice $=2$, yes, several times $=3$, yes, often $=4$ (and included prefer not to state). 


\section{S6 Perceived COVID-19 Burden Scale}

How much do you agree or disagree with the following statements?

1. I am in good health despite the coronavirus crisis.

2. I have felt extremely unwell as a consequence of the coronavirus crisis. [R]

3. The coronavirus crisis has affected negatively my financial situation. $[R]$

4. My finances are in good order despite the coronavirus crisis.

5. The extraordinary measures taken by the government in response to the coronavirus crisis make me concerned about my democratic rights. $[R]$

6. The government has not violated my democratic rights to fight the coronavirus beyond what is needed.

7. My social life has suffered a great deal due to the coronavirus crisis. $[\mathrm{R}]$

8. I have managed to stay in contact with my friends and family despite the physical distancing measures.

9. The coronavirus crisis made me realize that all individuals can only rely on themselves. $[\mathrm{R}]$

10. I believe the coronavirus crisis highlighted that the State can effectively protect its citizens.

Note: The answer options ranged from strongly agree $=0$ to strongly disagree $=6 . \mathrm{R}$ indicates items that were reverse-coded for the analyses, so that higher scores indicated higher COVID-19 burden. Items 1-4, 7-9 form the non-political PCBS sub-scale $\left(\mathrm{PCBS}_{\text {non-political }}\right)$. 


\section{S7 Police Violence Scale}

In some countries, the government or other authorities might use intimidation or violence against citizens. The government or other authorities might use intimidation or violence to stop people from participating in certain activities or having certain views.

The following are several things that may or may not happen to a person. Please indicate how often a typical person in the United States would experience these things.

1. Intimidated by police (or other security forces or people working for authorities).

2. Beaten up by police (or other security forces or people working for authorities).

3. Short-term detainment (for example, taken away by police for participating in a peaceful protest).

Please indicate how often people you care about (your friends and family) have experienced the following things.

1. Intimidated by police (or other security forces or people working for authorities).

2. Beaten up by police (or other security forces or people working for authorities).

3. Short-term detainment (for example, taken away by police for participating in a peaceful protest).

Please indicate how often you personally have experienced the following things.

1. Intimidated by police (or other security forces or people working for authorities).

2. Beaten up by police (or other security forces or people working for authorities).

3. Short-term detainment (for example, taken away by police for participating in a peaceful protest).

Note: For all questions, the answer options ranged from never $=0$ to often $=3$, and included prefer not to state. 


\section{S8 Descriptive Statistics}

Table S1: Descriptive statistics, pooled sample (Wave 1)

\begin{tabular}{lcccccc}
\hline \hline & $\mathrm{N}$ & Mean & Median & SD & Min & Max \\
\hline Need For Chaos Scale (NFC) & 4568 & 1.28 & 1.00 & 1.15 & 0.00 & 6.00 \\
Need For Chaos Scale, political (NFCp) & 4568 & 1.55 & 1.00 & 1.43 & 0.00 & 6.00 \\
Need For Chaos Scale, non-political (NFCnp) & 4568 & 1.12 & 0.80 & 1.16 & 0.00 & 6.00 \\
Perceived COVID-19 Burden Scale (PCBS) & 4568 & 2.59 & 2.70 & 0.89 & 0.00 & 5.80 \\
Perceived COVID-19 Burden Scale, non-political (PCBSnp) & 4568 & 2.61 & 2.71 & 0.90 & 0.00 & 6.00 \\
Age & 4568 & 5.90 & 6.00 & 3.19 & 0.00 & 14.00 \\
Gender & 4568 & 0.50 & 0.00 & 0.50 & 0.00 & 1.00 \\
Education & 4568 & 0.66 & 0.00 & 0.76 & 0.00 & 2.00 \\
\hline \hline
\end{tabular}

Note: The sample is limited to interviewees who participated in both survey waves.

Table S2: Descriptive statistics, pooled sample (Wave 2)

\begin{tabular}{|c|c|c|c|c|c|c|}
\hline & $\mathrm{N}$ & Mean & Median & $\mathrm{SD}$ & Min & Max \\
\hline Need For Chaos Scale (NFC) & 4568 & 1.31 & 1.00 & 1.16 & 0.00 & 6.00 \\
\hline Need For Chaos Scale, political (NFCp) & 4568 & 1.61 & 1.33 & 1.45 & 0.00 & 6.00 \\
\hline Need For Chaos Scale, non-political (NFCnp) & 4568 & 1.14 & 0.80 & 1.16 & 0.00 & 6.00 \\
\hline Activism Intention Scale (AIS) & 4315 & 2.69 & 2.75 & 1.75 & 0.00 & 6.00 \\
\hline Radicalism Intention Scale (RIS) & 4317 & 1.56 & 1.00 & 1.56 & 0.00 & 6.00 \\
\hline Police Violence Scale (PVS) & 4382 & 0.75 & 0.67 & 0.62 & 0.00 & 3.00 \\
\hline Participation in protests/demonstrations & 4313 & 0.95 & 1.00 & 1.12 & 0.00 & 4.00 \\
\hline Participation in political violence & 4339 & 0.21 & 0.00 & 0.66 & 0.00 & 4.00 \\
\hline Perceived COVID-19 Burden Scale (PCBS) & 4568 & 2.49 & 2.50 & 0.91 & 0.00 & 5.60 \\
\hline Perceived COVID-19 Burden Scale, non-political (PCBSnp) & 4568 & 2.44 & 2.57 & 0.94 & 0.00 & 5.57 \\
\hline Age & 4568 & 5.93 & 6.00 & 3.19 & 0.00 & 14.00 \\
\hline Gender & 4568 & 0.50 & 0.00 & 0.50 & 0.00 & 1.00 \\
\hline Education & 4568 & 0.68 & 0.00 & 0.76 & 0.00 & 2.00 \\
\hline
\end{tabular}


Table S3: Descriptive statistics, the US (Wave 1)

\begin{tabular}{|c|c|c|c|c|c|c|}
\hline & $\mathrm{N}$ & Mean & Median & SD & Min & Max \\
\hline Need For Chaos Scale (NFC) & 1151 & 1.29 & 0.88 & 1.28 & 0.00 & 6.00 \\
\hline Need For Chaos Scale, political (NFCp) & 1151 & 1.71 & 1.33 & 1.51 & 0.00 & 6.00 \\
\hline Need For Chaos Scale, non-political (NFCnp) & 1151 & 1.04 & 0.60 & 1.31 & 0.00 & 6.00 \\
\hline Perceived COVID-19 Burden Scale (PCBS) & 1151 & 2.50 & 2.60 & 0.78 & 0.40 & 5.80 \\
\hline Perceived COVID-19 Burden Scale, non-political (PCBSnp) & 1151 & 2.43 & 2.43 & 0.86 & 0.00 & 5.71 \\
\hline Age & 1151 & 6.09 & 7.00 & 3.33 & 0.00 & 14.00 \\
\hline Gender & 1151 & 0.50 & 1.00 & 0.50 & 0.00 & 1.00 \\
\hline Education & 1151 & 0.88 & 1.00 & 0.82 & 0.00 & 2.00 \\
\hline
\end{tabular}

Note: The sample is limited to interviewees who participated in both survey waves.

Table S4: Descriptive statistics, the US (Wave 2)

\begin{tabular}{lcccccc}
\hline \hline & $\mathrm{N}$ & Mean & Median & SD & Min & Max \\
\hline Need For Chaos Scale (NFC) & 1151 & 1.29 & 0.88 & 1.28 & 0.00 & 6.00 \\
Need For Chaos Scale, political (NFCp) & 1151 & 1.72 & 1.33 & 1.52 & 0.00 & 6.00 \\
Need For Chaos Scale, non-political (NFCnp) & 1151 & 1.03 & 0.60 & 1.31 & 0.00 & 6.00 \\
Activism Intention Scale (AIS) & 1094 & 3.05 & 3.13 & 1.75 & 0.00 & 6.00 \\
Radicalism Intention Scale (RIS) & 1092 & 1.79 & 1.50 & 1.65 & 0.00 & 6.00 \\
Police Violence Scale (PVS) & 1110 & 0.92 & 0.78 & 0.66 & 0.00 & 3.00 \\
Participation in protests/demonstrations & 1074 & 1.01 & 1.00 & 1.18 & 0.00 & 4.00 \\
Participation in political violence & 1082 & 0.24 & 0.00 & 0.73 & 0.00 & 4.00 \\
Protesting in support of BLM & 1079 & 0.57 & 0.00 & 0.84 & 0.00 & 4.00 \\
Protesting against rioting and looting & 1071 & 0.56 & 0.00 & 0.83 & 0.00 & 4.00 \\
Protecting property and safety & 1061 & 0.69 & 1.00 & 0.85 & 0.00 & 4.00 \\
Engagement in confrontation with police & 1078 & 0.24 & 0.00 & 0.72 & 0.00 & 4.00 \\
Engagement in confrontation with BLM & 1085 & 0.24 & 0.00 & 0.71 & 0.00 & 4.00 \\
Engagement in destruction of property & 1095 & 0.20 & 0.00 & 0.68 & 0.00 & 4.00 \\
Engagemnet in confrontation with others & 1085 & 0.26 & 0.00 & 0.73 & 0.00 & 4.00 \\
Perceived COVID-19 Burden Scale (PCBS) & 1151 & 2.51 & 2.60 & 0.80 & 0.20 & 5.10 \\
Perceived COVID-19 Burden Scale, non-political (PCBSnp) & 1151 & 2.35 & 2.43 & 0.92 & 0.00 & 5.43 \\
Age & 1151 & 6.15 & 7.00 & 3.32 & 0.00 & 14.00 \\
Gender & 1151 & 0.50 & 1.00 & 0.50 & 0.00 & 1.00 \\
Education & 1151 & 0.92 & 1.00 & 0.82 & 0.00 & 2.00 \\
\hline \hline
\end{tabular}


Table S5: Descriptive statistics, Denmark (Wave 1)

\begin{tabular}{|c|c|c|c|c|c|c|}
\hline & $\mathrm{N}$ & Mean & Median & $\mathrm{SD}$ & Min & Max \\
\hline Need For Chaos Scale (NFC) & 1286 & 1.01 & 0.69 & 1.05 & 0.00 & 6.00 \\
\hline Need For Chaos Scale, political (NFCp) & 1286 & 1.03 & 0.67 & 1.24 & 0.00 & 6.00 \\
\hline Need For Chaos Scale, non-political (NFCnp) & 1286 & 1.00 & 0.60 & 1.06 & 0.00 & 6.00 \\
\hline Perceived COVID-19 Burden Scale (PCBS) & 1286 & 2.13 & 2.10 & 0.82 & 0.10 & 5.50 \\
\hline Perceived COVID-19 Burden Scale, non-political (PCBSnp) & 1286 & 2.25 & 2.29 & 0.87 & 0.00 & 6.00 \\
\hline Age & 1286 & 5.87 & 6.00 & 3.41 & 0.00 & 13.00 \\
\hline Gender & 1286 & 0.50 & 1.00 & 0.50 & 0.00 & 1.00 \\
\hline Education & 1286 & 0.42 & 0.00 & 0.66 & 0.00 & 2.00 \\
\hline
\end{tabular}

Note: The sample is limited to interviewees who participated in both survey waves.

Table S6: Descriptive statistics, Denmark (Wave 2)

\begin{tabular}{lcccccc}
\hline \hline & $\mathrm{N}$ & Mean & Median & SD & Min & Max \\
\hline Need For Chaos Scale (NFC) & 1286 & 1.05 & 0.75 & 1.06 & 0.00 & 6.00 \\
Need For Chaos Scale, political (NFCp) & 1286 & 1.07 & 0.67 & 1.23 & 0.00 & 6.00 \\
Need For Chaos Scale, non-political (NFCnp) & 1286 & 1.04 & 0.80 & 1.07 & 0.00 & 6.00 \\
Activism Intention Scale (AIS) & 1199 & 2.21 & 2.25 & 1.69 & 0.00 & 6.00 \\
Radicalism Intention Scale (RIS) & 1206 & 1.11 & 0.50 & 1.34 & 0.00 & 6.00 \\
Police Violence Scale (PVS) & 1216 & 0.60 & 0.44 & 0.55 & 0.00 & 3.00 \\
Participation in protests/demonstrations & 1214 & 0.73 & 0.00 & 1.02 & 0.00 & 4.00 \\
Participation in political violence & 1217 & 0.18 & 0.00 & 0.61 & 0.00 & 4.00 \\
Perceived COVID-19 Burden Scale (PCBS) & 1286 & 2.06 & 2.10 & 0.87 & 0.00 & 5.30 \\
Perceived COVID-19 Burden Scale, non-political (PCBSnp) $)$ & 1286 & 2.11 & 2.14 & 0.91 & 0.00 & 5.57 \\
Age & 1286 & 5.91 & 6.00 & 3.41 & 0.00 & 13.00 \\
Gender & 1286 & 0.50 & 1.00 & 0.50 & 0.00 & 1.00 \\
Education & 1286 & 0.43 & 0.00 & 0.66 & 0.00 & 2.00 \\
\hline \hline
\end{tabular}


Table S7: Descriptive statistics, Italy (Wave 1)

\begin{tabular}{|c|c|c|c|c|c|c|}
\hline & $\mathrm{N}$ & Mean & Median & $\mathrm{SD}$ & Min & Max \\
\hline Need For Chaos Scale (NFC) & 1241 & 1.55 & 1.38 & 1.12 & 0.00 & 6.00 \\
\hline Need For Chaos Scale, political (NFCp) & 1241 & 1.92 & 1.67 & 1.41 & 0.00 & 6.00 \\
\hline Need For Chaos Scale, non-political (NFCnp) & 1241 & 1.33 & 1.00 & 1.13 & 0.00 & 6.00 \\
\hline Perceived COVID-19 Burden Scale (PCBS) & 1241 & 2.84 & 2.90 & 0.80 & 0.00 & 5.40 \\
\hline Perceived COVID-19 Burden Scale, non-political (PCBSnp) & 1241 & 2.90 & 3.00 & 0.83 & 0.00 & 5.57 \\
\hline Age & 1241 & 5.87 & 6.00 & 3.01 & 0.00 & 14.00 \\
\hline Gender & 1241 & 0.54 & 1.00 & 0.50 & 0.00 & 1.00 \\
\hline Education & 1241 & 0.77 & 1.00 & 0.74 & 0.00 & 2.00 \\
\hline
\end{tabular}

Note: The sample is limited to interviewees who participated in both survey waves.

Table S8: Descriptive statistics, Italy (Wave 2)

\begin{tabular}{lcccccc}
\hline \hline & $\mathrm{N}$ & Mean & Median & SD & Min & Max \\
\hline Need For Chaos Scale (NFC) & 1241 & 1.61 & 1.38 & 1.13 & 0.00 & 6.00 \\
Need For Chaos Scale, political (NFCp) & 1241 & 2.02 & 2.00 & 1.43 & 0.00 & 6.00 \\
Need For Chaos Scale, non-political (NFCnp) & 1241 & 1.36 & 1.00 & 1.14 & 0.00 & 6.00 \\
Activism Intention Scale (AIS) & 1166 & 2.75 & 3.00 & 1.75 & 0.00 & 6.00 \\
Radicalism Intention Scale (RIS) & 1167 & 1.81 & 1.50 & 1.63 & 0.00 & 6.00 \\
Police Violence Scale (PVS) & 1188 & 0.77 & 0.78 & 0.60 & 0.00 & 3.00 \\
Participation in protests/demonstrations & 1179 & 1.16 & 1.00 & 1.17 & 0.00 & 4.00 \\
Participation in political violence & 1188 & 0.22 & 0.00 & 0.66 & 0.00 & 4.00 \\
Perceived COVID-19 Burden Scale (PCBS) & 1241 & 2.68 & 2.80 & 0.84 & 0.00 & 5.60 \\
Perceived COVID-19 Burden Scale, non-political (PCBSnp) & 1241 & 2.69 & 2.71 & 0.86 & 0.00 & 5.43 \\
Age & 1241 & 5.87 & 6.00 & 3.03 & 0.00 & 14.00 \\
Gender & 1241 & 0.54 & 1.00 & 0.50 & 0.00 & 1.00 \\
Education & 1241 & 0.78 & 1.00 & 0.74 & 0.00 & 2.00 \\
\hline \hline
\end{tabular}


Table S9: Descriptive statistics, Hungary (Wave 1)

\begin{tabular}{|c|c|c|c|c|c|c|}
\hline & $\mathrm{N}$ & Mean & Median & SD & Min & Max \\
\hline Need For Chaos Scale (NFC) & 890 & 1.28 & 1.00 & 1.09 & 0.00 & 6.00 \\
\hline Need For Chaos Scale, political (NFCp) & 890 & 1.59 & 1.33 & 1.40 & 0.00 & 6.00 \\
\hline Need For Chaos Scale, non-political (NFCnp) & 890 & 1.09 & 0.80 & 1.10 & 0.00 & 6.00 \\
\hline Perceived COVID-19 Burden Scale (PCBS) & 890 & 3.02 & 3.00 & 0.89 & 0.00 & 5.40 \\
\hline Perceived COVID-19 Burden Scale, non-political (PCBSnp) & 890 & 2.94 & 3.00 & 0.85 & 0.00 & 5.43 \\
\hline Age & 890 & 5.74 & 6.00 & 2.90 & 0.00 & 11.00 \\
\hline Gender & 890 & 0.42 & 0.00 & 0.49 & 0.00 & 1.00 \\
\hline Education & 890 & 0.58 & 0.00 & 0.73 & 0.00 & 2.00 \\
\hline
\end{tabular}

Note: The sample is limited to interviewees who participated in both survey waves.

Table S10: Descriptive statistics, Hungary (Wave 2)

\begin{tabular}{|c|c|c|c|c|c|c|}
\hline & $\mathrm{N}$ & Mean & Median & SD & Min & $\operatorname{Max}$ \\
\hline Need For Chaos Scale (NFC) & 890 & 1.32 & 1.13 & 1.10 & 0.00 & 6.00 \\
\hline Need For Chaos Scale, political (NFCp) & 890 & 1.67 & 1.33 & 1.47 & 0.00 & 6.00 \\
\hline Need For Chaos Scale, non-political (NFCnp) & 890 & 1.11 & 0.80 & 1.08 & 0.00 & 6.00 \\
\hline Activism Intention Scale (AIS) & 856 & 2.80 & 3.00 & 1.72 & 0.00 & 6.00 \\
\hline Radicalism Intention Scale (RIS) & 852 & 1.52 & 1.00 & 1.50 & 0.00 & 6.00 \\
\hline Police Violence Scale (PVS) & 868 & 0.71 & 0.56 & 0.62 & 0.00 & 3.00 \\
\hline Participation in protests/demonstrations & 846 & 0.91 & 1.00 & 1.06 & 0.00 & 4.00 \\
\hline Participation in political violence & 852 & 0.19 & 0.00 & 0.63 & 0.00 & 4.00 \\
\hline Perceived COVID-19 Burden Scale (PCBS) & 890 & 2.80 & 2.90 & 1.00 & 0.00 & 5.60 \\
\hline Perceived COVID-19 Burden Scale, non-political (PCBSnp) & 890 & 2.68 & 2.86 & 0.97 & 0.00 & 5.43 \\
\hline Age & 890 & 5.76 & 6.00 & 2.90 & 0.00 & 11.00 \\
\hline Gender & 890 & 0.43 & 0.00 & 0.50 & 0.00 & 1.00 \\
\hline Education & 890 & 0.58 & 0.00 & 0.73 & 0.00 & 2.00 \\
\hline
\end{tabular}




\section{S9 Histograms}
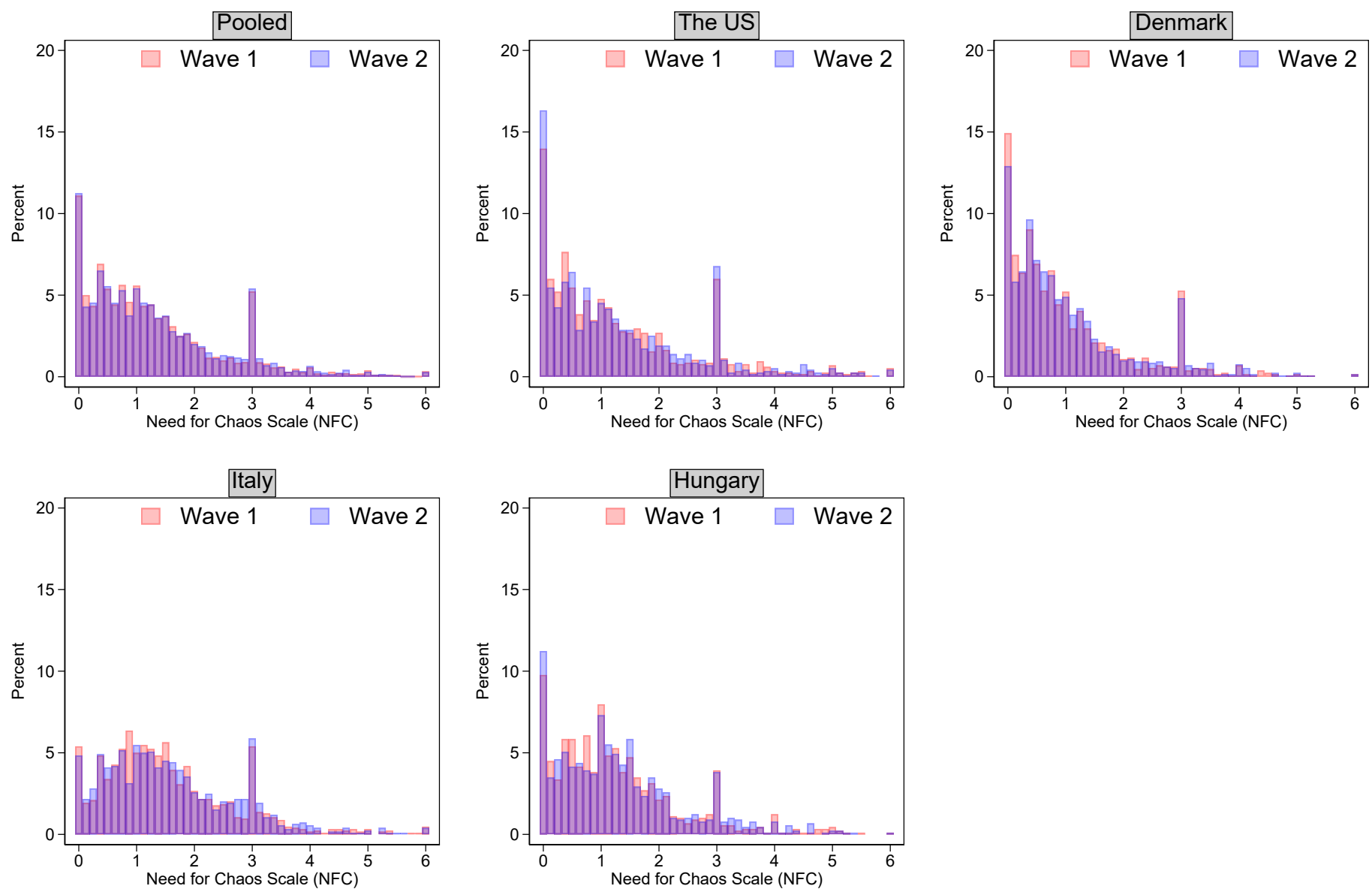

Figure S1: Need for chaos: Percentage frequency distribution by country 

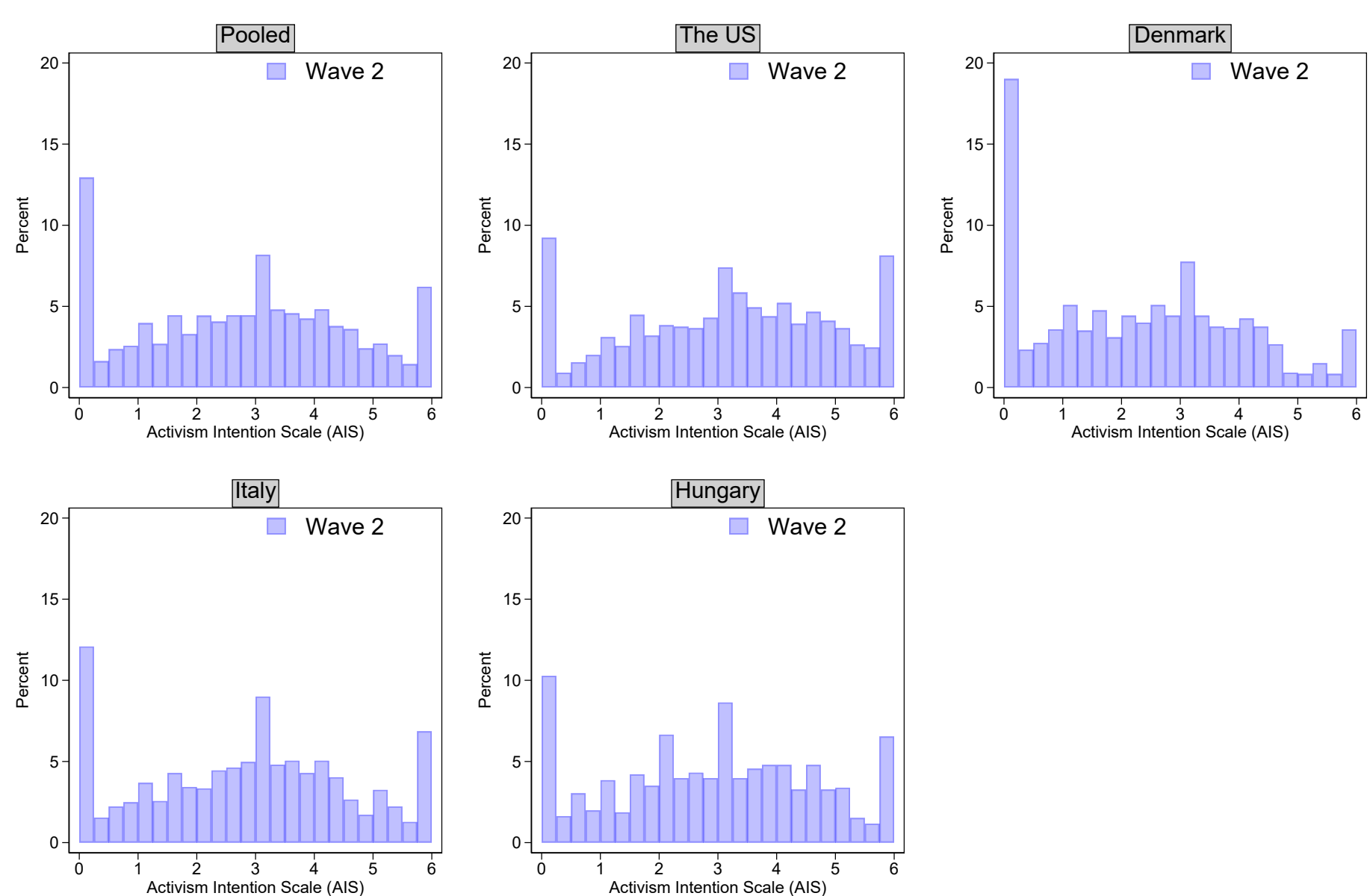

Figure S2: Activism intentions: Percentage frequency distribution by country 

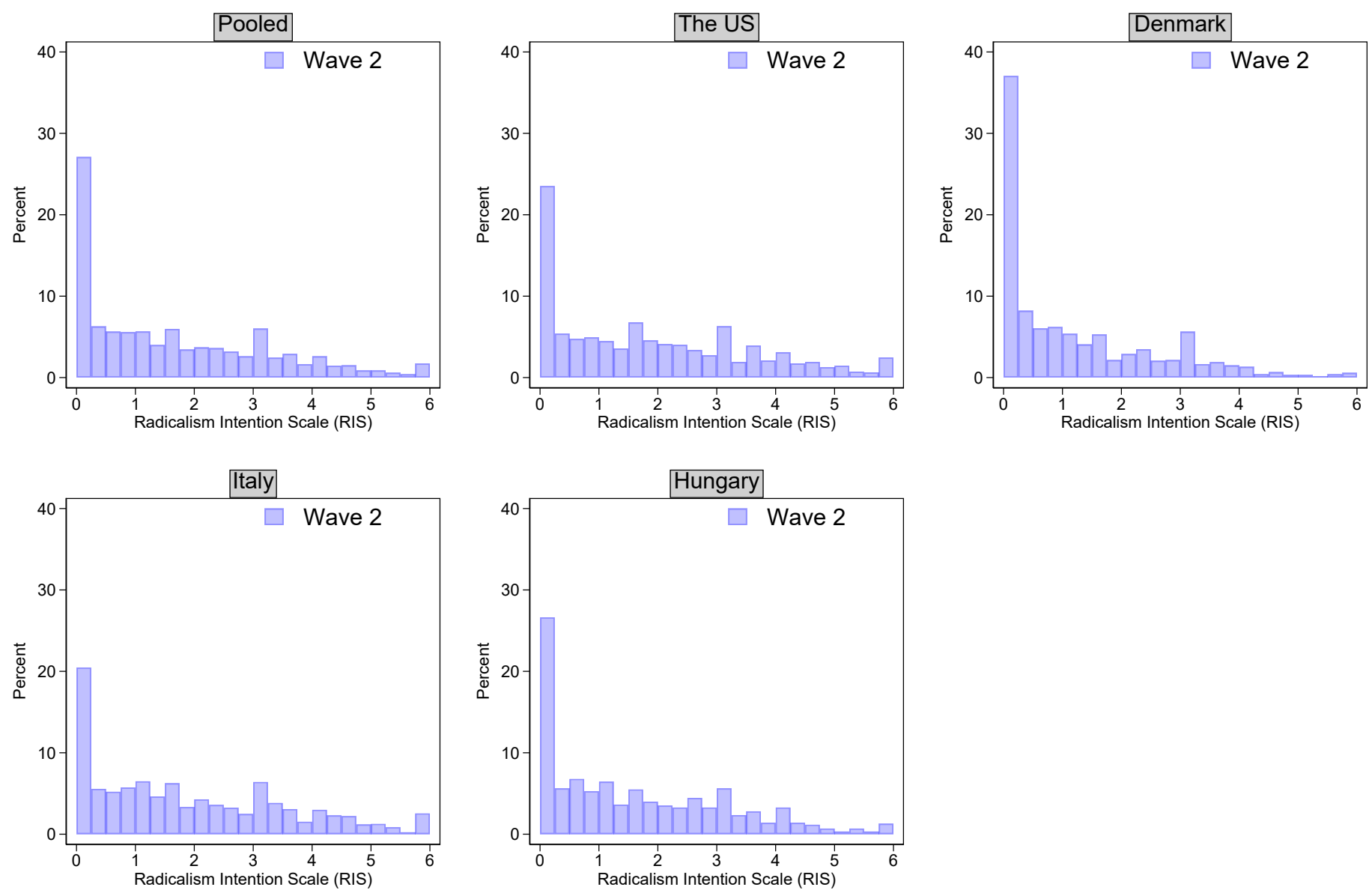

Figure S3: Radicalism intentions: Percentage frequency distribution by country 

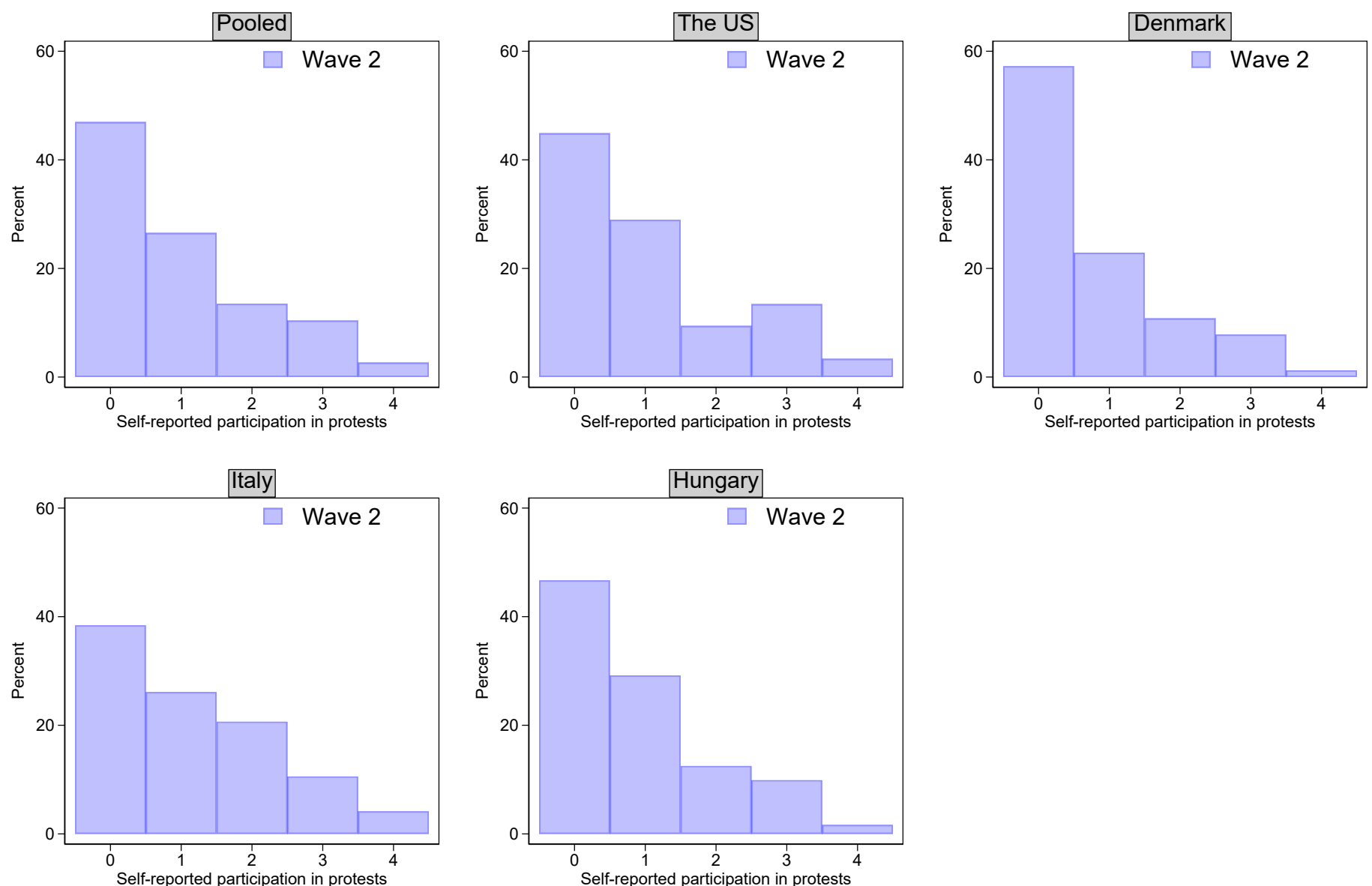

Figure S4: Self-reported participation in protests: Percentage frequency distribution by country 

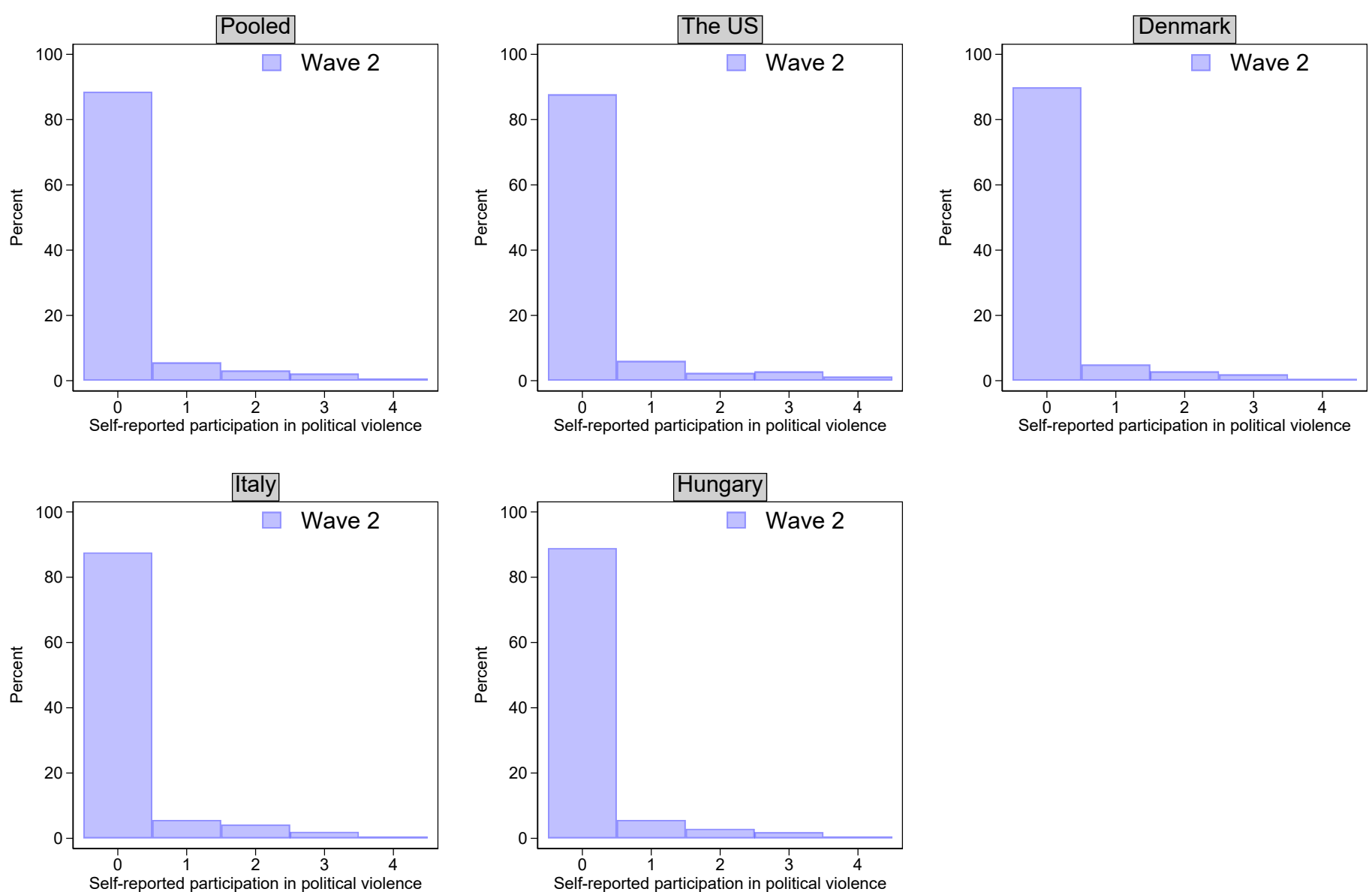

Figure S5: Self-reported participation in political violence: Percentage frequency distribution by country 

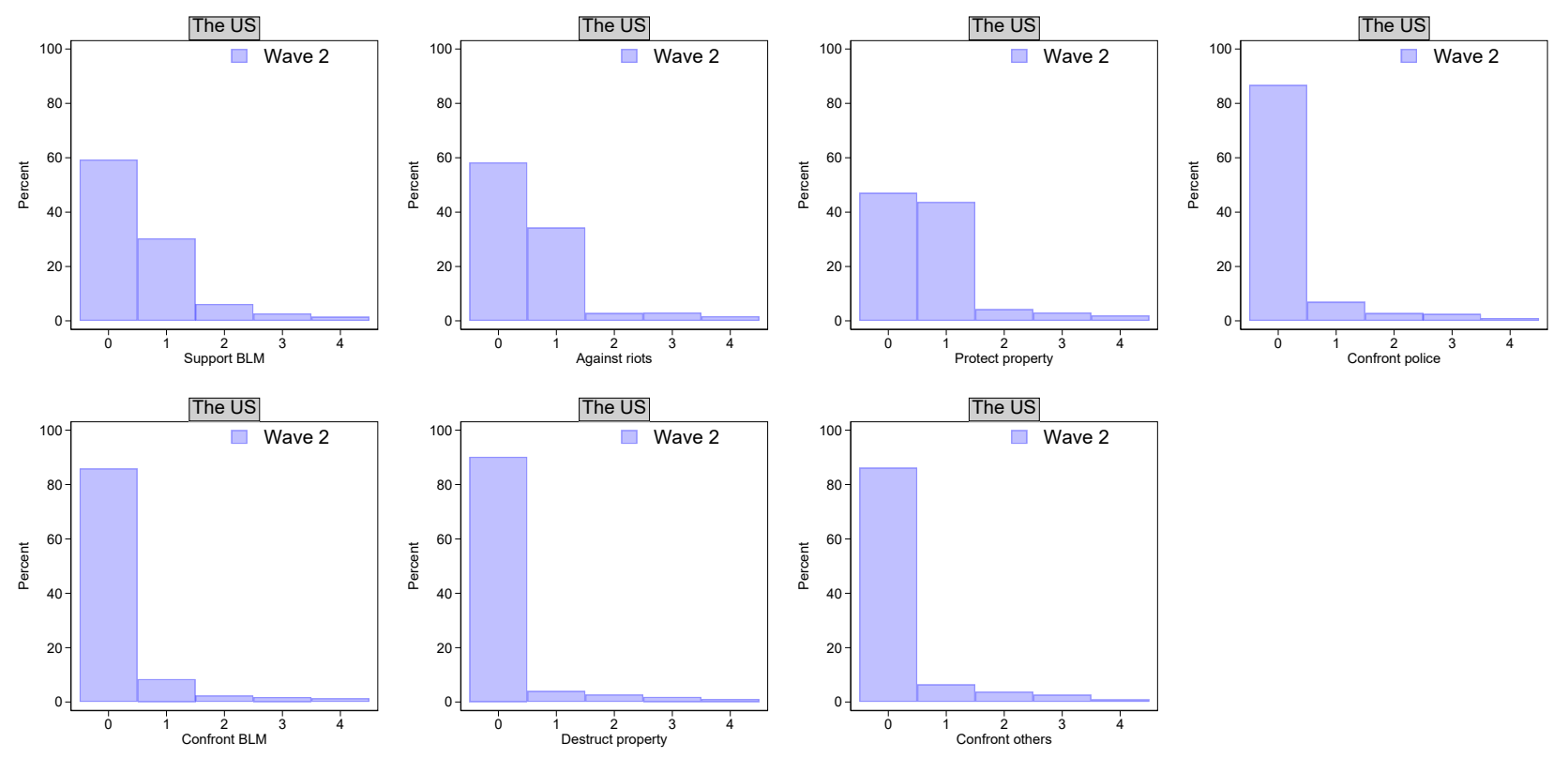

Figure S6: Self-reported participation in the BLM protests and counter-protests: Percentage frequency distributions 

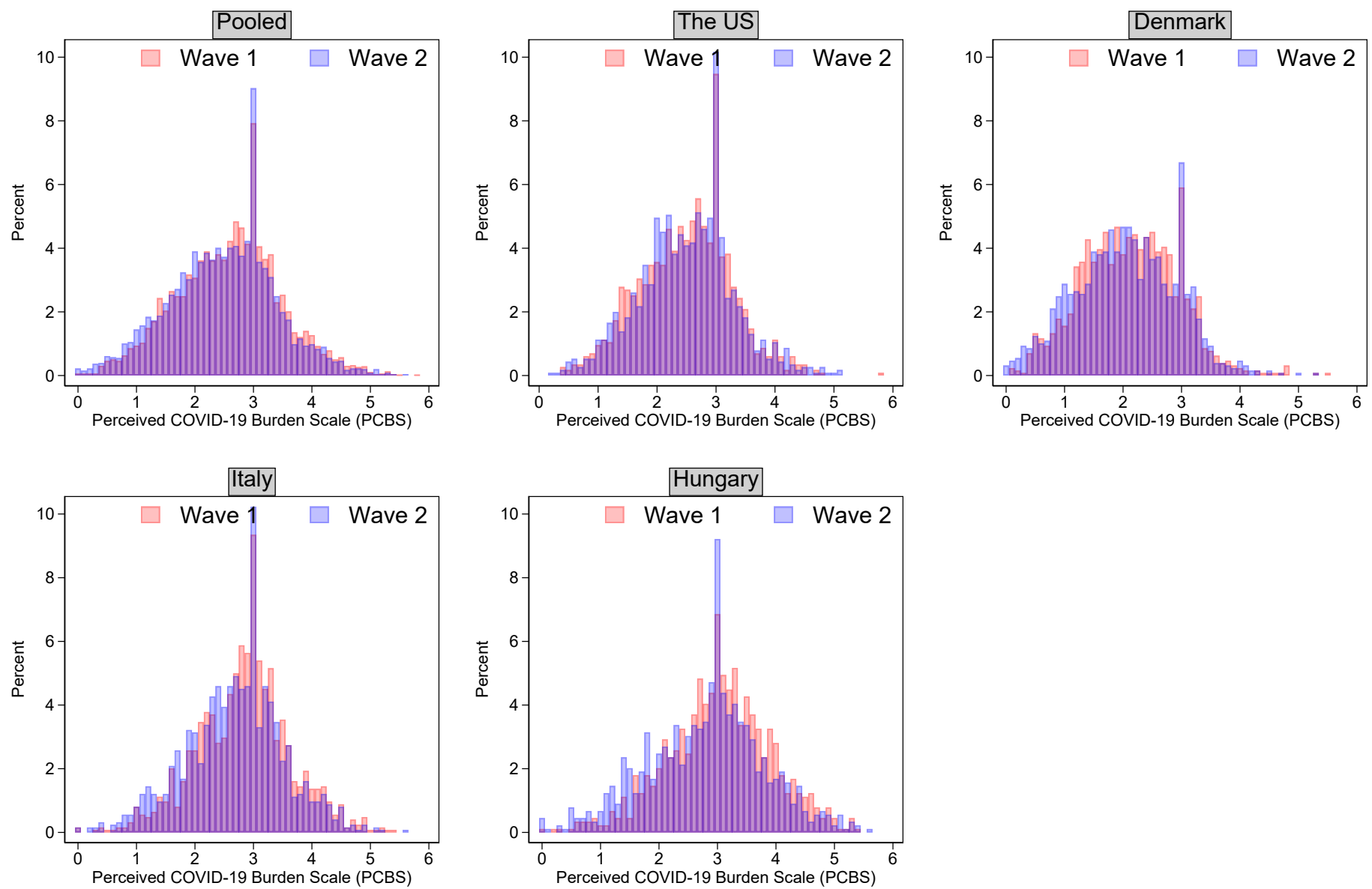

Figure S7: Perceived COVID-19 burden: Percentage frequency distribution by country 

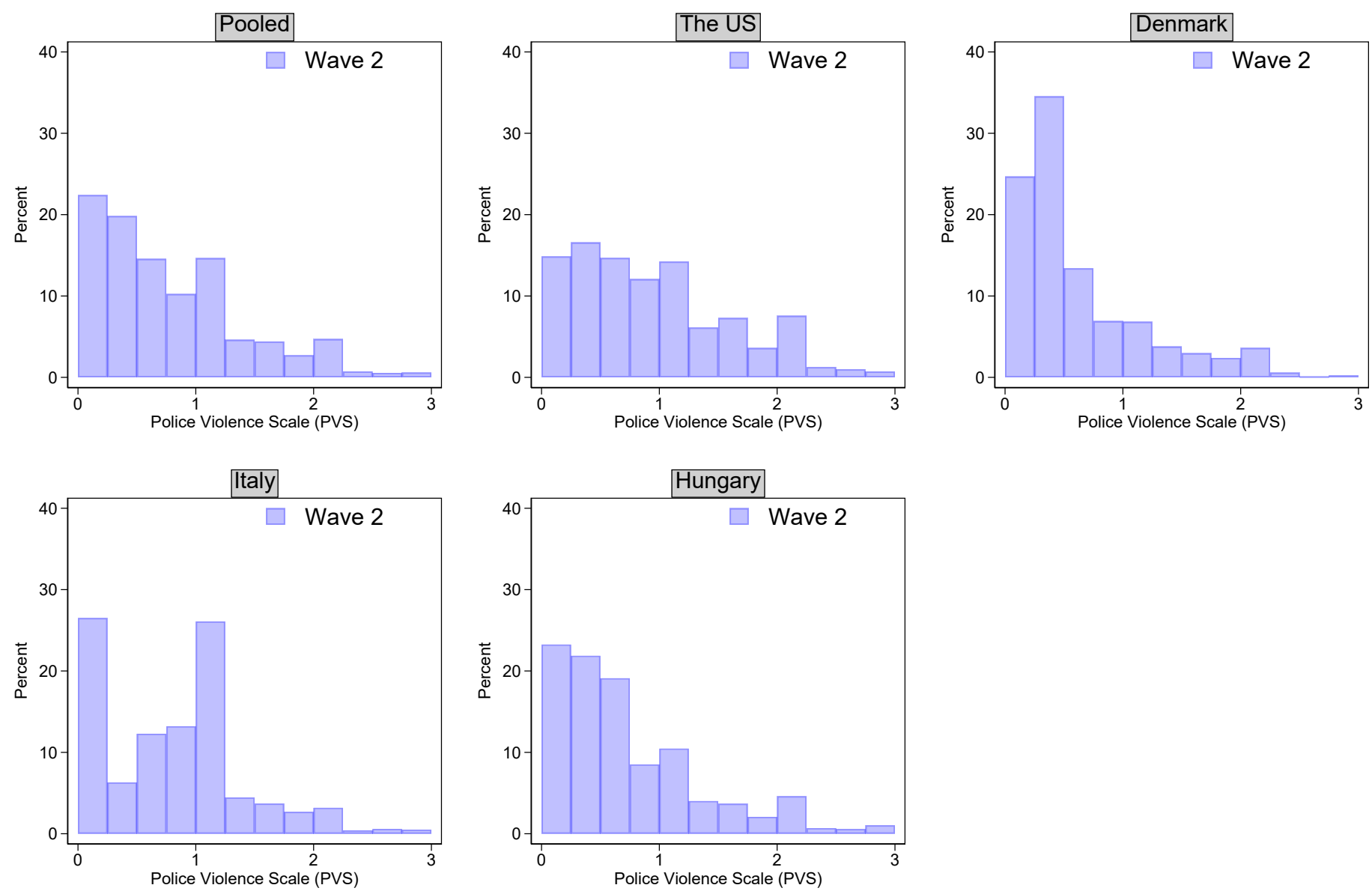

Figure S8: Perceptions and self-reported experience of police violence: Percentage frequency distribution by country 

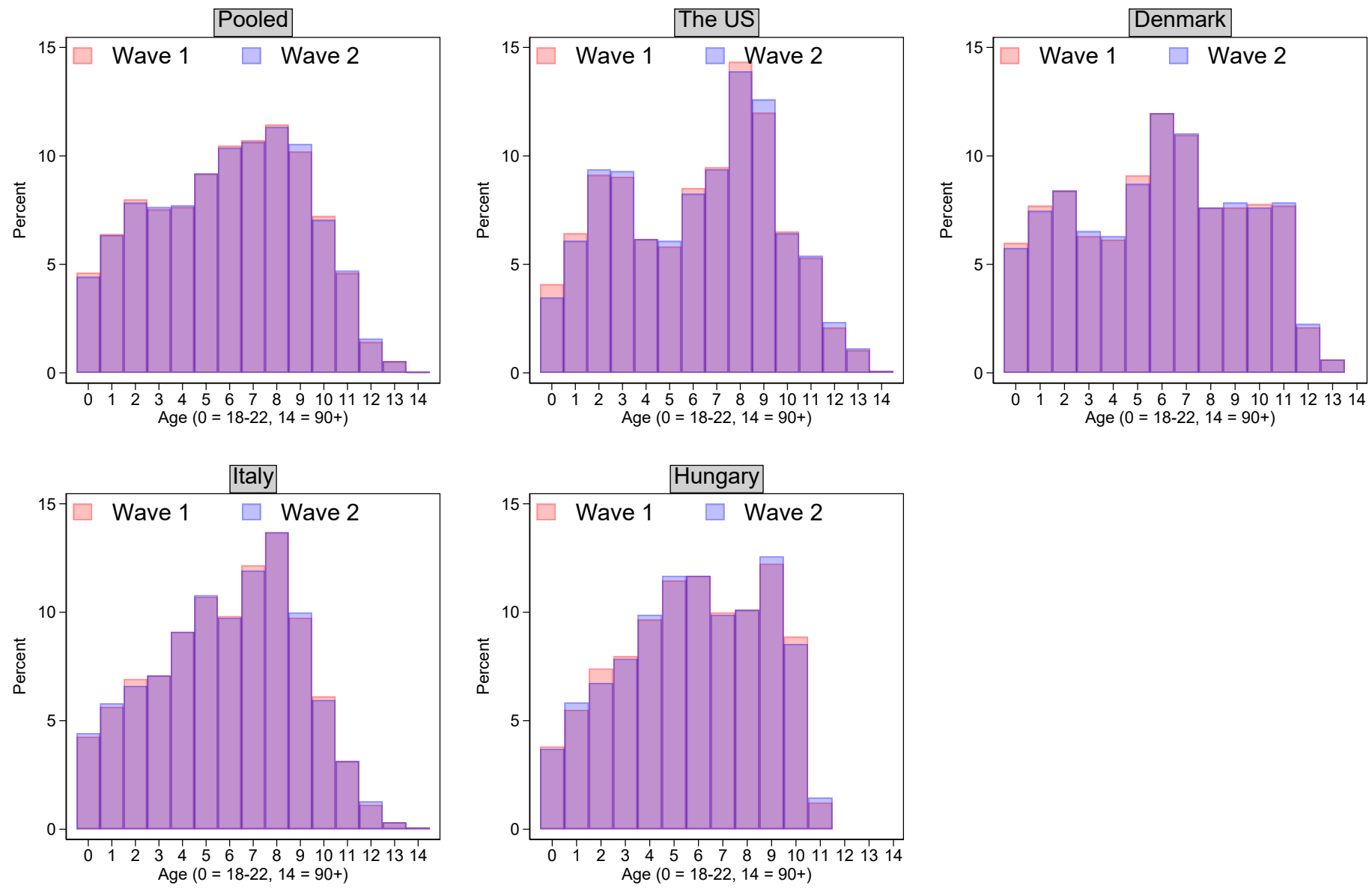

Figure S9: Age categories: Percentage frequency distribution by country 

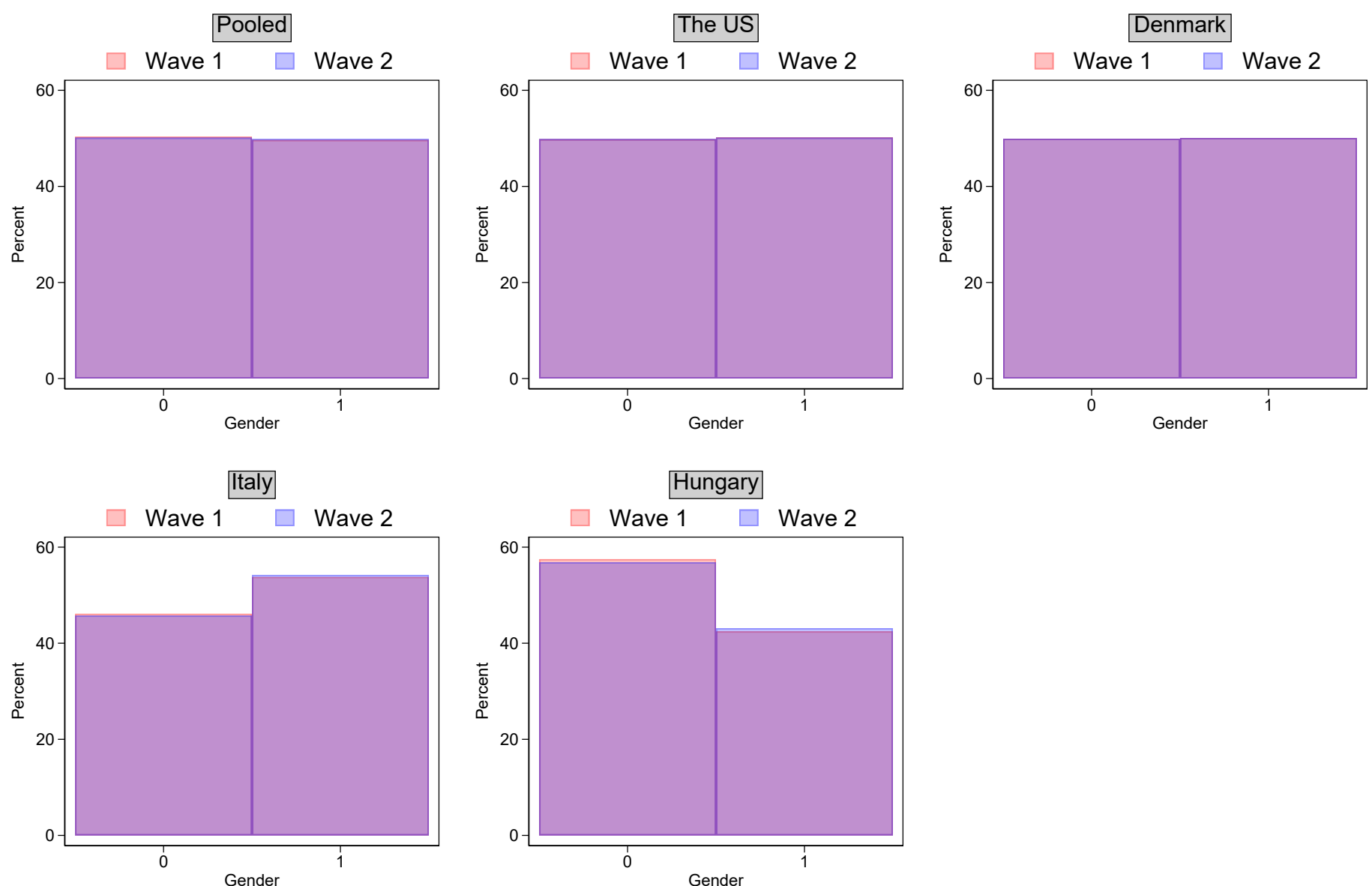

Figure S10: Gender: Percentage frequency distribution by country 

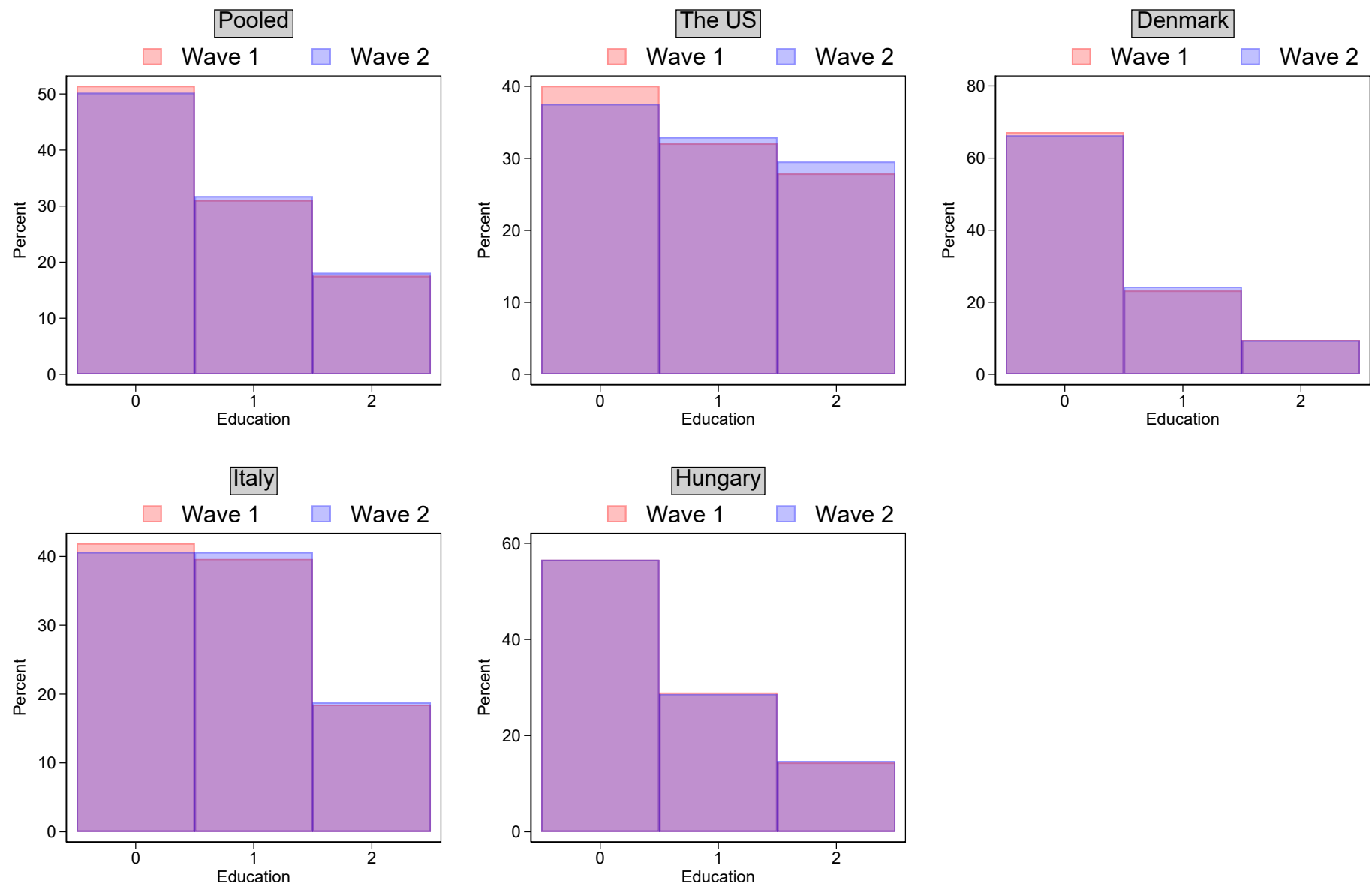

Figure S11: Education: Percentage frequency distribution by country 


\section{S10 Bivariate correlations}

Table S11: Bivariate correlation matrix for the main variables, pooled sample (Wave 2)

\begin{tabular}{|c|c|c|c|c|c|c|c|c|c|c|c|c|c|}
\hline & $(1)$ & $(2)$ & (3) & $(4)$ & $(5)$ & $(6)$ & $(7)$ & $(8)$ & (9) & $(10)$ & $(11)$ & $(12)$ & (13) \\
\hline (1) NFC & 1.000 & & & & & & & & & & & & \\
\hline (2) NFCp & 0.883 & 1.000 & & & & & & & & & & & \\
\hline (3) NFCnp & 0.936 & 0.662 & 1.000 & & & & & & & & & & \\
\hline (5) RIS & 0.443 & 0.386 & 0.418 & 1.000 & & & & & & & & & \\
\hline (4) AIS & 0.127 & 0.135 & 0.102 & 0.537 & 1.000 & & & & & & & & \\
\hline (6) PVS & 0.359 & 0.325 & 0.328 & 0.403 & 0.275 & 1.000 & & & & & & & \\
\hline (7) PDparticipation & 0.148 & 0.149 & 0.124 & 0.369 & 0.513 & 0.318 & 1.000 & & & & & & \\
\hline (8) PVparticipation & 0.487 & 0.365 & 0.505 & 0.423 & 0.198 & 0.460 & 0.334 & 1.000 & & & & & \\
\hline (9) PCBS & 0.328 & 0.360 & 0.255 & 0.212 & 0.115 & 0.226 & 0.080 & 0.158 & 1.000 & & & & \\
\hline (10) PCBSnp & 0.321 & 0.315 & 0.277 & 0.217 & 0.102 & 0.227 & 0.084 & 0.176 & 0.884 & 1.000 & & & \\
\hline (11) Age & -0.238 & -0.181 & -0.245 & -0.178 & -0.039 & -0.154 & -0.111 & -0.217 & -0.054 & -0.078 & 1.000 & & \\
\hline (12) Gender & -0.107 & -0.087 & -0.106 & -0.121 & -0.055 & -0.044 & -0.093 & -0.131 & -0.027 & 0.020 & 0.004 & 1.000 & \\
\hline (13) Education & -0.031 & -0.005 & -0.046 & 0.086 & 0.188 & 0.079 & 0.230 & 0.018 & -0.022 & -0.060 & -0.097 & -0.043 & 1.000 \\
\hline
\end{tabular}


Table S12: Bivariate correlation matrix for the items of the Perceived COVID-19 Burden Scale (PCBS), pooled sample (Wave 2)

\begin{tabular}{|c|c|c|c|c|c|c|c|c|c|c|}
\hline & $(1)$ & $(2)$ & $(3)$ & $(4)$ & $(5)$ & $\overline{(6)}$ & $(7)$ & $(8)$ & $(9)$ & $(10)$ \\
\hline (1) ...good health despite the coronavirus crisis & 1.000 & & & & & & & & & \\
\hline (2) ...felt extremely unwell... & -0.212 & 1.000 & & & & & & & & \\
\hline (3) ...affected negativelly my financial situation & -0.113 & 0.367 & 1.000 & & & & & & & \\
\hline (4) ...finances are in good order... & 0.294 & -0.224 & -0.589 & 1.000 & & & & & & \\
\hline (5) ...concerned about my democratic rights & -0.033 & 0.211 & 0.254 & -0.128 & 1.000 & & & & & \\
\hline (6) ...has not violated my democratic rights... & 0.124 & -0.026 & -0.130 & 0.205 & -0.546 & 1.000 & & & & \\
\hline (7) ...social life has suffered a great deal... & -0.043 & 0.398 & 0.281 & -0.085 & 0.198 & -0.036 & 1.000 & & & \\
\hline (8) ...in contact with my friends and family... & 0.341 & -0.135 & -0.067 & 0.199 & -0.062 & 0.156 & -0.141 & 1.000 & & \\
\hline (9) ...individuals can only rely on themselves & -0.052 & 0.257 & 0.275 & -0.168 & 0.400 & -0.230 & 0.197 & -0.027 & 1.000 & \\
\hline (10) ...State can effectively protect its citizens & 0.127 & 0.014 & -0.170 & 0.277 & -0.372 & 0.515 & -0.004 & 0.105 & -0.238 & 1.000 \\
\hline
\end{tabular}




\section{S11 Regression estimates: Main analyses}

Table S13: Perceived COVID-19 burden (PCBS) as predictor of need for chaos (NFC): between-individual models

\begin{tabular}{|c|c|c|c|c|c|c|c|c|c|c|}
\hline & (1) Pooled & & (2) The US & & (3) Denmark & & (4) Italy & & (5) Hungary & \\
\hline & $\mathrm{b}$ & ci95 & $\mathrm{b}$ & ci95 & $\mathrm{b}$ & ci95 & $\mathrm{b}$ & ci95 & $\mathrm{b}$ & ci95 \\
\hline PCBS & 0.32 & $0.28,0.35$ & 0.29 & $0.20,0.37$ & 0.43 & $0.37,0.49$ & 0.28 & $0.21,0.36$ & 0.19 & $0.12,0.27$ \\
\hline Age & -0.01 & $-0.02,-0.01$ & -0.02 & $-0.03,-0.02$ & -0.01 & $-0.01,-0.01$ & -0.01 & $-0.01,-0.01$ & -0.01 & $-0.02,-0.01$ \\
\hline Gender & -0.04 & $-0.05,-0.03$ & -0.03 & $-0.05,-0.00$ & -0.05 & $-0.07,-0.03$ & -0.05 & $-0.07,-0.03$ & -0.05 & $-0.07,-0.03$ \\
\hline $\mathrm{Edu}$ & -0.02 & $-0.03,-0.01$ & -0.02 & $-0.04,-0.01$ & -0.02 & $-0.03,-0.00$ & -0.03 & $-0.04,-0.01$ & -0.02 & $-0.03,-0.00$ \\
\hline Constant & 0.20 & $0.18,0.22$ & 0.27 & $0.22,0.32$ & 0.11 & $0.08,0.14$ & 0.23 & $0.18,0.28$ & 0.23 & $0.18,0.28$ \\
\hline$N$ & 4568 & & 1151 & & 1286 & & 1241 & & 890 & \\
\hline$R^{2}$ & 0.135 & & 0.205 & & 0.192 & & 0.086 & & 0.094 & \\
\hline
\end{tabular}

Note: The table reports unstandardised regression coefficients and the corresponding $95 \%$ CIs.

Table S14: Perceived COVID-19 burden (PCBS) as predictor of need for chaos (NFC): within-individual models

\begin{tabular}{lcc}
\hline \hline & (1) Pooled & \\
& $\mathrm{b}$ & ci95 \\
\hline PCBS & 0.11 & $0.07,0.15$ \\
Constant & 0.17 & $0.15,0.19$ \\
\hline$N$ & 10699 & \\
\hline \hline
\end{tabular}

Note: The table reports unstandardised regression coefficients and the corresponding $95 \%$ CIs. The specification includes unit- and time-fixed effects (not reported in the table). 
Table S15: Perceived COVID-19 burden (PCBS) as predictor of political need for chaos (NFCp): between-individual models

\begin{tabular}{|c|c|c|c|c|c|c|c|c|c|c|}
\hline & (1) Pooled & & (2) The US & & (3) Denmark & & (4) Italy & & (5) Hungary & \\
\hline & $\mathrm{b}$ & ci95 & $\mathrm{b}$ & ci95 & $\mathrm{b}$ & ci95 & $\mathrm{b}$ & ci95 & $\mathrm{b}$ & ci95 \\
\hline PCBS & 0.42 & $0.37,0.46$ & 0.26 & $0.16,0.36$ & 0.50 & $0.42,0.57$ & 0.43 & $0.34,0.52$ & 0.40 & $0.30,0.50$ \\
\hline Age & -0.01 & $-0.02,-0.01$ & -0.02 & $-0.03,-0.02$ & -0.01 & $-0.01,-0.01$ & -0.01 & $-0.01,-0.00$ & -0.01 & $-0.02,-0.01$ \\
\hline Gender & -0.04 & $-0.06,-0.03$ & -0.02 & $-0.05,0.00$ & -0.06 & $-0.08,-0.04$ & -0.05 & $-0.07,-0.02$ & -0.05 & $-0.08,-0.02$ \\
\hline Edu & -0.02 & $-0.03,-0.01$ & -0.02 & $-0.04,-0.00$ & -0.02 & $-0.03,-0.00$ & -0.04 & $-0.05,-0.02$ & -0.02 & $-0.04,0.01$ \\
\hline Constant & 0.20 & $0.17,0.23$ & 0.35 & $0.29,0.42$ & 0.09 & $0.05,0.13$ & 0.23 & $0.17,0.29$ & 0.17 & $0.11,0.24$ \\
\hline$N$ & 4568 & & 1151 & & 1286 & & 1241 & & 890 & \\
\hline$R^{2}$ & 0.114 & & 0.139 & & 0.171 & & 0.094 & & 0.098 & \\
\hline
\end{tabular}

Table S16: Perceived COVID-19 burden (PCBS) as predictor of political need for chaos (NFCp): within-individual models

\begin{tabular}{lcc}
\hline \hline & (1) Pooled & \\
& $\mathrm{b}$ & ci95 \\
\hline PCBS & 0.15 & $0.10,0.21$ \\
Constant & 0.19 & $0.17,0.22$ \\
\hline$N$ & 10699 & \\
\hline \hline
\end{tabular}

Note: The table reports unstandardised regression coefficients and the corresponding $95 \%$ CIs. The specification includes unit- and time-fixed effects (not reported in the table). 
Table S17: Perceived COVID-19 burden (PCBS) as predictor of non-political need for chaos (NFCnp): between-individual models

\begin{tabular}{|c|c|c|c|c|c|c|c|c|c|c|}
\hline & (1) Pooled & & (2) The US & & (3) Denmark & & (4) Italy & & (5) Hungary & \\
\hline & $\mathrm{b}$ & ci95 & $\mathrm{b}$ & ci95 & $\mathrm{b}$ & ci95 & $\mathrm{b}$ & ci95 & $\mathrm{b}$ & ci95 \\
\hline PCBS & 0.26 & $0.22,0.30$ & 0.30 & $0.22,0.39$ & 0.39 & $0.33,0.46$ & 0.20 & $0.12,0.27$ & 0.07 & $-0.01,0.14$ \\
\hline Age & -0.01 & $-0.02,-0.01$ & -0.02 & $-0.03,-0.02$ & -0.01 & $-0.01,-0.01$ & -0.01 & $-0.01,-0.01$ & -0.01 & $-0.02,-0.01$ \\
\hline Gender & -0.04 & $-0.05,-0.03$ & -0.03 & $-0.05,-0.01$ & -0.05 & $-0.07,-0.03$ & -0.04 & $-0.07,-0.02$ & -0.05 & $-0.07,-0.02$ \\
\hline $\mathrm{Edu}$ & -0.02 & $-0.03,-0.01$ & -0.02 & $-0.04,-0.01$ & -0.01 & $-0.03,-0.00$ & -0.02 & $-0.04,-0.01$ & -0.02 & $-0.03,-0.00$ \\
\hline Constant & 0.20 & $0.18,0.22$ & 0.22 & $0.17,0.28$ & 0.12 & $0.09,0.16$ & 0.23 & $0.18,0.28$ & 0.26 & $0.21,0.31$ \\
\hline$N$ & 4568 & & 1151 & & 1286 & & 1241 & & 890 & \\
\hline$R^{2}$ & 0.116 & & 0.200 & & 0.168 & & 0.059 & & 0.078 & \\
\hline
\end{tabular}

Note: The table reports unstandardised regression coefficients and the corresponding $95 \%$ CIs.

Table S18: Perceived COVID-19 burden (PCBS) as predictor of non-political need for chaos (NFCnp): within-individual models

\begin{tabular}{lcc}
\hline \hline & (1) Pooled & \\
& $\mathrm{b}$ & ci95 \\
\hline PCBS & 0.08 & $0.04,0.12$ \\
Constant & 0.15 & $0.14,0.17$ \\
\hline$N$ & 10699 & \\
\hline
\end{tabular}

Note: The table reports unstandardised regression coefficients and the corresponding $95 \%$ CIs. The specification includes unit- and time-fixed effects (not reported in the table). 
Table S19: Perceived COVID-19 burden (PCBS) as predictor of activism intentions (AIS): between-individual models

\begin{tabular}{|c|c|c|c|c|c|c|c|c|c|c|}
\hline & (1) Pooled & & (2) The US & & (3) Denmark & & (4) Italy & & (5) Hungary & \\
\hline & $\mathrm{b}$ & ci95 & $\mathrm{b}$ & ci95 & $\mathrm{b}$ & ci95 & $\mathrm{b}$ & ci95 & $\mathrm{b}$ & ci95 \\
\hline PCBS & 0.15 & $0.09,0.21$ & 0.01 & $-0.12,0.14$ & 0.24 & $0.13,0.35$ & -0.06 & $-0.18,0.06$ & 0.40 & $0.28,0.52$ \\
\hline Age & -0.00 & $-0.00,0.00$ & -0.00 & $-0.01,0.00$ & -0.00 & $-0.01,-0.00$ & -0.01 & $-0.01,-0.00$ & 0.01 & $0.00,0.02$ \\
\hline Gender & -0.03 & $-0.04,-0.01$ & -0.02 & $-0.05,0.02$ & -0.02 & $-0.06,0.01$ & -0.04 & $-0.08,-0.01$ & -0.02 & $-0.06,0.01$ \\
\hline $\mathrm{Edu}$ & 0.06 & $0.05,0.07$ & 0.07 & $0.04,0.09$ & 0.06 & $0.03,0.08$ & 0.05 & $0.03,0.08$ & 0.05 & $0.02,0.07$ \\
\hline Constant & 0.37 & $0.33,0.40$ & 0.48 & $0.40,0.56$ & 0.30 & $0.24,0.35$ & 0.51 & $0.43,0.58$ & 0.17 & $0.10,0.25$ \\
\hline$N$ & 4315 & & 1094 & & 1199 & & 1166 & & 856 & \\
\hline$R^{2}$ & 0.032 & & 0.040 & & 0.043 & & 0.037 & & 0.073 & \\
\hline
\end{tabular}

Note: The table reports unstandardised regression coefficients and the corresponding $95 \%$ CIs.

Table S20: Perceived COVID-19 burden (PCBS) as predictor of radicalism intentions (RIS): between-individual models

\begin{tabular}{|c|c|c|c|c|c|c|c|c|c|c|}
\hline & (1) Pooled & & (2) The US & & (3) Denmark & & (4) Italy & & (5) Hungary & \\
\hline & $\mathrm{b}$ & ci95 & $\mathrm{b}$ & ci95 & $\mathrm{b}$ & ci95 & $\mathrm{b}$ & ci95 & $\mathrm{b}$ & ci95 \\
\hline PCBS & 0.25 & $0.19,0.30$ & 0.13 & $0.02,0.25$ & 0.32 & $0.23,0.40$ & 0.18 & $0.07,0.29$ & 0.29 & $0.19,0.40$ \\
\hline Age & -0.01 & $-0.02,-0.01$ & -0.02 & $-0.03,-0.02$ & -0.01 & $-0.02,-0.01$ & -0.01 & $-0.02,-0.01$ & -0.01 & $-0.01,-0.00$ \\
\hline Gender & -0.06 & $-0.08,-0.05$ & -0.05 & $-0.08,-0.02$ & -0.07 & $-0.09,-0.05$ & -0.06 & $-0.09,-0.03$ & -0.08 & $-0.12,-0.05$ \\
\hline Edu & 0.01 & $-0.00,0.02$ & 0.02 & $-0.00,0.04$ & 0.00 & $-0.01,0.02$ & -0.00 & $-0.02,0.02$ & 0.01 & $-0.02,0.03$ \\
\hline Constant & 0.26 & $0.23,0.29$ & 0.39 & $0.32,0.47$ & 0.18 & $0.14,0.23$ & 0.31 & $0.24,0.38$ & 0.18 & $0.11,0.25$ \\
\hline$N$ & 4317 & & 1092 & & 1206 & & 1167 & & 852 & \\
\hline$R^{2}$ & 0.069 & & 0.103 & & 0.115 & & 0.031 & & 0.067 & \\
\hline
\end{tabular}

Note: The table reports unstandardised regression coefficients and the corresponding 95\% CIs. 
Table S21: Perceived COVID-19 burden (PCBS) as predictor of participation in protests and politcal violence in the US: between-individual models

\begin{tabular}{lcccc}
\hline \hline & (1) Protests & \multicolumn{3}{c}{ (2) Political violence } \\
& $\mathrm{b}$ & $\mathrm{ci95}$ & $\mathrm{b}$ & ci95 \\
\hline PCBS & 0.04 & $-0.08,0.17$ & 0.15 & $0.07,0.22$ \\
Age & -0.01 & $-0.02,-0.01$ & -0.01 & $-0.02,-0.01$ \\
Gender & -0.02 & $-0.06,0.01$ & -0.02 & $-0.04,-0.00$ \\
Edu & 0.07 & $0.05,0.09$ & -0.00 & $-0.02,0.01$ \\
Black & 0.06 & $0.00,0.12$ & 0.04 & $0.00,0.07$ \\
Hispanic & 0.00 & $-0.06,0.06$ & 0.05 & $0.01,0.08$ \\
Asian & -0.02 & $-0.13,0.10$ & 0.04 & $-0.02,0.11$ \\
Nat. Am. & 0.12 & $-0.06,0.31$ & 0.12 & $-0.00,0.24$ \\
Mixed & 0.01 & $-0.27,0.29$ & -0.03 & $-0.20,0.14$ \\
Other & 0.07 & $-0.02,0.17$ & 0.03 & $-0.03,0.09$ \\
Constant & 0.24 & $0.16,0.32$ & 0.09 & $0.05,0.14$ \\
\hline$N$ & 1074 & & 1082 & \\
$R^{2}$ & 0.072 & & 0.119 & \\
\hline \hline
\end{tabular}

Note: The table reports unstandardised regression coefficients and the corresponding 95\% CIs. "Black", "Hispanic", "Asian", "Native American", "Mixed", and "Other" are all binary variables with "White" as the baseline category. 
Table S22: Perceived COVID-19 burden (PCBS) as predictor of participation in the BLM protests and counter-protests: between-individual models

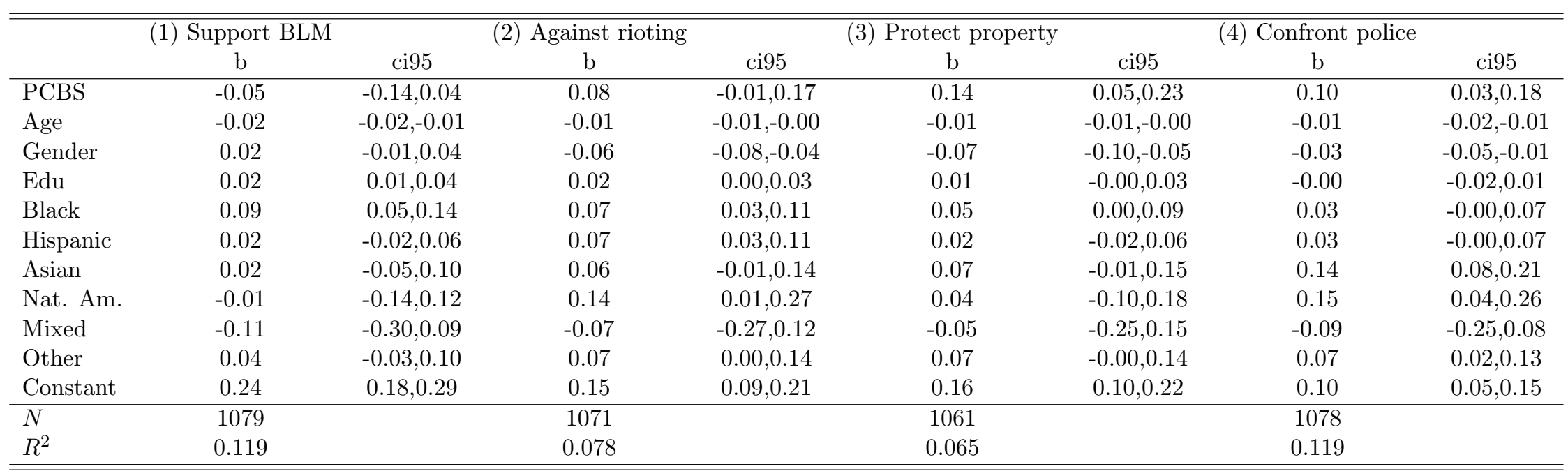

Note: The table reports unstandardised regression coefficients and the corresponding 95\% CIs. "Black", "Hispanic", "Asian", "Native American", "Mixed", and "Other" are all binary variables with "White" as the baseline category. 
Table S23: Perceived COVID-19 burden (PCBS) as predictor of participation in the BLM protests and counter-protests: between-individual models (Part 2)

\begin{tabular}{lcccccc}
\hline \hline & (5) Confront BLM & \multicolumn{3}{c}{ (6) Destruct property } & (7) Confront others \\
& $\mathrm{b}$ & $\mathrm{ci} 95$ & $\mathrm{~b}$ & $\mathrm{ci} 95$ & $\mathrm{~b}$ & ci95 \\
\hline PCBS & 0.19 & $0.11,0.27$ & 0.13 & $0.06,0.20$ & 0.14 & $0.06,0.22$ \\
Age & -0.01 & $-0.01,-0.01$ & -0.01 & $-0.02,-0.01$ & -0.01 & $-0.01,-0.01$ \\
Gender & -0.04 & $-0.06,-0.02$ & -0.03 & $-0.05,-0.01$ & -0.04 & $-0.06,-0.02$ \\
Edu & -0.00 & $-0.02,0.01$ & -0.00 & $-0.01,0.01$ & -0.00 & $-0.01,0.01$ \\
Black & 0.03 & $-0.00,0.07$ & 0.04 & $0.01,0.07$ & 0.03 & $-0.01,0.06$ \\
Hispanic & 0.02 & $-0.01,0.06$ & 0.04 & $0.01,0.07$ & 0.04 & $-0.00,0.07$ \\
Asian & 0.13 & $0.06,0.20$ & 0.14 & $0.07,0.20$ & 0.14 & $0.08,0.21$ \\
Nat. Am. & 0.01 & $-0.11,0.12$ & 0.08 & $-0.03,0.18$ & 0.01 & $-0.11,0.12$ \\
Mixed & -0.08 & $-0.25,0.08$ & -0.08 & $-0.23,0.08$ & -0.08 & $-0.26,0.09$ \\
Other & 0.01 & $-0.04,0.07$ & 0.01 & $-0.05,0.06$ & 0.02 & $-0.04,0.08$ \\
Constant & 0.05 & $0.01,0.10$ & 0.08 & $0.04,0.12$ & 0.08 & $0.03,0.13$ \\
\hline$N$ & 1085 & & 1095 & & 1085 & \\
$R^{2}$ & 0.097 & & 0.127 & & 0.092 & \\
\hline
\end{tabular}

Note: The table reports unstandardised regression coefficients and the corresponding 95\% CIs. "Black", "Hispanic", "Asian", "Native American", "Mixed", and "Other" are all binary variables with "White" as the baseline category. 
Table S24: Police violence salience as moderator of the perceived COVID-19 burden (PCBS) association with activism intentions (AIS): between-individual models

\begin{tabular}{|c|c|c|c|c|c|c|c|c|c|c|}
\hline & (1) Pooled & & (2) The US & & (3) Denmark & & (4) Italy & & (5) Hungary & \\
\hline & $\mathrm{b}$ & ci95 & $\mathrm{b}$ & ci95 & $\mathrm{b}$ & ci95 & b & ci95 & $\mathrm{b}$ & ci95 \\
\hline Treat & -0.01 & $-0.06,0.04$ & -0.03 & $-0.15,0.08$ & -0.03 & $-0.11,0.06$ & -0.03 & $-0.15,0.09$ & 0.03 & $-0.10,0.16$ \\
\hline PCBS & 0.15 & $0.07,0.23$ & -0.02 & $-0.20,0.15$ & 0.20 & $0.05,0.36$ & -0.07 & $-0.24,0.10$ & 0.45 & $0.27,0.62$ \\
\hline Treat*PCBS & 0.00 & $-0.11,0.11$ & 0.07 & $-0.18,0.32$ & 0.07 & $-0.15,0.30$ & 0.02 & $-0.21,0.26$ & -0.09 & $-0.33,0.15$ \\
\hline age & -0.00 & $-0.00,0.00$ & -0.00 & $-0.01,0.00$ & -0.00 & $-0.01,-0.00$ & -0.01 & $-0.01,-0.00$ & 0.01 & $0.00,0.02$ \\
\hline Gender & -0.03 & $-0.04,-0.01$ & -0.02 & $-0.05,0.02$ & -0.02 & $-0.06,0.01$ & -0.04 & $-0.08,-0.01$ & -0.02 & $-0.06,0.01$ \\
\hline Edu & 0.06 & $0.05,0.07$ & 0.07 & $0.04,0.09$ & 0.06 & $0.03,0.08$ & 0.05 & $0.03,0.08$ & 0.05 & $0.02,0.07$ \\
\hline Constant & 0.37 & $0.33,0.42$ & 0.50 & $0.40,0.59$ & 0.31 & $0.24,0.38$ & 0.52 & $0.43,0.62$ & 0.16 & $0.05,0.26$ \\
\hline$N$ & 4315 & & 1094 & & 1199 & & 1166 & & 856 & \\
\hline$R^{2}$ & 0.033 & & 0.040 & & 0.043 & & 0.038 & & 0.074 & \\
\hline
\end{tabular}

Note: The table reports unstandardised regression coefficients and the corresponding $95 \%$ CIs.

Table S25: Police violence salience as moderator of the perceived COVID-19 burden (PCBS) association with radicalism intentions (RIS): between-individual models

\begin{tabular}{|c|c|c|c|c|c|c|c|c|c|c|}
\hline & (1) Pooled & & (2) The US & & (3) Denmark & & (4) Italy & & (5) Hungary & \\
\hline & $\mathrm{b}$ & ci95 & $\mathrm{b}$ & ci95 & $\mathrm{b}$ & ci95 & $\mathrm{b}$ & ci95 & $\mathrm{b}$ & ci95 \\
\hline Treat & -0.03 & $-0.07,0.02$ & -0.06 & $-0.16,0.04$ & -0.07 & $-0.14,-0.01$ & 0.01 & $-0.10,0.13$ & -0.03 & $-0.14,0.09$ \\
\hline PCBS & 0.22 & $0.15,0.30$ & 0.09 & $-0.07,0.25$ & 0.21 & $0.09,0.33$ & 0.18 & $0.02,0.34$ & 0.30 & $0.15,0.46$ \\
\hline Treat*PCBS & 0.04 & $-0.06,0.13$ & 0.08 & $-0.15,0.31$ & 0.21 & $0.04,0.38$ & -0.01 & $-0.23,0.22$ & -0.03 & $-0.24,0.18$ \\
\hline age & -0.01 & $-0.02,-0.01$ & -0.02 & $-0.03,-0.02$ & -0.01 & $-0.02,-0.01$ & -0.01 & $-0.02,-0.01$ & -0.01 & $-0.01,-0.00$ \\
\hline Gender & -0.06 & $-0.08,-0.05$ & -0.05 & $-0.08,-0.02$ & -0.07 & $-0.10,-0.05$ & -0.06 & $-0.09,-0.03$ & -0.08 & $-0.12,-0.05$ \\
\hline Edu & 0.01 & $-0.00,0.02$ & 0.02 & $-0.00,0.04$ & 0.00 & $-0.01,0.02$ & 0.00 & $-0.02,0.02$ & 0.01 & $-0.02,0.03$ \\
\hline Constant & 0.28 & $0.24,0.31$ & 0.43 & $0.34,0.51$ & 0.22 & $0.17,0.28$ & 0.30 & $0.21,0.39$ & 0.19 & $0.10,0.28$ \\
\hline$N$ & 4317 & & 1092 & & 1206 & & 1167 & & 852 & \\
\hline$R^{2}$ & 0.070 & & 0.105 & & 0.120 & & 0.032 & & 0.075 & \\
\hline
\end{tabular}

Note: The table reports unstandardised regression coefficients and the corresponding $95 \%$ CIs. 
Table S26: Police violence salience as predictor of activism (AIS) and radicalism intentions (RIS): between-individual models

\begin{tabular}{lcccc}
\hline & (1) AIS, pooled & \multicolumn{3}{c}{ (2) RIS, pooled } \\
& $\mathrm{b}$ & $\mathrm{ci} 95$ & $\mathrm{~b}$ & $\mathrm{ci} 95$ \\
\hline Treat & -0.01 & $-0.03,0.00$ & -0.01 & $-0.03,0.00$ \\
Age & -0.00 & $-0.01,0.00$ & -0.01 & $-0.02,-0.01$ \\
Gender & -0.03 & $-0.05,-0.01$ & -0.06 & $-0.08,-0.05$ \\
Edu & 0.06 & $0.05,0.07$ & 0.01 & $-0.00,0.02$ \\
Constant & 0.44 & $0.42,0.47$ & 0.38 & $0.36,0.40$ \\
\hline$N$ & 4315 & & 4317 & \\
$R^{2}$ & 0.027 & & 0.051 & \\
\hline
\end{tabular}

Note: The table reports unstandardised regression coefficients and the corresponding $95 \%$ CIs. 
Table S27: Perceptions and self-reported experience of police violence (PVS) as moderator of the perceived COVID-19 burden (PCBS) association with activism intentions (AIS): between-individual models

\begin{tabular}{|c|c|c|c|c|c|c|c|c|c|c|}
\hline & (1) Pooled & & (2) The US & & (3) Denmark & & (4) Italy & & (5) Hungary & \\
\hline & $\mathrm{b}$ & ci95 & $\mathrm{b}$ & ci95 & $\mathrm{b}$ & ci95 & $\mathrm{b}$ & ci95 & $\mathrm{b}$ & ci95 \\
\hline PVS & 0.46 & $0.32,0.60$ & 0.63 & $0.36,0.90$ & 0.41 & $0.13,0.68$ & 0.48 & $0.15,0.81$ & 0.15 & $-0.20,0.49$ \\
\hline CBS & 0.12 & $0.03,0.20$ & 0.10 & $-0.10,0.31$ & 0.16 & $-0.00,0.33$ & 0.03 & $-0.17,0.22$ & 0.19 & $0.02,0.36$ \\
\hline PVS*PCBS & -0.24 & $-0.52,0.04$ & -0.54 & $-1.11,0.03$ & -0.22 & $-0.83,0.39$ & -0.36 & $-0.99,0.27$ & 0.31 & $-0.28,0.89$ \\
\hline age & 0.00 & $-0.00,0.00$ & 0.00 & $-0.00,0.01$ & -0.00 & $-0.01,0.00$ & -0.00 & $-0.01,0.00$ & 0.01 & $0.01,0.02$ \\
\hline Gender & -0.02 & $-0.04,-0.00$ & -0.02 & $-0.06,0.01$ & -0.01 & $-0.05,0.02$ & -0.04 & $-0.07,-0.00$ & -0.00 & $-0.04,0.03$ \\
\hline Edu & 0.06 & $0.05,0.07$ & 0.06 & $0.04,0.08$ & 0.06 & $0.04,0.08$ & 0.04 & $0.02,0.07$ & 0.05 & $0.02,0.07$ \\
\hline Constant & 0.27 & $0.23,0.32$ & 0.29 & $0.19,0.40$ & 0.24 & $0.17,0.31$ & 0.38 & $0.27,0.49$ & 0.19 & $0.09,0.29$ \\
\hline$N$ & 4245 & & 1082 & & 1172 & & 1144 & & 847 & \\
\hline$R^{2}$ & 0.087 & & 0.121 & & 0.075 & & 0.076 & & 0.121 & \\
\hline
\end{tabular}

Note: The table reports unstandardised regression coefficients and the corresponding $95 \%$ CIs.

¿ Table S28: Perceptions and self-reported experience of police violence (PVS) as moderator of the perceived COVID-19 burden (PCBS) association with radicalism intentions (RIS): between-individual models

\begin{tabular}{|c|c|c|c|c|c|c|c|c|c|c|}
\hline & (1) Pooled & & (2) The US & & (3) Denmark & & (4) Italy & & (5) Hungary & \\
\hline & $\mathrm{b}$ & ci95 & $\mathrm{b}$ & ci95 & $\mathrm{b}$ & ci95 & $\mathrm{b}$ & $\operatorname{ci} 95$ & $\mathrm{~b}$ & $\operatorname{ci95}$ \\
\hline PVS & 0.63 & $0.52,0.75$ & 0.59 & $0.35,0.83$ & 0.50 & $0.31,0.70$ & 0.66 & $0.36,0.97$ & 0.72 & $0.43,1.02$ \\
\hline PCBS & 0.22 & $0.15,0.30$ & 0.12 & $-0.06,0.29$ & 0.10 & $-0.01,0.22$ & 0.34 & $0.16,0.52$ & 0.18 & $0.04,0.33$ \\
\hline PVS*PCBS & -0.40 & $-0.64,-0.17$ & -0.23 & $-0.73,0.27$ & 0.06 & $-0.36,0.49$ & -0.66 & $-1.24,-0.08$ & -0.52 & $-1.03,-0.02$ \\
\hline age & -0.01 & $-0.01,-0.01$ & -0.02 & $-0.02,-0.01$ & -0.01 & $-0.01,-0.00$ & -0.01 & $-0.01,-0.00$ & -0.00 & $-0.01,0.00$ \\
\hline Gender & -0.06 & $-0.07,-0.04$ & -0.06 & $-0.08,-0.03$ & -0.06 & $-0.08,-0.04$ & -0.05 & $-0.08,-0.02$ & -0.06 & $-0.09,-0.03$ \\
\hline Edu & 0.01 & $-0.00,0.02$ & 0.02 & $-0.00,0.03$ & 0.01 & $-0.00,0.03$ & -0.01 & $-0.03,0.01$ & 0.01 & $-0.01,0.03$ \\
\hline Constant & 0.13 & $0.09,0.17$ & 0.21 & $0.12,0.30$ & 0.11 & $0.06,0.16$ & 0.14 & $0.03,0.24$ & 0.11 & $0.02,0.19$ \\
\hline$N$ & 4249 & & 1081 & & 1179 & & 1147 & & 842 & \\
\hline$R^{2}$ & 0.184 & & 0.246 & & 0.278 & & 0.093 & & 0.173 & \\
\hline
\end{tabular}

Note: The table reports unstandardised regression coefficients and the corresponding $95 \%$ CIs. 
Table S29: Perceptions and self-reported experience of police violence as predictor of activism (AIS) and radicalism intentions (RIS): between-individual models

\begin{tabular}{lcccc}
\hline \hline & (1) AIS, pooled & \multicolumn{3}{c}{ (2) RIS, pooled } \\
& $\mathrm{b}$ & $\mathrm{ci} 95$ & $\mathrm{~b}$ & $\mathrm{ci95}$ \\
\hline PVS & 0.35 & $0.31,0.40$ & 0.46 & $0.42,0.49$ \\
age & 0.00 & $-0.00,0.00$ & -0.01 & $-0.01,-0.01$ \\
Gender & -0.02 & $-0.04,-0.00$ & -0.05 & $-0.07,-0.04$ \\
Edu & 0.06 & $0.04,0.07$ & 0.01 & $-0.00,0.01$ \\
Constant & 0.32 & $0.30,0.35$ & 0.23 & $0.21,0.25$ \\
\hline$N$ & 4245 & & 4249 & \\
$R^{2}$ & 0.085 & & 0.176 & \\
\hline \hline
\end{tabular}

Note: The table reports unstandardised regression coefficients and the corresponding $95 \%$ CIs. 
Table S30: Perceptions and self-reported experience of police violence (PVS) as moderator of the perceived COVID-19 burden association with participation in protests and political violence in the US: between-individual models

\begin{tabular}{lcccc}
\hline \hline & (1) Protests & \multicolumn{3}{c}{ (2) Political violence } \\
& $\mathrm{b}$ & ci95 & $\mathrm{b}$ & ci95 \\
\hline PVS & 0.68 & $0.41,0.95$ & -0.05 & $-0.21,0.11$ \\
PCBS & 0.07 & $-0.13,0.26$ & -0.13 & $-0.24,-0.01$ \\
PCBS*PVS & -0.35 & $-0.91,0.21$ & 0.82 & $0.49,1.16$ \\
Age & -0.00 & $-0.01,0.00$ & -0.01 & $-0.01,-0.01$ \\
Gender & -0.02 & $-0.05,0.01$ & -0.02 & $-0.04,-0.01$ \\
Edu & 0.07 & $0.05,0.09$ & -0.01 & $-0.02,0.01$ \\
Black & -0.03 & $-0.08,0.03$ & 0.00 & $-0.03,0.03$ \\
Hispanic & -0.02 & $-0.08,0.03$ & 0.03 & $-0.00,0.07$ \\
Asian & -0.05 & $-0.15,0.05$ & 0.04 & $-0.02,0.10$ \\
Nat. Am. & 0.12 & $-0.05,0.29$ & 0.12 & $0.01,0.24$ \\
Mixed & -0.01 & $-0.27,0.25$ & -0.01 & $-0.17,0.15$ \\
Other & 0.01 & $-0.08,0.09$ & -0.01 & $-0.06,0.04$ \\
Constant & 0.05 & $-0.06,0.15$ & 0.10 & $0.04,0.16$ \\
\hline$N$ & 1067 & & 1073 & \\
$R^{2}$ & 0.205 & & 0.274 & \\
\hline
\end{tabular}

Note: The table reports unstandardised regression coefficients and the corresponding 95\% CIs. "Black", "Hispanic", "Asian", "Native American", "Mixed", and "Other" are all binary variables with "White" as the baseline category. 
Table S31: Perceptions and self-reported experience of police violence (PVS) as predictor of participation in protests and political violence in the US: between-individual models

\begin{tabular}{lcccc}
\hline \hline & (1) Protests & \multicolumn{3}{c}{ (2) Political violence } \\
& $\mathrm{b}$ & $\mathrm{c} 95$ & $\mathrm{~b}$ & $\mathrm{c} 95$ \\
\hline PVS & 0.52 & $0.44,0.59$ & 0.34 & $0.29,0.38$ \\
Age & -0.00 & $-0.01,0.00$ & -0.01 & $-0.01,-0.01$ \\
Gender & -0.02 & $-0.05,0.01$ & -0.03 & $-0.05,-0.01$ \\
Edu & 0.07 & $0.05,0.09$ & -0.01 & $-0.02,0.00$ \\
Black & -0.02 & $-0.08,0.03$ & -0.01 & $-0.04,0.02$ \\
Hispanic & -0.02 & $-0.08,0.03$ & 0.03 & $-0.00,0.07$ \\
Asian & -0.05 & $-0.15,0.06$ & 0.03 & $-0.03,0.09$ \\
Nat. Am. & 0.12 & $-0.05,0.29$ & 0.13 & $0.02,0.24$ \\
Mixed & 0.00 & $-0.26,0.26$ & -0.03 & $-0.19,0.13$ \\
Other & 0.00 & $-0.09,0.09$ & 0.00 & $-0.05,0.06$ \\
Constant & 0.08 & $0.02,0.13$ & 0.05 & $0.01,0.08$ \\
\hline$N$ & 1067 & & 1073 & \\
$R^{2}$ & 0.204 & & 0.252 & \\
\hline
\end{tabular}

Note: The table reports unstandardised regression coefficients and the corresponding 95\% CIs. "Black", "Hispanic", "Asian", "Native American", "Mixed", and "Other" are all binary variables with "White" as the baseline category. 
Table S32: Perceptions and self-reported experience of police violence (PVS) as moderator of the perceived COVID-19 burden (PCBS) association with participation in the BLM protests and counter-protests: between-individual models (Part 1)

\begin{tabular}{|c|c|c|c|c|c|c|c|c|}
\hline & (1) Support BLM & & (2) Against rioting & & (3) Protect property & & (4) Confront police & \\
\hline & $\mathrm{b}$ & ci95 & $\mathrm{b}$ & ci95 & $\mathrm{b}$ & ci95 & $\mathrm{b}$ & ci95 \\
\hline PVS & 0.40 & $0.22,0.59$ & -0.12 & $-0.32,0.08$ & -0.02 & $-0.23,0.19$ & -0.03 & $-0.19,0.13$ \\
\hline PCBS & -0.09 & $-0.23,0.04$ & -0.14 & $-0.29,0.01$ & 0.00 & $-0.15,0.16$ & -0.13 & $-0.24,-0.01$ \\
\hline PCBS*PVS & -0.04 & $-0.42,0.35$ & 0.68 & $0.27,1.10$ & 0.42 & $-0.01,0.85$ & 0.69 & $0.35,1.03$ \\
\hline Age & -0.01 & $-0.02,-0.01$ & -0.01 & $-0.01,-0.00$ & -0.00 & $-0.01,0.00$ & -0.01 & $-0.01,-0.01$ \\
\hline Gender & 0.02 & $-0.01,0.04$ & -0.06 & $-0.08,-0.04$ & -0.07 & $-0.10,-0.05$ & -0.04 & $-0.05,-0.02$ \\
\hline Edu & 0.02 & $0.01,0.03$ & 0.02 & $0.00,0.03$ & 0.01 & $-0.00,0.03$ & -0.00 & $-0.02,0.01$ \\
\hline Black & 0.03 & $-0.01,0.07$ & 0.05 & $0.01,0.10$ & 0.03 & $-0.02,0.07$ & 0.00 & $-0.03,0.04$ \\
\hline Hispanic & -0.00 & $-0.04,0.04$ & 0.06 & $0.02,0.10$ & 0.01 & $-0.03,0.05$ & 0.02 & $-0.02,0.05$ \\
\hline Asian & -0.00 & $-0.07,0.07$ & 0.06 & $-0.02,0.13$ & 0.06 & $-0.02,0.14$ & 0.14 & $0.07,0.20$ \\
\hline Nat. Am. & -0.01 & $-0.13,0.11$ & 0.14 & $0.01,0.27$ & 0.04 & $-0.09,0.17$ & 0.15 & $0.05,0.26$ \\
\hline Mixed & -0.11 & $-0.29,0.07$ & -0.06 & $-0.25,0.13$ & -0.04 & $-0.24,0.16$ & -0.07 & $-0.23,0.09$ \\
\hline Other & -0.01 & $-0.07,0.05$ & 0.05 & $-0.02,0.11$ & 0.05 & $-0.02,0.11$ & 0.04 & $-0.01,0.10$ \\
\hline Edu & & & 0.00 & $0.00,0.00$ & & & & \\
\hline Constant & 0.13 & $0.06,0.20$ & 0.18 & $0.10,0.26$ & 0.16 & $0.08,0.24$ & 0.10 & $0.04,0.17$ \\
\hline$N$ & 1067 & & 1059 & & 1050 & & 1066 & \\
\hline$R^{2}$ & 0.264 & & 0.125 & & 0.100 & & 0.239 & \\
\hline
\end{tabular}

Note: The table reports unstandardised regression coefficients and the corresponding 95\% CIs. "Black", "Hispanic", "Asian", "Native American", "Mixed", and "Other" are all binary variables with "White" as the baseline category. 
Table S33: Perceptions and self-reported experience of police violence (PVS) as moderator of the perceived COVID-19 burden (PCBS) association with participation in the BLM protests and counter-protests: between-individual models (Part 2)

\begin{tabular}{lcccccc}
\hline \hline & (5) Confront BLM & \multicolumn{3}{c}{ (6) Destruct property } & (7) Confront others \\
& $\mathrm{b}$ & ci95 & $\mathrm{b}$ & ci95 & $\mathrm{b}$ & ci95 \\
\hline PVS & -0.21 & $-0.38,-0.04$ & -0.20 & $-0.36,-0.05$ & -0.10 & $-0.27,0.07$ \\
PCBS & -0.08 & $-0.21,0.04$ & -0.17 & $-0.28,-0.06$ & -0.12 & $-0.24,0.01$ \\
PCBS*PVS & 0.88 & $0.53,1.23$ & 0.97 & $0.65,1.28$ & 0.80 & $0.44,1.15$ \\
Age & -0.01 & $-0.01,-0.00$ & -0.01 & $-0.01,-0.01$ & -0.01 & $-0.01,-0.00$ \\
Gender & -0.04 & $-0.06,-0.02$ & -0.03 & $-0.05,-0.02$ & -0.04 & $-0.06,-0.02$ \\
Edu & -0.00 & $-0.02,0.01$ & -0.00 & $-0.01,0.01$ & -0.00 & $-0.01,0.01$ \\
Black & 0.02 & $-0.02,0.05$ & 0.02 & $-0.01,0.05$ & 0.00 & $-0.03,0.04$ \\
Hispanic & 0.01 & $-0.02,0.05$ & 0.03 & $-0.00,0.06$ & 0.02 & $-0.01,0.06$ \\
Asian & 0.12 & $0.06,0.19$ & 0.13 & $0.07,0.18$ & 0.13 & $0.07,0.19$ \\
Nat. Am. & 0.01 & $-0.10,0.12$ & 0.08 & $-0.02,0.18$ & 0.01 & $-0.10,0.12$ \\
Mixed & -0.06 & $-0.22,0.10$ & -0.05 & $-0.20,0.10$ & -0.07 & $-0.23,0.10$ \\
Other & -0.01 & $-0.07,0.04$ & -0.02 & $-0.07,0.03$ & -0.01 & $-0.07,0.04$ \\
Constant & 0.11 & $0.04,0.17$ & 0.13 & $0.07,0.19$ & 0.10 & $0.03,0.16$ \\
\hline$N$ & 1073 & & 1083 & & 1073 & 0.198 \\
$R^{2}$ & 0.169 & 0.238 & & & \\
\hline
\end{tabular}

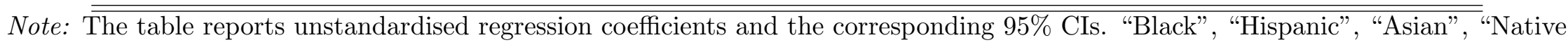
American", "Mixed", and "Other" are all binary variables with "White" as the baseline category. 
Table S34: Perceptions and self-reported experience of police violence (PVS) as predictor of participation in the BLM protests and counterprotests: between-individual models (Part 1)

\begin{tabular}{|c|c|c|c|c|c|c|c|c|}
\hline & (1) Support BLM & & (2) Against rioting & & (3) Protect property & & (4) Confront police & \\
\hline & $\mathrm{b}$ & ci95 & $\mathrm{b}$ & ci95 & $\mathrm{b}$ & ci95 & $\mathrm{b}$ & ci95 \\
\hline PVS & 0.38 & $0.33,0.43$ & 0.20 & $0.14,0.26$ & 0.18 & $0.12,0.24$ & 0.29 & $0.25,0.34$ \\
\hline Age & -0.01 & $-0.02,-0.01$ & -0.01 & $-0.01,-0.00$ & -0.00 & $-0.01,-0.00$ & -0.01 & $-0.01,-0.01$ \\
\hline Gender & 0.02 & $-0.00,0.04$ & -0.06 & $-0.09,-0.04$ & -0.07 & $-0.10,-0.05$ & -0.04 & $-0.06,-0.02$ \\
\hline Edu & 0.02 & $0.01,0.03$ & 0.01 & $-0.00,0.03$ & 0.01 & $-0.01,0.02$ & -0.01 & $-0.02,0.01$ \\
\hline Black & 0.04 & $-0.00,0.07$ & 0.04 & $0.00,0.08$ & 0.02 & $-0.02,0.06$ & -0.01 & $-0.04,0.03$ \\
\hline Hispanic & -0.00 & $-0.04,0.04$ & 0.06 & $0.02,0.10$ & 0.01 & $-0.03,0.05$ & 0.02 & $-0.02,0.05$ \\
\hline Asian & -0.00 & $-0.08,0.07$ & 0.05 & $-0.03,0.13$ & 0.06 & $-0.02,0.14$ & 0.13 & $0.07,0.19$ \\
\hline Nat. Am. & -0.02 & $-0.14,0.10$ & 0.14 & $0.01,0.27$ & 0.04 & $-0.09,0.18$ & 0.15 & $0.05,0.26$ \\
\hline Mixed & -0.11 & $-0.29,0.07$ & -0.08 & $-0.27,0.12$ & -0.05 & $-0.25,0.15$ & -0.09 & $-0.25,0.07$ \\
\hline Other & -0.01 & $-0.07,0.05$ & 0.05 & $-0.02,0.12$ & 0.05 & $-0.01,0.12$ & 0.05 & $-0.01,0.10$ \\
\hline Constant & 0.08 & $0.05,0.12$ & 0.12 & $0.08,0.16$ & 0.17 & $0.13,0.21$ & 0.05 & $0.02,0.08$ \\
\hline$N$ & 1067 & & 1059 & & 1050 & & 1066 & \\
\hline$R^{2}$ & 0.260 & & 0.115 & & 0.091 & & 0.225 & \\
\hline
\end{tabular}


Table S35: Perceptions and self-reported experience of police violence (PVS) as predictor of participation in the BLM protests and counterprotests: between-individual models (Part 2)

\begin{tabular}{lcccccc}
\hline \hline & (5) Confront BLM & \multicolumn{3}{c}{ (6) Destruct property } & (7) Confront others \\
& $\mathrm{b}$ & $\mathrm{ci95}$ & $\mathrm{b}$ & $\mathrm{ci95}$ & $\mathrm{b}$ & ci95 \\
\hline PVS & 0.21 & $0.16,0.26$ & 0.25 & $0.20,0.29$ & 0.28 & $0.23,0.32$ \\
Age & -0.01 & $-0.01,-0.00$ & -0.01 & $-0.01,-0.01$ & -0.01 & $-0.01,-0.00$ \\
Gender & -0.04 & $-0.07,-0.02$ & -0.04 & $-0.06,-0.02$ & -0.04 & $-0.06,-0.02$ \\
Edu & -0.01 & $-0.02,0.00$ & -0.01 & $-0.02,0.01$ & -0.00 & $-0.02,0.01$ \\
Black & 0.00 & $-0.03,0.04$ & 0.00 & $-0.03,0.04$ & -0.01 & $-0.05,0.02$ \\
Hispanic & 0.01 & $-0.02,0.05$ & 0.03 & $-0.00,0.06$ & 0.02 & $-0.01,0.06$ \\
Asian & 0.12 & $0.05,0.18$ & 0.12 & $0.06,0.18$ & 0.13 & $0.06,0.19$ \\
Nat. Am. & 0.01 & $-0.10,0.12$ & 0.08 & $-0.02,0.18$ & 0.01 & $-0.10,0.12$ \\
Mixed & -0.09 & $-0.25,0.08$ & -0.08 & $-0.23,0.07$ & -0.09 & $-0.25,0.08$ \\
Other & -0.00 & $-0.06,0.05$ & -0.01 & $-0.06,0.04$ & -0.00 & $-0.06,0.05$ \\
Constant & 0.08 & $0.04,0.11$ & 0.06 & $0.03,0.09$ & 0.05 & $0.02,0.09$ \\
\hline$N$ & 1073 & & 1083 & & 1073 & \\
$R^{2}$ & 0.135 & & 0.207 & & 0.177 & \\
\hline
\end{tabular}

Note: The table reports unstandardised regression coefficients and the corresponding 95\% CIs. "Black", "Hispanic", "Asian", "Native American", "Mixed", and "Other" are all binary variables with "White" as the baseline category. 


\section{S12 Analysis of list experiment: Extensions}

As reported in the main text, we first analyzed list experiment using a simple difference-inmeans estimator. We found that the proportion of interviewees who agreed with the sensitive statement was larger by 11 percentage points in the high-burden subsample, compared to the low-burden subsample (the two subsamples were generated using a median split).

Subsequently, using the KICT package in Stata (Tsai 2019), we conducted analogous analysis with a least-squares estimator. In absence of other covariates, this estimator produces a coefficient identical to the difference in proportions estimated above using the difference-in-means estimator: $b=0.11,95 \%$ CIs $=[0.00,0.22]$. This coefficient can also be interpreted as the change in the probability of agreeing with the sensitive item in response to one unit change in the predictor. The key advantage of the least-squares estimator is that is allows analyzing controls in a standard multivariate regression framework. Hence, we conducted analogous analyses with age, gender, education, and country dummies as controls, finding a similar coefficient $b$ $=0.11,95 \% \mathrm{CI}=[-0.01,0.22]$. The linear least-squares estimator is essentially a linear probability model (Tsai 2019): it predicts the probability of agreeing with the sensitive item but does not constrain the predictions to the interval between 0 and 1 . As a result, this estimator can produce implausible predicted values, i.e., probabilities of agreeing with the sensitive item that are below 0 or above 1 . To constrain the predictions to the $0-1$ range, we therefore used a non-linear (least-squares) estimator, finding significant estimates, logit $=3.31,95 \% \mathrm{CI}=[0.02$, 6.60]. Finally, instead of using the arbitrary median split, we used the continuous Perceived COVID-19 Burden Scale (from 0 to 6 ), also finding significant estimates, logit $=1.06,95 \% \mathrm{CI}=$ $[0.26,1.86]$. The interpretation of these estimates is analogous to those of a logit regression. An exponentiated logit of 1.06 equals 2.89; hence, a one unit increase in the Perceived COVID-19 Burden Scale is associated with a 2.89 increase in the odds of agreeing with the sensitive item, holding other controls constant. 


\section{S13 Ideology measures}

In political matters, people talk of "the left" and "the right". How would you place your views on this scale, generally speaking?

1. The left

2 .

3.

4 .

5.

6.

7.

8.

9.

10. The right

NotE: This question produced untypical nonresponse rate in the US sample: $88 \%$ in Wave 1 and $85 \%$ in Wave 2 (compared to $8 \%$ in Denmark, $30 \%$ in Italy, and $5 \%$ in Hungary in Wave 1; and $8 \%$ in Denmark, $18 \%$ in Italy, and $4 \%$ in Hungary in Wave 2). Therefore, we asked the survey agency to double-check the dataset for errors. YouGov confirmed that the nonresponse rate in the US reflects genuine refusal to answer this question. Given this, we asked YouGov to supply an alternative measure of ideology from among the background variables the survey agency collects by default. We received the measure of ideology presented below. For the pooled analyses, we substituted replies to the above question with the replies to the below question in the US sample (not sure was set to missing). The two measures correlated at $r=.66$.

In general, how would you describe your own political viewpoint?

1. Very liberal

2. Liberal

3. Moderate

4. Conservative

5. Very conservative

6. Not sure 


\section{S14 Affective polarization (right and left)}

What do you feel when you think about people on the right in political matters?
1. Angry
2. Frustrated
3. Afraid
4. Hopeful
5. Enthusiastic
6. Proud

What do you feel when you think about people on the left in political matters?
1. Angry
2. Frustrated
3. Afraid
4. Hopeful
5. Enthusiastic
6. Proud

Note: For both questions, the answer options ranged from very strongly $=0$ to not at all $=6$. 


\section{S15 Regression estimates: Robustness tests and extensions}

Table S36: Non-political COVID-19 burden (PCBSnp) as predictor of need for chaos (NFC): between-individual models

\begin{tabular}{|c|c|c|c|c|c|c|c|c|c|c|}
\hline & (1) Pooled & & (2) The US & & (3) Denmark & & (4) Italy & & (5) Hungary & \\
\hline & $\mathrm{b}$ & ci95 & $\mathrm{b}$ & ci95 & $\mathrm{b}$ & ci95 & $\mathrm{b}$ & ci95 & $\mathrm{b}$ & ci95 \\
\hline PCBSnp & 0.29 & $0.25,0.33$ & 0.33 & $0.25,0.41$ & 0.35 & $0.28,0.41$ & 0.25 & $0.17,0.32$ & 0.15 & $0.06,0.23$ \\
\hline Age & -0.01 & $-0.02,-0.01$ & -0.02 & $-0.03,-0.02$ & -0.01 & $-0.01,-0.01$ & -0.01 & $-0.01,-0.01$ & -0.01 & $-0.02,-0.01$ \\
\hline Gender & -0.05 & $-0.06,-0.04$ & -0.03 & $-0.05,-0.01$ & -0.06 & $-0.08,-0.04$ & -0.05 & $-0.07,-0.03$ & -0.05 & $-0.07,-0.03$ \\
\hline Edu & -0.02 & $-0.03,-0.01$ & -0.02 & $-0.03,-0.01$ & -0.01 & $-0.03,0.00$ & -0.03 & $-0.04,-0.02$ & -0.02 & $-0.03,-0.00$ \\
\hline Constant & 0.21 & $0.19,0.24$ & 0.26 & $0.21,0.31$ & 0.14 & $0.11,0.17$ & 0.25 & $0.20,0.30$ & 0.25 & $0.20,0.31$ \\
\hline$N$ & 4568 & & 1151 & & 1286 & & 1241 & & 890 & \\
\hline$R^{2}$ & 0.126 & & 0.220 & & 0.153 & & 0.076 & & 0.080 & \\
\hline
\end{tabular}

Note: The table reports unstandardised regression coefficients and the corresponding $95 \%$ CIs.

Table S37: Non-political COVID-19 burden (PCBSnp) as predictor of need for chaos (NFC): within-individual models

\begin{tabular}{lcc}
\hline \hline & (1) Pooled & \\
& $\mathrm{b}$ & ci95 \\
\hline PCBSnp & 0.10 & $0.06,0.14$ \\
Constant & 0.17 & $0.16,0.19$ \\
\hline$N$ & 10699 & \\
\hline \hline
\end{tabular}

Note: The table reports unstandardised regression coefficients and the corresponding $95 \%$ CIs. The specification includes unit- and time-fixed effects (not reported in the table). 
Table S38: Non-political COVID-19 burden (PCBSnp) as predictor of activism intentions (AIS): between-individual models

\begin{tabular}{|c|c|c|c|c|c|c|c|c|c|c|}
\hline & (1) Pooled & & (2) The US & & (3) Denmark & & (4) Italy & & (5) Hungary & \\
\hline & $\mathrm{b}$ & ci95 & b & ci95 & b & ci95 & b & ci95 & b & ci95 \\
\hline PCBSnp & 0.13 & $0.07,0.19$ & 0.09 & $-0.04,0.21$ & 0.27 & $0.16,0.38$ & -0.04 & $-0.16,0.08$ & 0.21 & $0.07,0.34$ \\
\hline Age & -0.00 & $-0.00,0.00$ & -0.00 & $-0.01,0.00$ & -0.00 & $-0.01,-0.00$ & -0.01 & $-0.01,-0.00$ & 0.01 & $0.01,0.02$ \\
\hline Gender & -0.03 & $-0.05,-0.01$ & -0.02 & $-0.05,0.02$ & -0.03 & $-0.06,0.00$ & -0.04 & $-0.08,-0.01$ & -0.02 & $-0.06,0.01$ \\
\hline Edu & 0.06 & $0.05,0.07$ & 0.07 & $0.05,0.09$ & 0.06 & $0.04,0.08$ & 0.06 & $0.03,0.08$ & 0.04 & $0.02,0.07$ \\
\hline Constant & 0.38 & $0.34,0.41$ & 0.44 & $0.37,0.52$ & 0.29 & $0.23,0.34$ & 0.50 & $0.42,0.57$ & 0.28 & $0.20,0.36$ \\
\hline$N$ & 4315 & & 1094 & & 1199 & & 1166 & & 856 & \\
\hline$R^{2}$ & 0.031 & & 0.042 & & 0.047 & & 0.036 & & 0.037 & \\
\hline
\end{tabular}

Note: The table reports unstandardised regression coefficients and the corresponding $95 \%$ CIs.

Table S39: Non-political COVID-19 burden (PCBSnp) as predictor of radicalism intentions (RIS): between-individual models

\begin{tabular}{|c|c|c|c|c|c|c|c|c|c|c|}
\hline & (1) Pooled & & (2) The US & & (3) Denmark & & (4) Italy & & (5) Hungary & \\
\hline & $\mathrm{b}$ & ci95 & $\mathrm{b}$ & ci95 & $\mathrm{b}$ & ci95 & $\mathrm{b}$ & ci95 & $\mathrm{b}$ & ci95 \\
\hline PCBSnp & 0.26 & $0.21,0.31$ & 0.29 & $0.18,0.39$ & 0.30 & $0.21,0.38$ & 0.21 & $0.09,0.32$ & 0.17 & $0.06,0.29$ \\
\hline Age & -0.01 & $-0.02,-0.01$ & -0.02 & $-0.03,-0.02$ & -0.01 & $-0.02,-0.01$ & -0.01 & $-0.02,-0.01$ & -0.01 & $-0.01,-0.00$ \\
\hline Gender & -0.07 & $-0.08,-0.05$ & -0.05 & $-0.08,-0.02$ & -0.08 & $-0.10,-0.05$ & -0.06 & $-0.09,-0.03$ & -0.08 & $-0.12,-0.05$ \\
\hline Edu & 0.01 & $0.00,0.02$ & 0.02 & $0.00,0.04$ & 0.01 & $-0.01,0.02$ & 0.00 & $-0.02,0.02$ & 0.01 & $-0.02,0.03$ \\
\hline Constant & 0.26 & $0.23,0.29$ & 0.32 & $0.26,0.39$ & 0.19 & $0.15,0.23$ & 0.30 & $0.23,0.37$ & 0.24 & $0.17,0.31$ \\
\hline$N$ & 4317 & & 1092 & & 1206 & & 1167 & & 852 & \\
\hline$R^{2}$ & 0.071 & & 0.121 & & 0.112 & & 0.033 & & 0.044 & \\
\hline
\end{tabular}

Note: The table reports unstandardised regression coefficients and the corresponding $95 \%$ CIs. 
Table S40: Non-political COVID-19 burden (PCBSnp) as predictor of participation in protests and political violence in the US: betweenindividual models

\begin{tabular}{lcccc}
\hline \hline & (1) Protests & \multicolumn{3}{c}{ (2) Political violence } \\
& $\mathrm{b}$ & $\mathrm{ci95}$ & $\mathrm{b}$ & ci95 \\
\hline PCBSnp & 0.16 & $0.04,0.28$ & 0.20 & $0.13,0.27$ \\
Age & -0.01 & $-0.02,-0.00$ & -0.01 & $-0.02,-0.01$ \\
Gender & -0.02 & $-0.06,0.01$ & -0.03 & $-0.05,-0.01$ \\
Edu & 0.08 & $0.05,0.10$ & -0.00 & $-0.02,0.01$ \\
Black & 0.06 & $0.00,0.12$ & 0.04 & $0.00,0.07$ \\
Hispanic & -0.00 & $-0.06,0.06$ & 0.04 & $0.01,0.08$ \\
Asian & -0.03 & $-0.14,0.09$ & 0.03 & $-0.03,0.10$ \\
Nat. Am. & 0.12 & $-0.07,0.30$ & 0.11 & $-0.01,0.23$ \\
Mixed & 0.00 & $-0.28,0.28$ & -0.04 & $-0.21,0.13$ \\
Other & 0.07 & $-0.03,0.16$ & 0.03 & $-0.02,0.09$ \\
Constant & 0.19 & $0.11,0.26$ & 0.07 & $0.03,0.12$ \\
\hline$N$ & 1074 & & 1082 & \\
$R^{2}$ & 0.078 & & 0.131 & \\
\hline \hline
\end{tabular}

Note: The table reports unstandardised regression coefficients and the corresponding 95\% CIs. "Black", "Hispanic", "Asian", "Native American", "Mixed", and "Other" are all binary variables with "White" as the baseline category. 
Table S41: Non-political COVID-19 burden (PCBSnp) as predictor of participation in the BLM protests and counter-protests: betweenindividual models

\begin{tabular}{|c|c|c|c|c|c|c|c|c|}
\hline & (1) Support BLM & & (2) Against rioting & & (3) Protect property & & (4) Confront police & \\
\hline & $\mathrm{b}$ & ci95 & $\mathrm{b}$ & ci95 & $\mathrm{b}$ & ci95 & $\mathrm{b}$ & ci95 \\
\hline PCBSnp & 0.12 & $0.04,0.20$ & 0.10 & $0.01,0.18$ & 0.10 & $0.02,0.19$ & 0.16 & $0.09,0.23$ \\
\hline Age & -0.02 & $-0.02,-0.01$ & -0.01 & $-0.01,-0.00$ & -0.01 & $-0.01,-0.00$ & -0.01 & $-0.02,-0.01$ \\
\hline Gender & 0.02 & $-0.01,0.04$ & -0.06 & $-0.09,-0.04$ & -0.07 & $-0.10,-0.05$ & -0.04 & $-0.06,-0.02$ \\
\hline Edu & 0.03 & $0.01,0.04$ & 0.02 & $0.00,0.03$ & 0.01 & $-0.00,0.03$ & -0.00 & $-0.01,0.01$ \\
\hline Black & 0.09 & $0.05,0.14$ & 0.07 & $0.03,0.11$ & 0.05 & $0.00,0.09$ & 0.03 & $-0.00,0.07$ \\
\hline Hispanic & 0.02 & $-0.02,0.06$ & 0.07 & $0.02,0.11$ & 0.02 & $-0.03,0.06$ & 0.03 & $-0.01,0.06$ \\
\hline Asian & 0.02 & $-0.06,0.09$ & 0.06 & $-0.02,0.14$ & 0.07 & $-0.01,0.15$ & 0.14 & $0.07,0.20$ \\
\hline Nat. Am. & -0.02 & $-0.15,0.11$ & 0.14 & $0.01,0.27$ & 0.04 & $-0.09,0.18$ & 0.15 & $0.04,0.26$ \\
\hline Mixed & -0.11 & $-0.31,0.08$ & -0.08 & $-0.27,0.12$ & -0.05 & $-0.26,0.15$ & -0.09 & $-0.26,0.07$ \\
\hline Other & 0.03 & $-0.03,0.10$ & 0.07 & $0.01,0.14$ & 0.07 & $0.00,0.14$ & 0.08 & $0.02,0.13$ \\
\hline Edu & & & 0.00 & $0.00,0.00$ & & & & \\
\hline Constant & 0.16 & $0.10,0.21$ & 0.15 & $0.09,0.20$ & 0.18 & $0.13,0.24$ & 0.08 & $0.03,0.12$ \\
\hline$N$ & 1079 & & 1071 & & 1061 & & 1078 & \\
\hline$R^{2}$ & 0.125 & & 0.080 & & 0.063 & & 0.130 & \\
\hline
\end{tabular}

Note: The table reports unstandardised regression coefficients and the corresponding 95\% CIs. "Black", "Hispanic", "Asian", "Native American", "Mixed", and "Other" are all binary variables with "White" as the baseline category. 
Table S42: Non-political COVID-19 burden (PCBSnp) as predictor of participation in the BLM protests and counter-protests: betweenindividual models (Part 2)

\begin{tabular}{lcccccc}
\hline \hline & (5) Confront BLM & \multicolumn{3}{c}{ (6) Destruct property } & \multicolumn{2}{c}{ (7) Confront others } \\
& $\mathrm{b}$ & $\mathrm{ci95}$ & $\mathrm{b}$ & $\mathrm{ci95}$ & $\mathrm{b}$ & $\mathrm{ci95}$ \\
\hline PCBSnp & 0.17 & $0.10,0.25$ & 0.18 & $0.11,0.24$ & 0.17 & $0.10,0.25$ \\
Age & -0.01 & $-0.01,-0.01$ & -0.01 & $-0.01,-0.01$ & -0.01 & $-0.01,-0.01$ \\
Gender & -0.04 & $-0.07,-0.02$ & -0.04 & $-0.05,-0.02$ & -0.04 & $-0.06,-0.02$ \\
Edu & -0.00 & $-0.02,0.01$ & -0.00 & $-0.01,0.01$ & 0.00 & $-0.01,0.01$ \\
Black & 0.03 & $-0.00,0.07$ & 0.04 & $0.00,0.07$ & 0.03 & $-0.01,0.06$ \\
Hispanic & 0.02 & $-0.02,0.05$ & 0.04 & $0.00,0.07$ & 0.03 & $-0.00,0.07$ \\
Asian & 0.12 & $0.06,0.19$ & 0.13 & $0.07,0.19$ & 0.14 & $0.07,0.20$ \\
Nat. Am. & 0.01 & $-0.10,0.12$ & 0.07 & $-0.03,0.18$ & 0.01 & $-0.11,0.12$ \\
Mixed & -0.09 & $-0.26,0.08$ & -0.08 & $-0.24,0.07$ & -0.09 & $-0.26,0.08$ \\
Other & 0.02 & $-0.04,0.08$ & 0.01 & $-0.04,0.06$ & 0.02 & $-0.04,0.08$ \\
Constant & 0.07 & $0.02,0.11$ & 0.06 & $0.02,0.10$ & 0.07 & $0.02,0.11$ \\
\hline$N$ & 1085 & & 1095 & & 1085 & \\
$R^{2}$ & 0.096 & & 0.138 & & 0.100 & \\
\hline
\end{tabular}

Note: The table reports unstandardised regression coefficients and the corresponding 95\% CIs. "Black", "Hispanic", "Asian", "Native American", "Mixed", and "Other" are all binary variables with "White" as the baseline category. 
Table S43: Perceived COVID-19 burden (PCBS) as predictor of need for chaos (NFC): between-individual models with additional controls

\begin{tabular}{|c|c|c|c|c|c|c|c|c|c|c|}
\hline & (1) Pooled & & (2) The US & & "(3) Denmark & & (4) Italy & & (5) Hungary & \\
\hline & $\mathrm{b}$ & ci95 & $\mathrm{b}$ & ci95 & $\mathrm{b}$ & ci95 & $\mathrm{b}$ & ci95 & $\mathrm{b}$ & ci95 \\
\hline PCBS & 0.30 & $0.26,0.34$ & 0.27 & $0.18,0.36$ & 0.38 & $0.31,0.44$ & 0.26 & $0.17,0.35$ & 0.16 & $0.07,0.25$ \\
\hline Age & -0.01 & $-0.02,-0.01$ & -0.02 & $-0.03,-0.02$ & -0.01 & $-0.01,-0.01$ & -0.01 & $-0.01,-0.00$ & -0.01 & $-0.02,-0.01$ \\
\hline Gender & -0.04 & $-0.05,-0.03$ & -0.03 & $-0.05,-0.00$ & -0.05 & $-0.07,-0.03$ & -0.04 & $-0.06,-0.02$ & -0.05 & $-0.08,-0.03$ \\
\hline Edu & -0.02 & $-0.03,-0.01$ & -0.03 & $-0.04,-0.01$ & -0.01 & $-0.03,0.00$ & -0.02 & $-0.04,-0.00$ & -0.02 & $-0.04,-0.00$ \\
\hline SES & 0.01 & $-0.02,0.04$ & 0.09 & $0.03,0.15$ & -0.02 & $-0.07,0.03$ & 0.00 & $-0.06,0.06$ & -0.05 & $-0.12,0.02$ \\
\hline Infection & 0.06 & $0.04,0.09$ & 0.08 & $0.03,0.12$ & 0.07 & $0.03,0.12$ & 0.02 & $-0.03,0.06$ & 0.12 & $0.04,0.21$ \\
\hline Ideology & 0.02 & $-0.00,0.04$ & -0.02 & $-0.06,0.02$ & 0.03 & $-0.01,0.07$ & 0.07 & $0.03,0.12$ & -0.02 & $-0.07,0.03$ \\
\hline Constant & 0.18 & $0.15,0.21$ & 0.23 & $0.16,0.29$ & 0.11 & $0.07,0.16$ & 0.18 & $0.12,0.25$ & 0.29 & $0.20,0.37$ \\
\hline$N$ & 3810 & & 955 & & 1120 & & 950 & & 785 & \\
\hline$R^{2}$ & 0.135 & & 0.197 & & 0.191 & & 0.097 & & 0.116 & \\
\hline
\end{tabular}

Note: The table reports unstandardised regression coefficients and the corresponding 95\% CIs.

Table S44: Perceived COVID-19 burden (PCBS) as predictor of need for chaos (NFC): between-individual models with additional controls

\begin{tabular}{|c|c|c|c|c|c|c|c|c|c|c|}
\hline & (1) Pooled & & (2) The US & & (3) Denmark & & (4) Italy & & (5) Hungary & \\
\hline & $\mathrm{b}$ & ci95 & $\mathrm{b}$ & ci95 & $\mathrm{b}$ & ci95 & $\mathrm{b}$ & ci95 & $\mathrm{b}$ & ci95 \\
\hline PCBS & 0.31 & $0.27,0.35$ & 0.30 & $0.21,0.39$ & 0.39 & $0.33,0.46$ & 0.27 & $0.19,0.35$ & 0.14 & $0.05,0.23$ \\
\hline Age & -0.01 & $-0.02,-0.01$ & -0.02 & $-0.03,-0.02$ & -0.01 & $-0.01,-0.01$ & -0.01 & $-0.01,-0.01$ & -0.01 & $-0.02,-0.01$ \\
\hline Gender & -0.04 & $-0.05,-0.03$ & -0.03 & $-0.05,-0.00$ & -0.05 & $-0.07,-0.03$ & -0.04 & $-0.07,-0.02$ & -0.06 & $-0.08,-0.03$ \\
\hline Edu & -0.02 & $-0.03,-0.01$ & -0.03 & $-0.04,-0.01$ & -0.01 & $-0.03,0.00$ & -0.02 & $-0.04,-0.01$ & -0.02 & $-0.03,-0.00$ \\
\hline SES & 0.01 & $-0.02,0.04$ & 0.09 & $0.03,0.15$ & -0.02 & $-0.06,0.03$ & -0.00 & $-0.06,0.06$ & -0.04 & $-0.11,0.02$ \\
\hline Infection & 0.06 & $0.04,0.08$ & 0.06 & $0.02,0.10$ & 0.07 & $0.03,0.11$ & 0.03 & $-0.02,0.07$ & 0.13 & $0.04,0.21$ \\
\hline Affect right & 0.00 & $-0.02,0.03$ & 0.01 & $-0.04,0.06$ & 0.01 & $-0.03,0.06$ & 0.04 & $-0.01,0.09$ & -0.07 & $-0.14,-0.01$ \\
\hline Affect left & 0.01 & $-0.01,0.04$ & 0.07 & $0.02,0.12$ & -0.01 & $-0.06,0.04$ & -0.01 & $-0.07,0.04$ & -0.01 & $-0.08,0.06$ \\
\hline Constant & 0.17 & $0.14,0.21$ & 0.17 & $0.10,0.24$ & 0.11 & $0.06,0.17$ & 0.21 & $0.14,0.29$ & 0.32 & $0.23,0.41$ \\
\hline$N$ & 4184 & & 1020 & & 1203 & & 1138 & & 823 & \\
\hline$R^{2}$ & 0.133 & & 0.211 & & 0.187 & & 0.087 & & 0.119 & \\
\hline
\end{tabular}

Note: The table reports unstandardised regression coefficients and the corresponding 95\% CIs. 
Table S45: Perceived COVID-19 burden (PCBS) as predictor of need for chaos (NFC): within-individual models with additional controls

\begin{tabular}{lcc}
\hline \hline & (1) Pooled & \\
& $\mathrm{b}$ & ci95 \\
\hline PCBS & 0.10 & $0.06,0.15$ \\
SES & -0.00 & $-0.03,0.02$ \\
Infection & 0.00 & $-0.02,0.03$ \\
Ideology & -0.00 & $-0.04,0.03$ \\
Constant & 0.17 & $0.14,0.20$ \\
\hline$N$ & 8520 & \\
\hline
\end{tabular}

Note: The table reports unstandardised regression coefficients and the corresponding $95 \%$ CIs. The specification includes unit- and time-fixed effects (not reported in the table).

Table S46: Perceived COVID-19 burden (PCBS) as predictor of need for chaos (NFC): within-individual models with additional controls

\begin{tabular}{lcc}
\hline \hline & (1) Pooled & \\
& $\mathrm{b}$ & ci95 \\
\hline PCBS & 0.10 & $0.06,0.14$ \\
SES & -0.01 & $-0.03,0.02$ \\
Infection & 0.01 & $-0.02,0.03$ \\
Affect right & -0.02 & $-0.04,0.01$ \\
Affect left & -0.03 & $-0.06,-0.01$ \\
Constant & 0.20 & $0.17,0.23$ \\
\hline$N$ & 9597 & \\
\hline
\end{tabular}

Note: The table reports unstandardised regression coefficients and the corresponding $95 \%$ CIs. The specification includes unit- and time-fixed effects (not reported in the table). 
Table S47: Perceived COVID-19 burden (PCBS) as predictor of activism intentions (AIS): between-individual models with additional controls

\begin{tabular}{|c|c|c|c|c|c|c|c|c|c|c|}
\hline & (1) Pooled & & (2) The US & & (3) Denmark & & (4) Italy & & (5) Hungary & \\
\hline & $\mathrm{b}$ & ci95 & $\mathrm{b}$ & ci95 & $\mathrm{b}$ & ci95 & $\mathrm{b}$ & $\operatorname{ci} 95$ & $\mathrm{~b}$ & ci95 \\
\hline PCBS & 0.17 & $0.11,0.24$ & 0.11 & $-0.03,0.25$ & 0.24 & $0.12,0.36$ & 0.07 & $-0.08,0.22$ & 0.30 & $0.15,0.44$ \\
\hline Age & -0.00 & $-0.00,0.00$ & -0.00 & $-0.01,0.00$ & -0.00 & $-0.01,0.00$ & -0.00 & $-0.01,0.00$ & 0.01 & $0.00,0.02$ \\
\hline Gender & -0.03 & $-0.05,-0.01$ & -0.01 & $-0.04,0.03$ & -0.04 & $-0.07,-0.00$ & -0.03 & $-0.07,0.00$ & -0.03 & $-0.07,0.01$ \\
\hline Edu & 0.05 & $0.04,0.06$ & 0.05 & $0.03,0.07$ & 0.05 & $0.03,0.08$ & 0.04 & $0.01,0.06$ & 0.04 & $0.01,0.07$ \\
\hline SES & 0.02 & $-0.03,0.07$ & 0.09 & $0.00,0.19$ & -0.07 & $-0.16,0.02$ & 0.13 & $0.03,0.23$ & -0.05 & $-0.16,0.06$ \\
\hline Infection & 0.04 & $-0.00,0.08$ & 0.04 & $-0.02,0.11$ & 0.06 & $-0.01,0.13$ & -0.00 & $-0.08,0.07$ & 0.05 & $-0.09,0.19$ \\
\hline Ideology & -0.20 & $-0.24,-0.17$ & -0.20 & $-0.26,-0.14$ & -0.19 & $-0.26,-0.12$ & -0.22 & $-0.29,-0.15$ & -0.12 & $-0.20,-0.03$ \\
\hline Constant & 0.46 & $0.41,0.50$ & 0.50 & $0.40,0.59$ & 0.43 & $0.35,0.51$ & 0.49 & $0.38,0.59$ & 0.33 & $0.20,0.47$ \\
\hline$N$ & 3680 & & 935 & & 1075 & & 906 & & 764 & \\
\hline$R^{2}$ & 0.068 & & 0.085 & & 0.074 & & 0.076 & & 0.082 & \\
\hline
\end{tabular}

Note: The table reports unstandardised regression coefficients and the corresponding $95 \%$ CIs.

Table S48: Perceived COVID-19 burden (PCBS) as predictor of activism intentions (AIS): between-individual models with additional controls

\begin{tabular}{|c|c|c|c|c|c|c|c|c|c|c|}
\hline & (1) Pooled & & (2) The US & & (3) Denmark & & (4) Italy & & (5) Hungary & \\
\hline & $\mathrm{b}$ & ci95 & $\mathrm{b}$ & ci95 & $\mathrm{b}$ & ci95 & $\mathrm{b}$ & ci95 & $\mathrm{b}$ & ci95 \\
\hline PCBS & 0.19 & $0.12,0.25$ & 0.13 & $0.00,0.27$ & 0.27 & $0.15,0.39$ & 0.07 & $-0.06,0.21$ & 0.27 & $0.12,0.41$ \\
\hline Age & -0.00 & $-0.00,0.00$ & -0.00 & $-0.01,0.00$ & -0.00 & $-0.01,0.00$ & -0.01 & $-0.01,-0.00$ & 0.01 & $0.00,0.02$ \\
\hline Gender & -0.04 & $-0.05,-0.02$ & -0.02 & $-0.06,0.01$ & -0.04 & $-0.07,-0.01$ & -0.05 & $-0.08,-0.01$ & -0.03 & $-0.07,0.01$ \\
\hline Edu & 0.05 & $0.04,0.07$ & 0.06 & $0.03,0.08$ & 0.05 & $0.03,0.08$ & 0.05 & $0.02,0.07$ & 0.04 & $0.02,0.07$ \\
\hline SES & 0.01 & $-0.03,0.06$ & 0.09 & $0.00,0.18$ & -0.05 & $-0.14,0.03$ & 0.10 & $0.00,0.19$ & -0.06 & $-0.17,0.04$ \\
\hline Infection & 0.02 & $-0.01,0.06$ & 0.04 & $-0.02,0.10$ & 0.05 & $-0.02,0.12$ & -0.03 & $-0.09,0.04$ & 0.04 & $-0.10,0.18$ \\
\hline Affect right & -0.09 & $-0.13,-0.05$ & -0.17 & $-0.25,-0.09$ & -0.08 & $-0.16,0.01$ & -0.04 & $-0.11,0.04$ & -0.04 & $-0.14,0.06$ \\
\hline Affect left & 0.18 & $0.14,0.22$ & 0.10 & $0.02,0.18$ & 0.19 & $0.11,0.28$ & 0.20 & $0.11,0.28$ & 0.18 & $0.07,0.28$ \\
\hline Constant & 0.30 & $0.25,0.36$ & 0.41 & $0.30,0.52$ & 0.25 & $0.15,0.35$ & 0.32 & $0.21,0.44$ & 0.22 & $0.07,0.36$ \\
\hline$N$ & 4006 & & 993 & & 1140 & & 1079 & & 794 & \\
\hline$R^{2}$ & 0.071 & & 0.100 & & 0.073 & & 0.070 & & 0.092 & \\
\hline
\end{tabular}

Note: The table reports unstandardised regression coefficients and the corresponding 95\% CIs. 
Table S49: Perceived COVID-19 burden (PCBS) as predictor of radicalism intentions (AIS): between-individual models with additional controls

\begin{tabular}{|c|c|c|c|c|c|c|c|c|c|c|}
\hline & (1) Pooled & & (2) The US & & (3) Denmark & & (4) Italy & & (5) Hungary & \\
\hline & $\mathrm{b}$ & ci95 & $\mathrm{b}$ & ci95 & $\mathrm{b}$ & ci95 & $\mathrm{b}$ & ci95 & $\mathrm{b}$ & ci95 \\
\hline PCBS & 0.24 & $0.18,0.30$ & 0.15 & $0.03,0.28$ & 0.30 & $0.21,0.39$ & 0.27 & $0.13,0.41$ & 0.25 & $0.12,0.38$ \\
\hline Age & -0.01 & $-0.02,-0.01$ & -0.02 & $-0.03,-0.02$ & -0.01 & $-0.02,-0.01$ & -0.01 & $-0.02,-0.00$ & -0.01 & $-0.01,-0.00$ \\
\hline Gender & -0.07 & $-0.08,-0.05$ & -0.04 & $-0.08,-0.01$ & -0.07 & $-0.10,-0.05$ & -0.06 & $-0.09,-0.03$ & -0.09 & $-0.13,-0.06$ \\
\hline Edu & 0.00 & $-0.01,0.01$ & 0.01 & $-0.01,0.03$ & -0.00 & $-0.02,0.02$ & -0.01 & $-0.03,0.02$ & 0.00 & $-0.02,0.03$ \\
\hline SES & 0.03 & $-0.01,0.07$ & 0.09 & $0.01,0.17$ & 0.00 & $-0.06,0.07$ & 0.11 & $0.01,0.21$ & -0.06 & $-0.15,0.04$ \\
\hline Infection & 0.07 & $0.04,0.10$ & 0.07 & $0.02,0.13$ & 0.11 & $0.06,0.17$ & 0.02 & $-0.05,0.09$ & 0.03 & $-0.09,0.15$ \\
\hline Ideology & -0.12 & $-0.15,-0.09$ & -0.20 & $-0.25,-0.14$ & -0.08 & $-0.13,-0.03$ & -0.11 & $-0.18,-0.04$ & -0.02 & $-0.09,0.06$ \\
\hline Constant & 0.30 & $0.26,0.34$ & 0.43 & $0.34,0.51$ & 0.22 & $0.16,0.28$ & 0.26 & $0.16,0.36$ & 0.24 & $0.12,0.36$ \\
\hline$N$ & 3683 & & 935 & & 1079 & & 909 & & 760 & \\
\hline$R^{2}$ & 0.085 & & 0.153 & & 0.132 & & 0.043 & & 0.070 & \\
\hline
\end{tabular}

Note: The table reports unstandardised regression coefficients and the corresponding $95 \%$ CIs.

Table S50: Perceived COVID-19 burden (PCBS) as predictor of radicalism intentions (AIS): between-individual models with additional controls

\begin{tabular}{|c|c|c|c|c|c|c|c|c|c|c|}
\hline & (1) Pooled & & (2) The US & & "(3) Denmark & & (4) Italy & & (5) Hungary & \\
\hline & $\mathrm{b}$ & ci95 & $\mathrm{b}$ & ci95 & $\mathrm{b}$ & ci95 & $\mathrm{b}$ & ci95 & $\mathrm{b}$ & ci95 \\
\hline PCBS & 0.26 & $0.21,0.32$ & 0.20 & $0.08,0.32$ & 0.31 & $0.22,0.40$ & 0.29 & $0.17,0.42$ & 0.22 & $0.09,0.34$ \\
\hline Age & -0.01 & $-0.02,-0.01$ & -0.02 & $-0.03,-0.02$ & -0.01 & $-0.02,-0.01$ & -0.01 & $-0.02,-0.01$ & -0.01 & $-0.01,-0.00$ \\
\hline Gender & -0.07 & $-0.09,-0.06$ & -0.06 & $-0.09,-0.02$ & -0.08 & $-0.10,-0.05$ & -0.07 & $-0.10,-0.03$ & -0.09 & $-0.13,-0.06$ \\
\hline $\mathrm{Edu}$ & 0.01 & $-0.01,0.02$ & 0.01 & $-0.01,0.03$ & -0.00 & $-0.02,0.02$ & -0.00 & $-0.02,0.02$ & 0.01 & $-0.02,0.03$ \\
\hline SES & 0.02 & $-0.02,0.06$ & 0.08 & $0.00,0.16$ & 0.01 & $-0.06,0.07$ & 0.07 & $-0.02,0.16$ & -0.06 & $-0.16,0.03$ \\
\hline Infection & 0.06 & $0.03,0.09$ & 0.06 & $0.01,0.12$ & 0.11 & $0.06,0.17$ & 0.02 & $-0.05,0.08$ & 0.03 & $-0.09,0.15$ \\
\hline Affect right & -0.03 & $-0.06,0.01$ & -0.07 & $-0.14,-0.00$ & -0.02 & $-0.08,0.05$ & 0.01 & $-0.06,0.09$ & -0.01 & $-0.10,0.08$ \\
\hline Affect left & 0.15 & $0.11,0.19$ & 0.18 & $0.11,0.25$ & 0.10 & $0.03,0.16$ & 0.20 & $0.12,0.28$ & 0.08 & $-0.02,0.18$ \\
\hline Constant & 0.17 & $0.13,0.22$ & 0.27 & $0.17,0.37$ & 0.13 & $0.05,0.21$ & 0.12 & $0.01,0.23$ & 0.21 & $0.09,0.34$ \\
\hline$N$ & 4011 & & 992 & & 1147 & & 1080 & & 792 & \\
\hline$R^{2}$ & 0.097 & & 0.162 & & 0.133 & & 0.064 & & 0.074 & \\
\hline
\end{tabular}

Note: The table reports unstandardised regression coefficients and the corresponding 95\% CIs. 
Table S51: Perceived COVID-19 burden (PCBS) as predictor of participation in protests and political violence in the US: between-individual models with additional controls

\begin{tabular}{lcccc}
\hline \hline & (1) Protests & \multicolumn{3}{c}{ (2) Political violence } \\
& $\mathrm{b}$ & $\mathrm{c} 95$ & $\mathrm{~b}$ & ci95 \\
\hline PCBS & 0.15 & $0.02,0.29$ & 0.15 & $0.07,0.24$ \\
Age & -0.01 & $-0.01,-0.00$ & -0.01 & $-0.02,-0.01$ \\
Gender & -0.02 & $-0.05,0.02$ & -0.02 & $-0.04,0.01$ \\
Edu & 0.05 & $0.03,0.07$ & -0.01 & $-0.02,0.00$ \\
Black & 0.03 & $-0.03,0.09$ & 0.03 & $-0.01,0.07$ \\
Hispanic & 0.01 & $-0.05,0.08$ & 0.03 & $-0.01,0.07$ \\
Asian & -0.04 & $-0.16,0.08$ & 0.03 & $-0.04,0.10$ \\
Nat. Am. & 0.24 & $0.04,0.45$ & 0.12 & $-0.01,0.25$ \\
Mixed & 0.03 & $-0.28,0.34$ & 0.03 & $-0.16,0.21$ \\
Other & 0.16 & $0.04,0.27$ & -0.02 & $-0.09,0.05$ \\
SES & 0.11 & $0.02,0.20$ & 0.07 & $0.01,0.12$ \\
Infection & 0.04 & $-0.02,0.11$ & 0.09 & $0.05,0.13$ \\
Ideology & -0.31 & $-0.36,-0.25$ & -0.00 & $-0.04,0.03$ \\
Constant & 0.30 & $0.20,0.39$ & 0.05 & $-0.01,0.10$ \\
\hline$N$ & 914 & & 925 & \\
$R^{2}$ & 0.175 & & 0.131 & \\
\hline \hline
\end{tabular}

Note: The table reports unstandardised regression coefficients and the corresponding 95\% CIs. "Black", "Hispanic", "Asian", "Native American", "Mixed", and "Other" are all binary variables with "White" as the baseline category. 
Table S52: Perceived COVID-19 burden (PCBS) as predictor of participation in protests and political violence in the US: between-individual models with additional controls

\begin{tabular}{lcccc}
\hline \hline & (1) Protests & & (2) Political violence & \\
& $\mathrm{b}$ & $\mathrm{ci95}$ & $\mathrm{b}$ & $\mathrm{ci95}$ \\
\hline PCBS & 0.18 & $0.05,0.31$ & 0.16 & $0.08,0.24$ \\
Age & -0.01 & $-0.01,-0.00$ & -0.01 & $-0.02,-0.01$ \\
Gender & -0.02 & $-0.06,0.01$ & -0.02 & $-0.04,0.00$ \\
Edu & 0.06 & $0.03,0.08$ & -0.01 & $-0.02,0.01$ \\
Black & 0.04 & $-0.02,0.10$ & 0.02 & $-0.02,0.06$ \\
Hispanic & 0.01 & $-0.05,0.07$ & 0.02 & $-0.02,0.05$ \\
Asian & -0.05 & $-0.16,0.07$ & 0.03 & $-0.04,0.10$ \\
Nat. Am. & 0.18 & $-0.01,0.37$ & 0.16 & $0.03,0.28$ \\
Mixed & -0.00 & $-0.27,0.27$ & -0.03 & $-0.19,0.13$ \\
Other & 0.12 & $0.02,0.23$ & -0.01 & $-0.08,0.05$ \\
SES & 0.11 & $0.02,0.20$ & 0.06 & $0.01,0.12$ \\
Infection & 0.03 & $-0.03,0.10$ & 0.08 & $0.04,0.12$ \\
Affect right & -0.19 & $-0.26,-0.11$ & 0.04 & $-0.01,0.08$ \\
Affect left & 0.15 & $0.07,0.22$ & 0.06 & $0.01,0.11$ \\
Constant & 0.15 & $0.04,0.26$ & 0.00 & $-0.06,0.07$ \\
\hline$N$ & 968 & & 979 & \\
$R^{2}$ & 0.160 & & 0.136 & \\
\hline
\end{tabular}

Note: The table reports unstandardised regression coefficients and the corresponding 95\% CIs. "Black", "Hispanic", "Asian", "Native American", "Mixed", and "Other" are all binary variables with "White" as the baseline category. 
Table S53: Perceived COVID-19 burden (PCBS) as predictor of participation in the BLM protests and counter-protests: between-individual models with additional controls (Part 1)

\begin{tabular}{|c|c|c|c|c|c|c|c|c|}
\hline & (1) Support BLM & & (2) Against rioting & & (3) Protect property & & (4) Confront police & \\
\hline & $\mathrm{b}$ & ci95 & $\mathrm{b}$ & ci95 & $\mathrm{b}$ & ci95 & $\mathrm{b}$ & ci95 \\
\hline PCBS & 0.01 & $-0.08,0.10$ & 0.10 & $0.00,0.20$ & 0.17 & $0.07,0.27$ & 0.11 & $0.03,0.18$ \\
\hline Age & -0.02 & $-0.02,-0.01$ & -0.01 & $-0.01,-0.00$ & -0.01 & $-0.01,-0.00$ & -0.01 & $-0.01,-0.01$ \\
\hline Gender & 0.02 & $-0.00,0.05$ & -0.05 & $-0.07,-0.02$ & -0.05 & $-0.08,-0.03$ & -0.02 & $-0.04,0.00$ \\
\hline $\mathrm{Edu}$ & 0.01 & $-0.00,0.03$ & 0.01 & $-0.00,0.03$ & 0.02 & $-0.00,0.03$ & -0.00 & $-0.02,0.01$ \\
\hline Black & 0.06 & $0.02,0.10$ & 0.07 & $0.02,0.11$ & 0.05 & $0.00,0.10$ & 0.00 & $-0.03,0.04$ \\
\hline Hispanic & 0.02 & $-0.02,0.07$ & 0.06 & $0.02,0.11$ & 0.02 & $-0.02,0.07$ & 0.02 & $-0.02,0.05$ \\
\hline Asian & 0.02 & $-0.06,0.11$ & 0.01 & $-0.08,0.10$ & 0.02 & $-0.07,0.11$ & 0.06 & $-0.00,0.13$ \\
\hline Nat. Am. & -0.00 & $-0.15,0.14$ & 0.08 & $-0.07,0.23$ & -0.01 & $-0.16,0.14$ & 0.12 & $0.01,0.24$ \\
\hline Mixed & -0.11 & $-0.33,0.10$ & -0.03 & $-0.26,0.19$ & 0.02 & $-0.21,0.25$ & -0.05 & $-0.23,0.12$ \\
\hline Other & 0.01 & $-0.07,0.09$ & 0.05 & $-0.03,0.14$ & -0.00 & $-0.09,0.08$ & 0.02 & $-0.04,0.09$ \\
\hline SES & 0.07 & $0.01,0.13$ & 0.05 & $-0.01,0.12$ & 0.04 & $-0.03,0.11$ & 0.05 & $0.00,0.11$ \\
\hline Infection & 0.05 & $0.01,0.10$ & 0.07 & $0.02,0.12$ & 0.08 & $0.03,0.13$ & 0.09 & $0.05,0.13$ \\
\hline Ideology & -0.20 & $-0.24,-0.16$ & 0.02 & $-0.03,0.06$ & 0.07 & $0.03,0.11$ & -0.00 & $-0.04,0.03$ \\
\hline Constant & 0.28 & $0.21,0.35$ & 0.10 & $0.03,0.17$ & 0.08 & $0.00,0.15$ & 0.05 & $-0.00,0.11$ \\
\hline$N$ & 928 & & 919 & & 911 & & 926 & \\
\hline$R^{2}$ & 0.216 & & 0.076 & & 0.080 & & 0.107 & \\
\hline
\end{tabular}

American", "Mixed", and "Other" are all binary variables with "White" as the baseline category. 
Table S54: Perceived COVID-19 burden (PCBS) as predictor of participation in the BLM protests and counter-protests: between-individual models with additional controls (Part 2)

\begin{tabular}{lcccccc}
\hline \hline & (5) Confront BLM & \multicolumn{3}{c}{ (6) Destruct property } & (7) Confront others \\
& $\mathrm{b}$ & $\mathrm{ci95}$ & $\mathrm{b}$ & $\mathrm{ci} 95$ & $\mathrm{~b}$ & ci95 \\
\hline PCBS & 0.20 & $0.12,0.28$ & 0.14 & $0.06,0.21$ & 0.14 & $0.05,0.22$ \\
Age & -0.01 & $-0.01,-0.01$ & -0.01 & $-0.02,-0.01$ & -0.01 & $-0.01,-0.01$ \\
Gender & -0.03 & $-0.05,-0.01$ & -0.02 & $-0.04,-0.00$ & -0.03 & $-0.05,-0.00$ \\
Edu & -0.00 & $-0.02,0.01$ & -0.00 & $-0.02,0.01$ & 0.00 & $-0.01,0.02$ \\
Black & 0.02 & $-0.02,0.06$ & 0.02 & $-0.02,0.05$ & 0.02 & $-0.02,0.05$ \\
Hispanic & 0.02 & $-0.01,0.06$ & 0.03 & $-0.00,0.06$ & 0.03 & $-0.01,0.07$ \\
Asian & 0.06 & $-0.01,0.13$ & 0.05 & $-0.01,0.11$ & 0.06 & $-0.01,0.14$ \\
Nat. Am. & -0.00 & $-0.12,0.12$ & 0.06 & $-0.05,0.17$ & 0.00 & $-0.12,0.13$ \\
Mixed & -0.04 & $-0.22,0.15$ & -0.04 & $-0.20,0.13$ & -0.04 & $-0.24,0.15$ \\
Other & -0.07 & $-0.14,0.00$ & -0.02 & $-0.09,0.04$ & -0.02 & $-0.09,0.06$ \\
SES & 0.09 & $0.04,0.14$ & 0.08 & $0.03,0.13$ & 0.06 & $0.01,0.12$ \\
Infection & 0.08 & $0.04,0.12$ & 0.06 & $0.03,0.10$ & 0.08 & $0.04,0.12$ \\
Ideology & 0.03 & $-0.00,0.07$ & 0.01 & $-0.02,0.04$ & 0.02 & $-0.01,0.06$ \\
Constant & -0.02 & $-0.08,0.03$ & 0.02 & $-0.03,0.07$ & 0.02 & $-0.04,0.08$ \\
\hline$N$ & 930 & & 941 & & 934 & \\
$R^{2}$ & 0.123 & & 0.127 & & 0.092 & \\
\hline
\end{tabular}

Note: The table reports unstandardised regression coefficients and the corresponding 95\% CIs. "Black", "Hispanic", "Asian", "Native American", "Mixed", and "Other" are all binary variables with "White" as the baseline category. 
Table S55: Perceived COVID-19 burden (PCBS) as predictor of participation in the BLM protests and counter-protests: between-individual models with additional controls (Part 1)

\begin{tabular}{|c|c|c|c|c|c|c|c|c|}
\hline & "(1) Support BLM & & (2) Against rioting & & "(3) Protect property & & (4) Confront police & \\
\hline & $\mathrm{b}$ & ci95 & $\mathrm{b}$ & ci95 & $\mathrm{b}$ & ci95 & $\mathrm{b}$ & ci95 \\
\hline PCBS & 0.05 & $-0.04,0.13$ & 0.10 & $-0.00,0.19$ & 0.14 & $0.05,0.24$ & 0.11 & $0.04,0.19$ \\
\hline Age & -0.02 & $-0.02,-0.01$ & -0.01 & $-0.01,-0.00$ & -0.01 & $-0.01,-0.00$ & -0.01 & $-0.01,-0.01$ \\
\hline Gender & 0.01 & $-0.01,0.04$ & -0.05 & $-0.07,-0.02$ & -0.06 & $-0.08,-0.03$ & -0.03 & $-0.05,-0.01$ \\
\hline Edu & 0.02 & $0.00,0.03$ & 0.01 & $-0.00,0.03$ & 0.01 & $-0.00,0.03$ & -0.00 & $-0.02,0.01$ \\
\hline Black & 0.07 & $0.03,0.11$ & 0.06 & $0.02,0.10$ & 0.04 & $-0.00,0.09$ & 0.01 & $-0.03,0.04$ \\
\hline Hispanic & 0.01 & $-0.03,0.06$ & 0.05 & $0.01,0.10$ & 0.02 & $-0.03,0.06$ & 0.01 & $-0.03,0.04$ \\
\hline Asian & 0.01 & $-0.06,0.09$ & 0.02 & $-0.07,0.10$ & 0.03 & $-0.05,0.12$ & 0.09 & $0.03,0.16$ \\
\hline Nat. Am. & 0.02 & $-0.11,0.15$ & 0.17 & $0.04,0.31$ & 0.07 & $-0.08,0.21$ & 0.19 & $0.08,0.30$ \\
\hline Mixed & -0.13 & $-0.31,0.06$ & -0.08 & $-0.27,0.12$ & -0.05 & $-0.25,0.15$ & -0.09 & $-0.24,0.07$ \\
\hline Other & 0.02 & $-0.06,0.09$ & 0.03 & $-0.04,0.11$ & -0.00 & $-0.08,0.08$ & 0.01 & $-0.05,0.08$ \\
\hline SES & 0.07 & $0.01,0.13$ & 0.04 & $-0.02,0.10$ & 0.03 & $-0.03,0.10$ & 0.05 & $0.00,0.10$ \\
\hline Infection & 0.04 & $0.00,0.09$ & 0.07 & $0.02,0.11$ & 0.08 & $0.03,0.13$ & 0.08 & $0.05,0.12$ \\
\hline Affect right & -0.11 & $-0.16,-0.06$ & 0.04 & $-0.01,0.09$ & 0.05 & $-0.00,0.11$ & 0.01 & $-0.03,0.06$ \\
\hline Affect left & 0.19 & $0.13,0.24$ & 0.03 & $-0.03,0.08$ & -0.05 & $-0.10,0.01$ & 0.06 & $0.01,0.10$ \\
\hline Constant & 0.13 & $0.06,0.20$ & 0.09 & $0.01,0.17$ & 0.13 & $0.05,0.21$ & 0.02 & $-0.04,0.08$ \\
\hline$N$ & 978 & & 971 & & 961 & & 976 & \\
\hline$R^{2}$ & 0.254 & & 0.083 & & 0.085 & & 0.125 & \\
\hline
\end{tabular}

Note: The table reports unstandardised regression coefficients and the corresponding 95\% CIs. "Black", "Hispanic", "Asian", "Native American", "Mixed", and "Other" are all binary variables with "White" as the baseline category. 
Table S56: Perceived COVID-19 burden (PCBS) as predictor of participation in the BLM protests and counter-protests: between-individual models with additional controls (Part 2)

\begin{tabular}{|c|c|c|c|c|c|c|}
\hline & (5) Confront BLM & & (6) Destruct property & & (7) Confront others & \\
\hline & $\mathrm{b}$ & ci95 & $\mathrm{b}$ & ci95 & $\mathrm{b}$ & ci95 \\
\hline PCBS & 0.19 & $0.11,0.27$ & 0.14 & $0.07,0.21$ & 0.14 & $0.06,0.22$ \\
\hline Age & -0.01 & $-0.01,-0.01$ & -0.01 & $-0.02,-0.01$ & -0.01 & $-0.01,-0.01$ \\
\hline Gender & -0.03 & $-0.05,-0.01$ & -0.02 & $-0.04,-0.00$ & -0.03 & $-0.05,-0.01$ \\
\hline Edu & -0.00 & $-0.01,0.01$ & -0.01 & $-0.02,0.01$ & -0.00 & $-0.02,0.01$ \\
\hline Black & 0.02 & $-0.02,0.05$ & 0.02 & $-0.02,0.05$ & 0.02 & $-0.02,0.05$ \\
\hline Hispanic & 0.02 & $-0.02,0.05$ & 0.02 & $-0.01,0.05$ & 0.02 & $-0.02,0.06$ \\
\hline Asian & 0.06 & $-0.01,0.12$ & 0.08 & $0.02,0.14$ & 0.09 & $0.02,0.16$ \\
\hline Nat. Am. & 0.02 & $-0.09,0.13$ & 0.10 & $-0.00,0.21$ & 0.02 & $-0.09,0.14$ \\
\hline Mixed & -0.07 & $-0.23,0.09$ & -0.07 & $-0.22,0.08$ & -0.08 & $-0.25,0.09$ \\
\hline Other & -0.05 & $-0.11,0.01$ & -0.03 & $-0.09,0.03$ & -0.02 & $-0.09,0.05$ \\
\hline SES & 0.08 & $0.03,0.13$ & 0.07 & $0.02,0.11$ & 0.07 & $0.01,0.12$ \\
\hline Infection & 0.08 & $0.04,0.11$ & 0.06 & $0.02,0.09$ & 0.07 & $0.03,0.11$ \\
\hline Affect right & 0.06 & $0.01,0.10$ & 0.03 & $-0.01,0.07$ & 0.03 & $-0.02,0.08$ \\
\hline Affect left & 0.02 & $-0.03,0.06$ & 0.05 & $0.01,0.09$ & 0.03 & $-0.02,0.08$ \\
\hline Constant & -0.03 & $-0.10,0.03$ & -0.01 & $-0.06,0.05$ & 0.01 & $-0.06,0.07$ \\
\hline$N$ & 980 & & 991 & & 984 & \\
\hline$R^{2}$ & 0.123 & & 0.134 & & 0.096 & \\
\hline
\end{tabular}

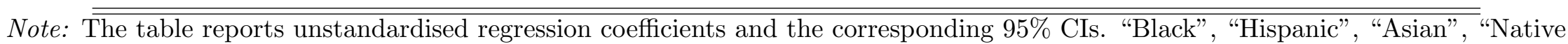
American", "Mixed", and "Other" are all binary variables with "White" as the baseline category. 
Table S57: Components of perceived COVID-19 burden as predictors of need for chaos (NFC): within-individual models (Part 1)

\begin{tabular}{|c|c|c|c|c|c|c|c|c|c|c|}
\hline & (1) Pooled & & (2) Pooled & & (3) Pooled & & (4) Pooled & & (5) Pooled & \\
\hline & $\mathrm{b}$ & ci95 & $\mathrm{b}$ & ci95 & b & ci95 & b & ci95 & b & ci95 \\
\hline PCBShealth & 0.06 & $0.04,0.09$ & & & & & & & & \\
\hline PCBSfinances & & & 0.03 & $0.01,0.05$ & & & & & & \\
\hline PCBSrights & & & & & 0.03 & $0.01,0.05$ & & & & \\
\hline PCBScontact & & & & & & & 0.02 & $-0.00,0.04$ & & \\
\hline PCBSstate & & & & & & & & & 0.02 & $0.00,0.05$ \\
\hline Constant & 0.20 & $0.19,0.21$ & 0.20 & $0.19,0.21$ & 0.20 & $0.20,0.21$ & 0.21 & $0.20,0.22$ & 0.21 & $0.20,0.22$ \\
\hline$N$ & 10699 & & 10699 & & 10699 & & 10699 & & 10699 & \\
\hline
\end{tabular}

Note: The table reports unstandardised regression coefficients and the corresponding 95\% CIs. The specification includes unit- and time-fixed effects (not reported in the table).

Table S58: Components of perceived COVID-19 burden as predictors of need for chaos (NFC): within-individual models (Part 2)

\begin{tabular}{lcc}
\hline \hline & (1) Pooled & \\
& $\mathrm{b}$ & ci95 \\
\hline PCBShealth & 0.05 & $0.03,0.08$ \\
PCBSfinances & 0.02 & $0.00,0.04$ \\
PCBSrights & 0.03 & $0.01,0.05$ \\
PCBScontact & 0.01 & $-0.01,0.03$ \\
PCBSstate & 0.01 & $-0.01,0.03$ \\
Constant & 0.17 & $0.15,0.19$ \\
\hline$N$ & 10699 & \\
\hline \hline
\end{tabular}

Note: The table reports unstandardised regression coefficients and the corresponding $95 \%$ CIs. The specification includes unit- and time-fixed effects (not reported in the table). 
Table S59: Components of perceived COVID-19 burden as predictors of activism intentions (AIS): between-individual models (Part 1)

\begin{tabular}{|c|c|c|c|c|c|c|c|c|c|c|}
\hline & (1) Pooled & & (2) Pooled & & (3) Pooled & & (4) Pooled & & (5) Pooled & \\
\hline & $\mathrm{b}$ & ci95 & $\mathrm{b}$ & ci95 & $\mathrm{b}$ & ci95 & $\mathrm{b}$ & ci95 & $\mathrm{b}$ & ci95 \\
\hline PCBShealth & 0.13 & $0.08,0.17$ & & & & & & & & \\
\hline PCBSfinances & & & 0.07 & $0.03,0.10$ & & & & & & \\
\hline PCBSrights & & & & & 0.06 & $0.02,0.09$ & & & & \\
\hline PCBScontact & & & & & & & 0.04 & $-0.00,0.09$ & & \\
\hline PCBSstate & & & & & & & & & 0.00 & $-0.04,0.04$ \\
\hline Age & -0.00 & $-0.00,0.00$ & -0.00 & $-0.00,0.00$ & -0.00 & $-0.01,0.00$ & -0.00 & $-0.01,0.00$ & -0.00 & $-0.01,0.00$ \\
\hline Gender & -0.03 & $-0.05,-0.02$ & -0.03 & $-0.05,-0.01$ & -0.03 & $-0.04,-0.01$ & -0.03 & $-0.04,-0.01$ & -0.03 & $-0.05,-0.01$ \\
\hline Edu & 0.06 & $0.05,0.07$ & 0.06 & $0.05,0.07$ & 0.06 & $0.05,0.07$ & 0.06 & $0.05,0.07$ & 0.06 & $0.05,0.07$ \\
\hline Constant & 0.39 & $0.36,0.42$ & 0.40 & $0.37,0.43$ & 0.41 & $0.39,0.44$ & 0.42 & $0.39,0.45$ & 0.44 & $0.41,0.46$ \\
\hline$N$ & 4315 & & 4315 & & 4315 & & 4315 & & 4315 & \\
\hline$R^{2}$ & 0.034 & & 0.030 & & 0.030 & & 0.028 & & 0.027 & \\
\hline
\end{tabular}

Note: The table reports unstandardised regression coefficients and the corresponding $95 \%$ CIs.

Table S60: Components of perceived COVID-19 burden as predictors of activism intentions (AIS): between-individual models (Part 2)

\begin{tabular}{lcc}
\hline \hline & $\begin{array}{c}\text { (1) Pooled } \\
\text { b }\end{array}$ & ci95 \\
\hline PCBShealth & 0.11 & $0.06,0.16$ \\
PCBSfinances & 0.04 & $0.01,0.08$ \\
PCBSrights & 0.06 & $0.02,0.10$ \\
PCBScontact & -0.00 & $-0.05,0.04$ \\
PCBSstate & -0.06 & $-0.11,-0.01$ \\
Age & -0.00 & $-0.00,0.00$ \\
Gender & -0.03 & $-0.05,-0.01$ \\
Edu & 0.06 & $0.05,0.07$ \\
Constant & 0.38 & $0.34,0.42$ \\
\hline$N$ & 4315 & \\
$R^{2}$ & 0.038 & \\
\hline
\end{tabular}

Note: The table reports unstandardised regression coefficients and the corresponding $95 \%$ CIs. 
Table S61: Components of perceived COVID-19 burden as predictors of radicalism intentions (RIS): between-individual models (Part 1)

\begin{tabular}{|c|c|c|c|c|c|c|c|c|c|c|}
\hline & (1) Pooled & & (2) Pooled & & (3) Pooled & & (4) Pooled & & (5) Pooled & \\
\hline & $\mathrm{b}$ & ci95 & $\mathrm{b}$ & ci95 & $\mathrm{b}$ & ci95 & $\mathrm{b}$ & ci95 & $\mathrm{b}$ & ci95 \\
\hline PCBShealth & 0.22 & $0.18,0.26$ & & & & & & & & \\
\hline PCBSfinances & & & 0.07 & $0.04,0.10$ & & & & & & \\
\hline PCBSrights & & & & & 0.08 & $0.06,0.11$ & & & & \\
\hline PCBScontact & & & & & & & 0.06 & $0.02,0.10$ & & \\
\hline PCBSstate & & & & & & & & & 0.07 & $0.04,0.11$ \\
\hline Age & -0.01 & $-0.02,-0.01$ & -0.01 & $-0.02,-0.01$ & -0.01 & $-0.02,-0.01$ & -0.01 & $-0.02,-0.01$ & -0.01 & $-0.02,-0.01$ \\
\hline Gender & -0.07 & $-0.09,-0.06$ & -0.07 & $-0.08,-0.05$ & -0.06 & $-0.08,-0.05$ & -0.06 & $-0.08,-0.05$ & -0.06 & $-0.08,-0.05$ \\
\hline Edu & 0.01 & $0.00,0.02$ & 0.01 & $-0.00,0.02$ & 0.01 & $-0.00,0.02$ & 0.01 & $-0.00,0.02$ & 0.01 & $-0.00,0.02$ \\
\hline Constant & 0.30 & $0.27,0.32$ & 0.34 & $0.31,0.36$ & 0.34 & $0.32,0.36$ & 0.35 & $0.32,0.37$ & 0.34 & $0.31,0.37$ \\
\hline$N$ & 4317 & & 4317 & & 4317 & & 4317 & & 4317 & \\
\hline$R^{2}$ & 0.078 & & 0.056 & & 0.058 & & 0.053 & & 0.054 & \\
\hline
\end{tabular}

Table S62: Components of perceived COVID-19 burden as predictors of radicalism intentions (RIS): between-individual models (Part 2)

\begin{tabular}{lcc}
\hline \hline & (1) Pooled & \\
& $\mathrm{b}$ & ci95 \\
\hline PCBShealth & 0.20 & $0.16,0.25$ \\
PCBSfinances & 0.02 & $-0.01,0.05$ \\
PCBSrights & 0.06 & $0.03,0.09$ \\
PCBScontact & -0.02 & $-0.06,0.02$ \\
PCBSstate & 0.00 & $-0.04,0.04$ \\
Age & -0.01 & $-0.02,-0.01$ \\
Gender & -0.07 & $-0.08,-0.05$ \\
Edu & 0.01 & $0.00,0.02$ \\
Constant & 0.27 & $0.24,0.31$ \\
\hline$N$ & 4317 & \\
$R^{2}$ & 0.082 & \\
\hline \hline
\end{tabular}

Note: The table reports unstandardised regression coefficients and the corresponding $95 \%$ CIs. 


\section{S16 Analyses of non-linear interactions}

To assess whether police violence moderates the association between perceived COVID-19 burden and anti-systemic attitudes and behavior (i.e., H3), we first estimated linear multiplicative interaction models. Research shows that these models are vulnerable to two potential problems that are often overlooked in empirical studies (Hainmueller et al. 2019). First, the models assume linear interaction effects, i.e., that the association between the predictor (in our case perceived COVID-19 burden) and the outcome (anti-systemic attitudes/behavior) changes at a constant rate with the moderator (police violence). Hainmueller et al. (2019) suggest that this assumption often fails in practice. Second, the estimates of linear multiplicative interaction models can be misleading if there is a lack of common support of the moderator (i.e., insufficient data at the required level of the moderator and insufficient variation in the predictor at the required level of the moderator).

In this section, we explore non-linear interactions using the INTERFLEX package introduced by Hainmueller et al. (2019). Specifically, using a kernel estimator, we estimated fully flexible models to detect any non-linearities in the interactions. However, the estimates of the flexible models suggested that the results reported in the main text (i.e., results produced by the linear models) are unlikely to be artefacts of implausible modelling assumptions. To specify, the fully flexible estimator, analogously to the linear estimator, suggested (1) that the Police Violence Scale (PVS) did not increase the association between the Perceived COVID-19 Burden Scale (PCBS) and Activism Intention Scale (AIS) (see the upper panel in Figure S12), (2) that the association between PCBS and Radicalism Intention Scale (RIS) significantly decreased over a range of PVS scores (see the lower panel in Figure S12), and (3) that the significant results for the BLM-related outcomes reported in the main text (Figure 2) were robust for approximately $95 \%$ of the moderator values (i.e., we see robust increases in the marginal effects of PCBS for the PVS values between 0.0 and 0.7; see Figure S13) 
Figure S12: Marginal effects of perceived COVID-19 burden on activism and radicalism intentions for different levels of police violence
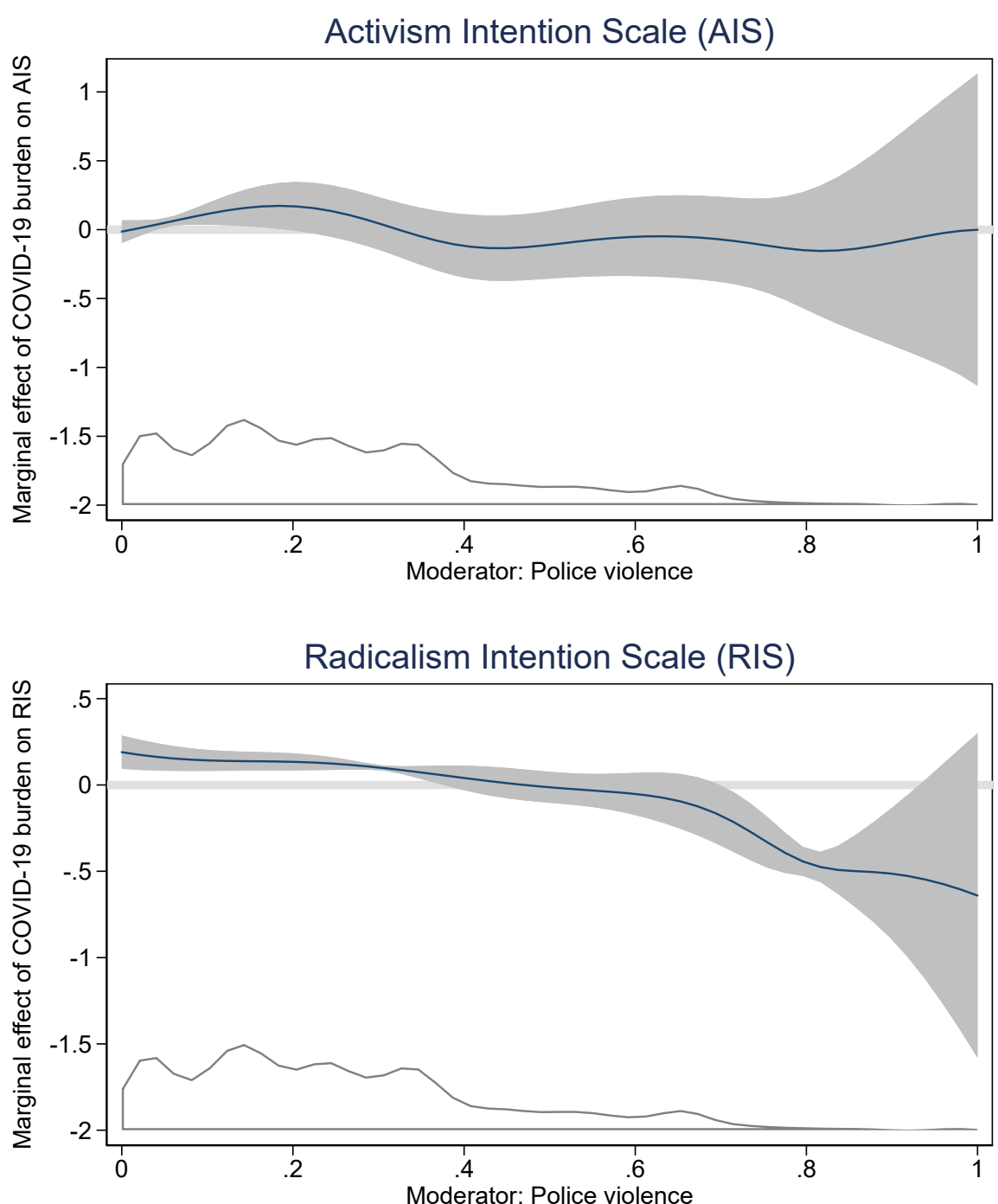

Note: Solid dark blue lines display the marginal effects of perceived COVID-19 burden (PCBS) on Activism Intention Scale (AIS) and Radicalism Intention Scale (RIS) for different values of the Police Violence Scale (PVS), estimated using fully flexible (kernel) estimator from the INTERFLEX package (Hainmueller et al. 2019). Grey areas represent $95 \%$ confidence intervals of the marginal effects. 
Figure S13: Marginal effects of perceived COVID-19 burden on participation in BLM protests and counter protests for different levels of police violence
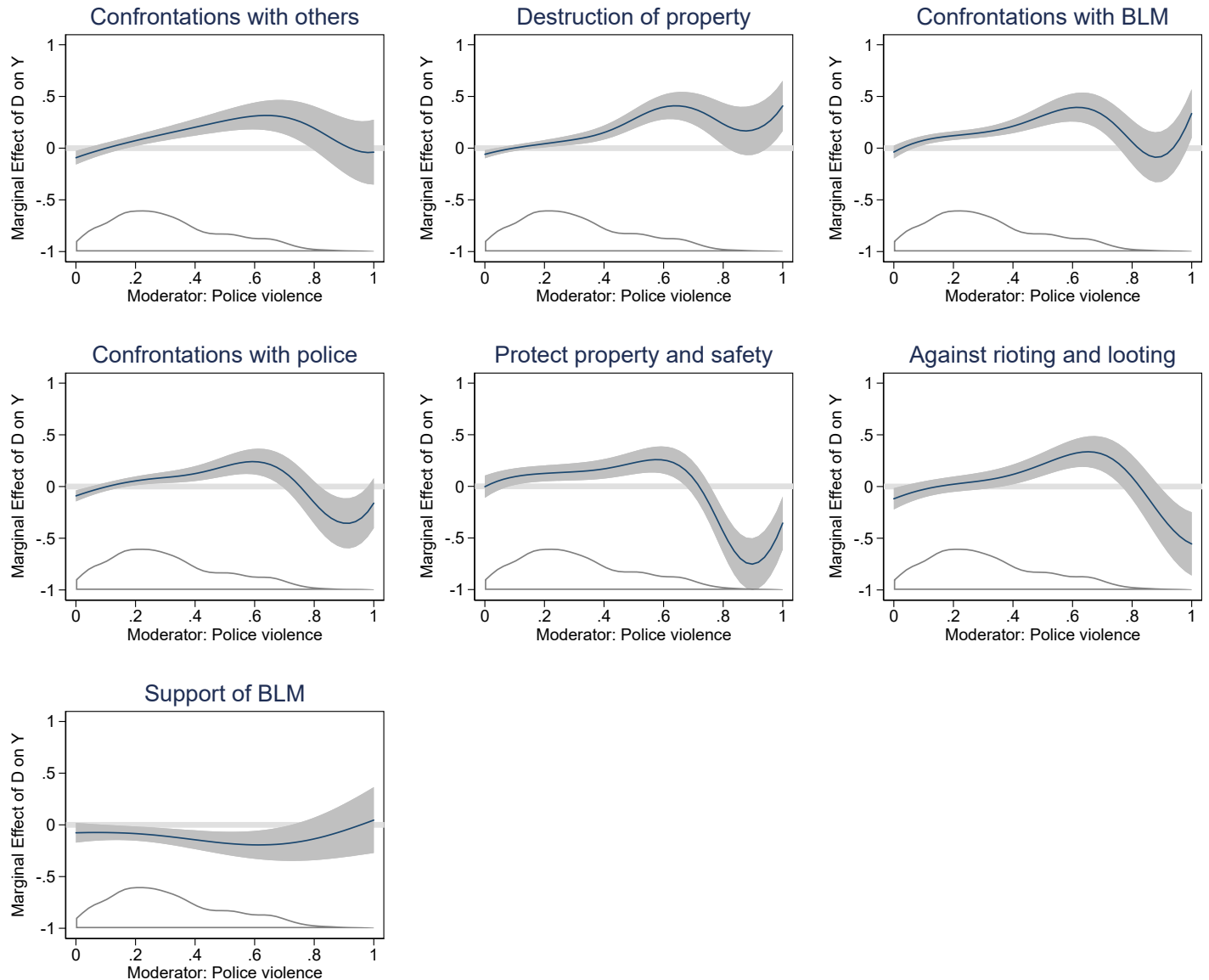

Note: Solid dark blue lines display the marginal effects of perceived COVID-19 burden (PCBS) on various outcomes for different values of the Police Violence Scale (PVS), estimated using fully flexible (kernel) estimator from the INTERFLEX package (Hainmueller et al. 2019). Grey areas represent $95 \%$ confidence intervals of the marginal effects. 


\section{S17 Post hoc sensitivity analyses}

We calculated the sensitivity of our design by taking the standard errors of the main coefficients and then identifying the minimum detectable effect at $80 \%$ power and $5 \%$ alpha (two-sided) as an effect 2.8 times the standard error (Bloom 1995; Gelman, Hill, \& Vehtari 2020). We then standardized these raw minimum detectable effect size (MDE) estimates by dividing them by the corresponding standard deviations in the outcomes. We used the pooled sample for these calculations and took the uncertainty estimates (i.e., standard errors) and the variability in our outcomes (i.e. standard deviations) at face value.

The results displayed in Table S63 show that most of our models are highly sensitive. The between-individual models estimated on the pooled sample can detect minimum effects of as little as $5 \%$ of a standard deviation. Estimating relationships on the US subsample (16\%) or employing within-individual models $(28 \%)$ come at a cost to sensitivity; still, these MDEs are relatively small and much smaller than the effect sizes we found.

The sensitivity is more mixed when it comes to interaction models. Although the models on the pooled sample are highly sensitive (between $9 \%$ and $22 \%$ of a standard deviation of the outcome), the interactions estimated on the US subsample are less sensitive and can reliably detect only large minimum effects $(71-75 \%)$. 
Table S63: Minimum detectable effects (MDE) at $80 \%$ power and $5 \%$ alpha for the main statistical tests

\begin{tabular}{lllcccc}
\hline Outcome & Sample & Model & SE of estimate & MDE & SD & MDE as \%SD \\
\hline Need for Chaos & Pooled & Within-individual & 0.02 & 0.056 & 0.20 & $28 \%$ \\
Activism Intention Scale & Pooled & Between-individual & 0.03 & 0.084 & 1.75 & $5 \%$ \\
Radicalism intention Scale & Pooled & Between-individual & 0.03 & 0.077 & 1.56 & $5 \%$ \\
Participation in protest & USA & Between-individual & 0.06 & 0.175 & 1.12 & $16 \%$ \\
Participation in violence & USA & Between-individual & 0.04 & 0.105 & 0.66 & $16 \%$ \\
Participation in BLM protest & USA & Between-individual & 0.05 & 0.126 & 0.80 & $16 \%$ \\
Activism Intention Scale & Pooled & Moderator: Prime & 0.06 & 0.154 & 1.75 & $9 \%$ \\
Radicalism Intention Scale & Pooled & Moderator: Prime & 0.05 & 0.133 & 1.56 & $9 \%$ \\
Activism Intentions Scale & Pooled & Moderator: Perception & 0.14 & 0.392 & 1.75 & $22 \%$ \\
Radicalism Intention Scale & Pooled & Moderator: Perception & 0.12 & 0.329 & 1.56 & $21 \%$ \\
Participation in protest & USA & Moderator: Perception & 0.30 & 0.840 & 1.12 & $75 \%$ \\
Participation in violence & USA & Moderator: Perception & 0.17 & 0.469 & 0.66 & $71 \%$ \\
Participation in BLM protest & USA & Moderator: Perception & 0.22 & 0.602 & 0.80 & $75 \%$ \\
\hline
\end{tabular}




\section{References}

Afrobarometer. (2015). Merged dataset, Round 5, 2011-2013. Retrieved 2020-11-18, from https://www . afrobarometer.org/

Bloom, H. S. (1995). Minimum detectable effects: A simple way to report the statistical power of experimental designs. Evaluation Review, 19(5), 547-556.

Gelman, A., Hill, J., \& Vehtari, A. (2020). Regression and other stories. Cambridge University Press.

Hainmueller, J., Mummolo, J., \& Xu, Y. (2019). How much should we trust estimates from multiplicative interaction models? Simple tools to improve empirical practice. Political Analysis, 27(2), 163-192.

Moskalenko, S., \& McCauley, C. (2009). Measuring political mobilization: The distinction between activism and radicalism. Terrorism and Political Violence, 21(2), 239-260.

Petersen, M. B., Osmundsen, M., \& Arceneaux, K. (2018). A "need for chaos" and the sharing of hostile political rumors in advanced democracies. PsyArXiv. doi: 10.31234/osf.io/6m4ts

Tsai, C.-l. (2019). Statistical analysis of the item-count technique using Stata. The Stata Journal, 19(2), 390-434. 